University of Louisville

ThinkIR: The University of Louisville's Institutional Repository

Electronic Theses and Dissertations

$12-2016$

\title{
Exploring the relation between school pushout and future outlook for black youth.
}

Kish Cumi

University of Louisville

Follow this and additional works at: https://ir.library.louisville.edu/etd

Part of the Student Counseling and Personnel Services Commons

\section{Recommended Citation}

Cumi, Kish, "Exploring the relation between school pushout and future outlook for black youth." (2016). Electronic Theses and Dissertations. Paper 2573.

https://doi.org/10.18297/etd/2573

This Doctoral Dissertation is brought to you for free and open access by ThinkIR: The University of Louisville's Institutional Repository. It has been accepted for inclusion in Electronic Theses and Dissertations by an authorized administrator of ThinkIR: The University of Louisville's Institutional Repository. This title appears here courtesy of the author, who has retained all other copyrights. For more information, please contact thinkir@louisville.edu. 


\title{
EXPLORING THE RELATION BETWEEN SCHOOL PUSHOUT AND FUTURE OUTLOOK FOR BLACK YOUTH
}

\author{
By \\ Kish Cumi \\ B.A., Wake Forest University, 2001 \\ M.A.Ed., Wake Forest University, 2003
}

\begin{abstract}
A Dissertation
Submitted to the Faculty of the College of Education and Human Development of the University of Louisville in Partial Fulfillment of the Requirements for the Degree of
\end{abstract}

Doctor of Philosophy in Counseling and Personnel Services

Department of Counseling and Human Development University of Louisville Louisville, Kentucky

December 2016 
Copyright 2016 by Kish Cumi

All rights reserved 

EXPLORING THE RELATION BETWEEN SCHOOL PUSHOUT AND FUTURE OUTLOOK FOR BLACK YOUTH

\author{
By \\ Kish Cumi \\ B.A., Wake Forest University, 2001 \\ M.A.Ed., Wake Forest University, 2003 \\ A Dissertation Approved on
}

November 18, 2016

by the following Dissertation Committee:

Dr. Lisa M. Hooper, Dissertation Chair

\author{
Dr. Sara Tomek
}

Dr. Ahmad Washington

Dr. Hongryun Woo 


\section{DEDICATION}

This dissertation is dedicated to my sons, Timothy, Gabriel, and Solomon, for your patience in the process. I love you forever.

And to my brother, Clay, for inspiring my research and advocacy. I love you dearly. 


\section{ACKNOWLEDGMENTS}

I must give honor, recognition, glory, and praise to You, God, as my beloved, my treasure, my sustainer, my best friend, my motivation, my purpose-maker, my peace, my joy, my energy, and my First Love! Thank you for always keeping me and providing for me. I appreciate your endless encouragement and ubiquitous presence. I would not and could not have started or completed this doctoral journey without You. Thank you for trusting me with the task and great privilege of advocating for youth and their families.

I thank you, Father, for my greatest gifts and teachers on earth, my sons, Timothy (11), Gabriel (9), and Solomon (7), who were ages 8, 6, and 4, respectively, when I began this process. Thank you for blessing me with children who are so loving, understanding, supportive, gifted, encouraging, hilarious, and beautiful! Please help them to forget the many meetings they had to endure and endless deadlines they prayed that I would meet, so that they too may choose to pursue this journey if it is in Your will for them to do so.

Thank you for my grandparents, Bessie, Inez, Walter, and Theodore. I thank you for my mother and father, Patricia and Clay, who are the best parents on earth and unfailingly exude and share Your love with me daily. Thank you for my sister, Katrina, and my brother, Clay. I love that You have tethered us together as siblings in ways that only You can understand and we can feel.

Thank you for my dissertation chair, Dr. Lisa Hooper, a stalwart in clinical counseling research and one of my greatest mentors and advocates while on this journey. I also thank you for such committed dissertation committee members: Drs. Sara Tomek, 
Ahmad Washington, and Hongryun Woo. It has been a privilege working with them, and I am grateful for their patience and support.

Thank you for the youth (and families) of the Mobile Youth Survey (MYS) Study, as I would not have had an opportunity to do this study without them. Thank you for Drs. Anneliese and John Bolland and the MYS research team for their kindness in granting access to their database. Thank you for the support and encouragement of Dean Larson, Associate Dean Lingo, and the Academic Affairs and Unit Effectiveness family.

And I would be remiss if I did not thank you for the village that assisted me and/or supported my sons as we made this journey in a time where single Black mothers are told that they can only live and exist in prescribed boxes designed by society's ills. Thank you for our homeschooling community; the Bishop family and their amazing love; my ex-husband and father of my sons, Tim; my spirit sisters, Robyn, Shaun, Kristyn, Tisha, Brooke, Kala, Janelle, Mel, Chrystal, Pamela, Mariam, Ra’'Tonya, Destiny, Sierra, Mahogany, Sheena, Angelique, Keeley, Bianca, Tytianna, Candace, Taleia, Tia and Chaiqua; my spirit brothers, C.J., Dwayne, Jelani, and Devonte; my mentors, Drs. Balkin, Cunningham, Hooper, and Washington, and my Holmes Scholars family. And last, but not least, thank you for our Kingdom Fellowship Christian Life Center family and our fearless leader, Pastor Timothy Findley, Jr., for embracing us and challenging us to a life of faith in action. Thank you, God. You have blessed me (us) abundantly. In Jesus' name, Amen. 


\section{ABSTRACT \\ EXPLORING THE RELATION BETWEEN SCHOOL PUSHOUT AND FUTURE OUTLOOK FOR BLACK YOUTH}

\section{Kish Cumi}

November 18, 2016

This dissertation study is an examination of the relation between school pushout and future outlook for Black youth. Theoretically, this dissertation study is framed by Bronfenbrenner's Ecological Model (Bronfenbrenner, 1977) and Racial Encounter Coping Appraisal and Socialization Theory (RECAST). In light of the systemic racial disparities entrenched in school pushout phenomena among Black youth, the researcher sought to explore parental warmth as a protective factor for youth subjected to school pushout. School pushout as praxis was discussed in conjunction with the school-toprison pipeline (STPP), as school pushout is identified as an entry point within the STPP.

This dissertation study explored a sample $(N=1728)$ of Black youth, ages 13-17, who participated in the last wave of the Mobile Youth Survey (MYS). Approximately $85 \%(n=1465)$ of the sample experienced school pushout. The sample was equally divided regarding gender. Regression analyses revealed that (a) there was an indirect relation between school pushout and future outlook and (b) parental warmth did not moderate the relation between school pushout and future outlook; however, (c) when age and gender were added to the model, parental warmth moderated the relation between school pushout and future outlook. 


\section{TABLE OF CONTENTS}

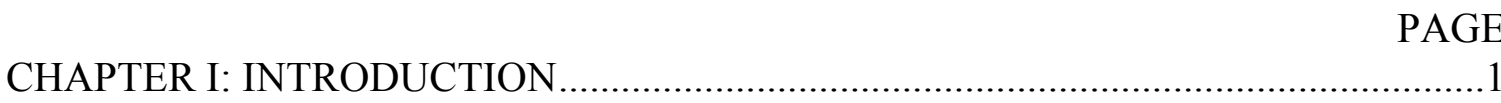

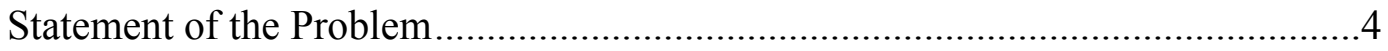

School Pushout and Race ................................................................

School Pushout and Gender ...............................................................6

School Pushout and Future Outlook ..........................................................8

School Pushout and Future Outlook: Exploring Parental Warmth .............8

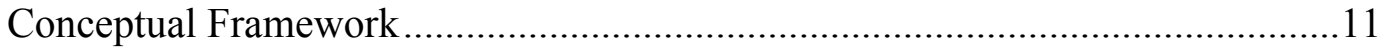

Bronfenbrenner's Ecological Model.................................................11

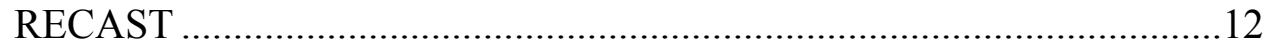

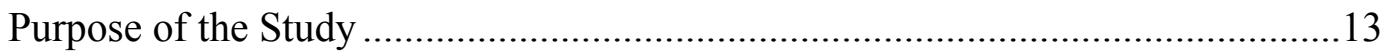

Research Questions and Hypotheses ......................................................... 14

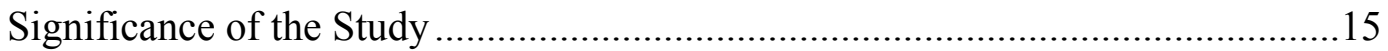

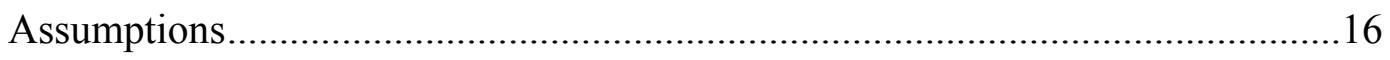

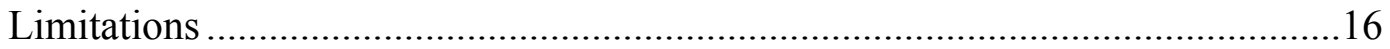

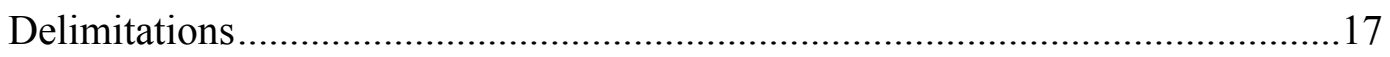

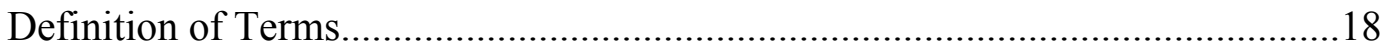

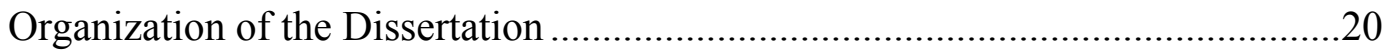

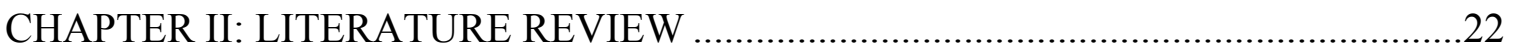

Elucidating the School-to-Prison Pipeline: Relevance to the Dissertation Study..22 
Zero Tolerance School Policies

School Pushout

Suspensions

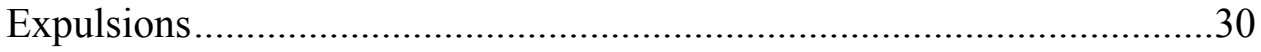

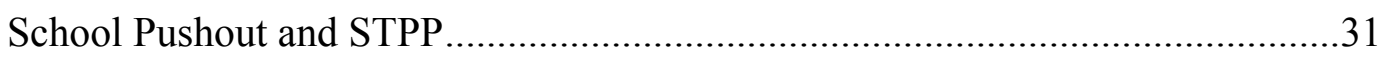

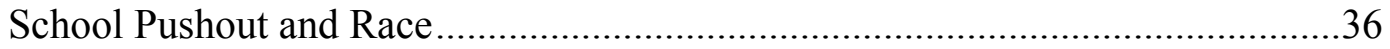

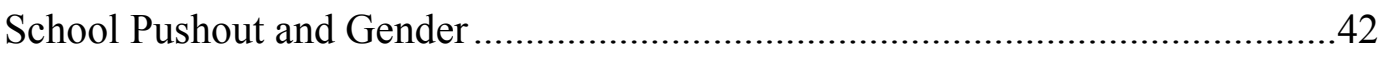

School Pushout and Future Outlook ...............................................................48

School Pushout and Parental Warmth..................................................................51

School Pushout and Future Outlook: Exploring Parental Warmth ......................53

Summary of Study Constructs and Identified Gaps in the Literature ....................58

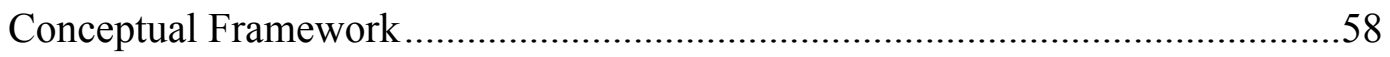

Bronfenbrenner's Ecological Model................................................59

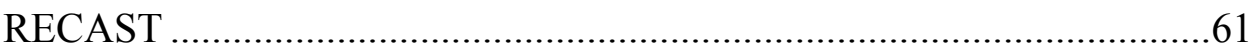

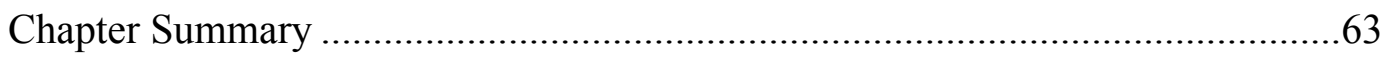

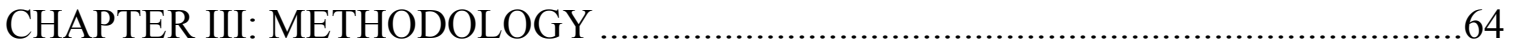

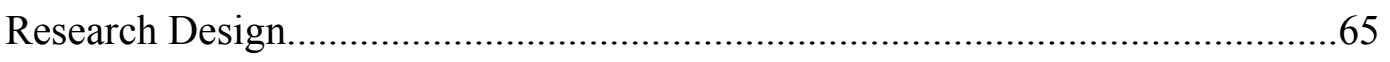

Research Questions and Hypotheses .....................................................66

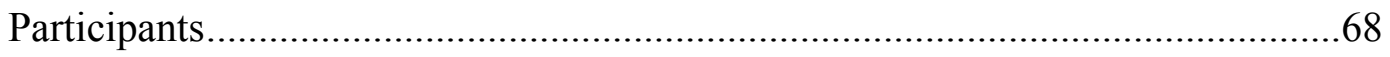

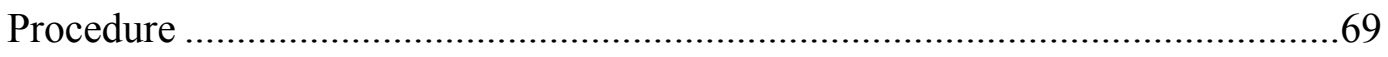

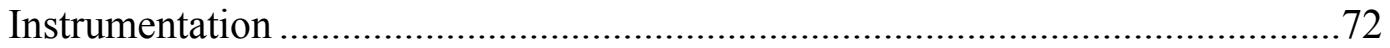

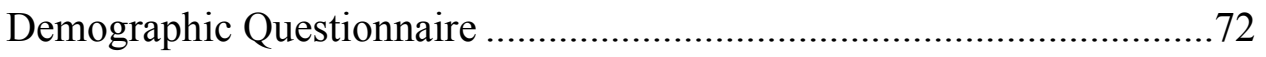

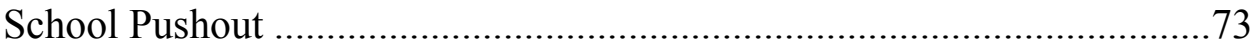


Future Outlook

Parental Warmth ............................................................................... 75

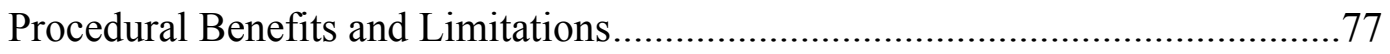

Benefits and Limitations of the Dissertation Study …......................................77

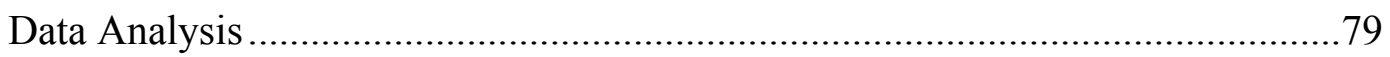

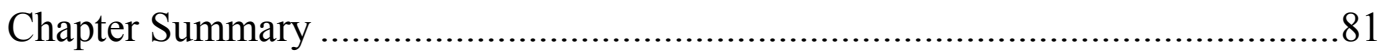

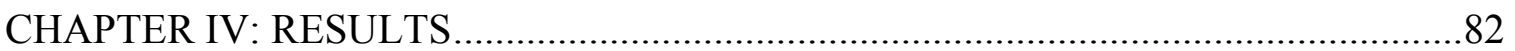

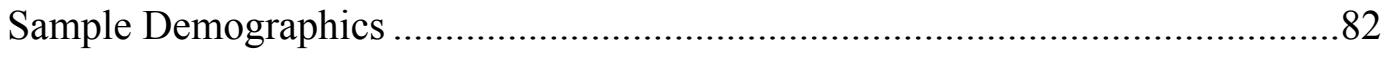

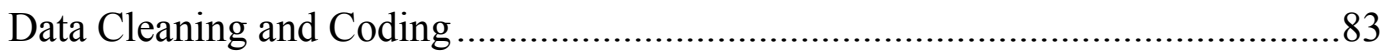

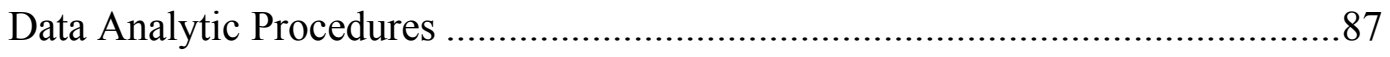

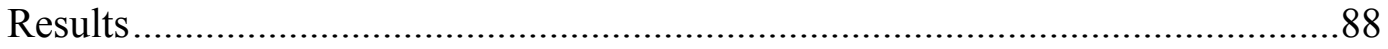

Descriptive Statistics and Frequencies............................................ 88

School Pushout and Hopelessness ...................................................91

School Pushout and Self-Worth....................................................... 91

Parental Warmth, School Pushout, Hopelessness, and Self-Worth ...........93

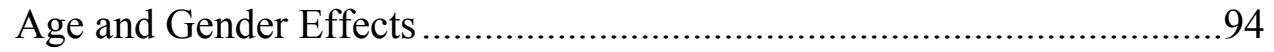

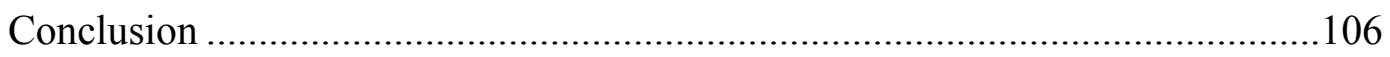

CHAPTER V: DISCUSSION, IMPLICATIONS, AND CONCLUSION .....................108

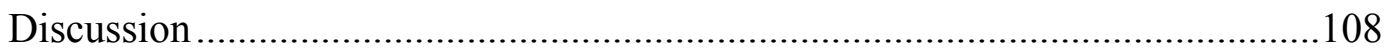

School Pushout and Future Outlook ...............................................110

School Pushout, Future Outlook, and Parental Warmth .......................111

Age and Gender Effects: School Pushout, Outlook, and Warmth..........113

School Pushout and Gender .......................................................114 


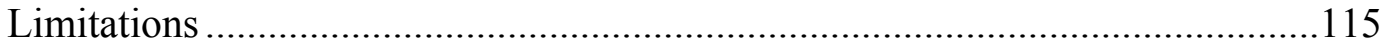

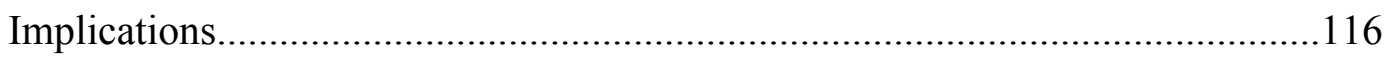

Implications for Research ........................................................116

Implications for Practice .................................................................118

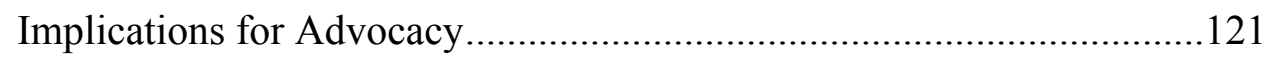

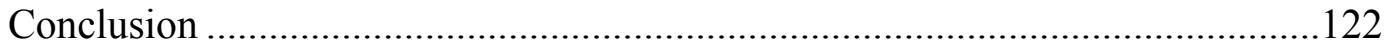

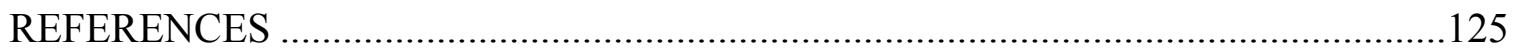

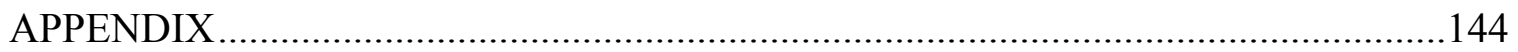

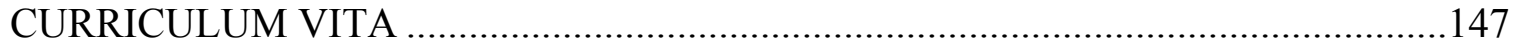




\section{LIST OF TABLES}

TABLE $\quad$ PAGE

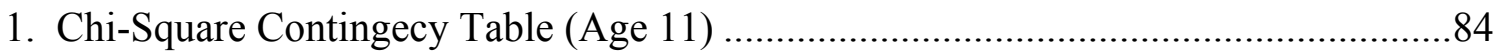

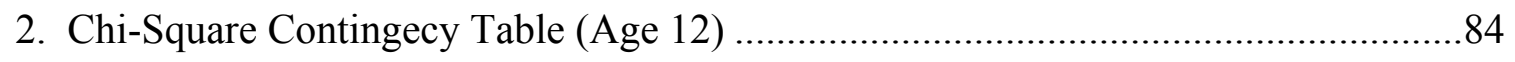

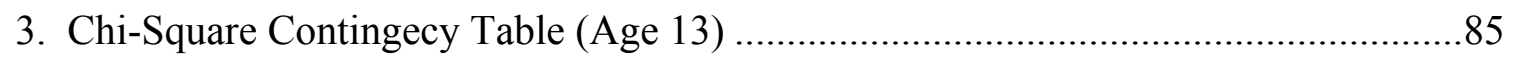

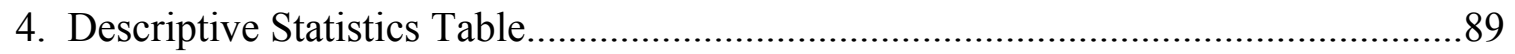

5. Frequency Table (School Pushout) ……………………….....................................89

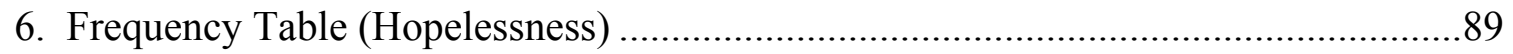

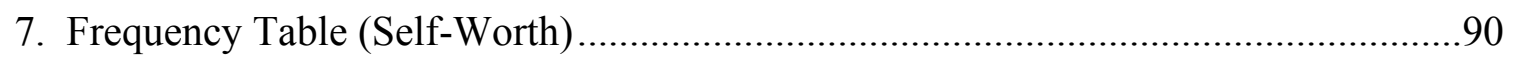

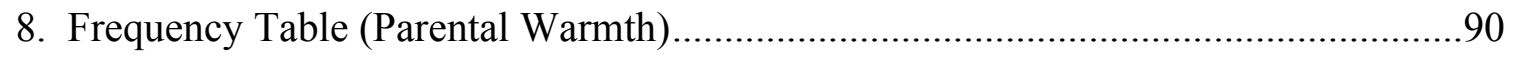

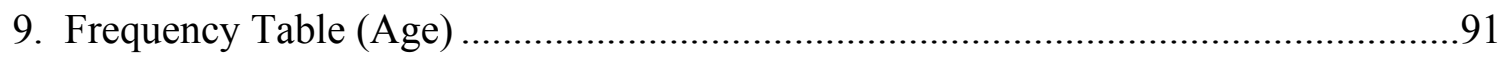

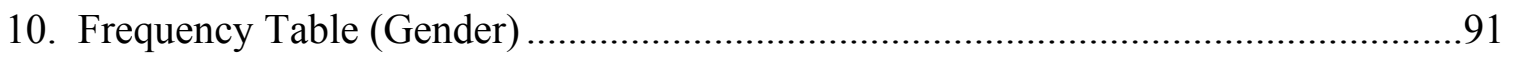

11. School Pushout and Hopelessness Parameter Estimates ...........................................92

12. School Pushout and Self-Worth Parameter Estimates .............................................92

13. Parental Warmth, School Pushout, and Hopelessness Parameter Estimates ...............94

14. Parental Warmth, School Pushout, and Self-Worth Parameter Estimates..................94

15. Full Hopelessness Model Parameter Estimates .......................................................98

16. Full Self-Worth Model Parameter Estimates ............................................................104

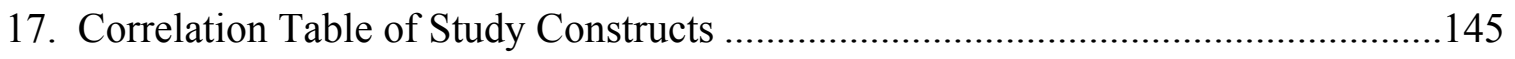




\section{LIST OF FIGURES}

FIGURE

PAGE

1. Bronfenbrenner's (1977) Ecological Model with Dissertation Study Foci . .12

2. Conceptual Model for the Dissertation Study .67

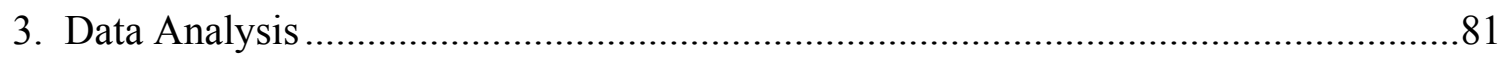

4. Full Hopelessness Model: Female School Pushout Plot..........................................98

5. Full Hopelessness Model: Male School Pushout Plot .............................................99

6. Full Hopelessness Model: Female No School Pushout Plot....................................99

7. Full Hopelessness Model: Male No School Pushout Plot .......................................100

8. Full Self-Worth Model: Female School Pushout Plot ............................................105

9. Full Self-Worth Model: Male School Pushout Plot................................................105

10. Full Self-Worth Model: Female No School Pushout Plot ......................................106

11. Full Self-Worth Model: Male No School Pushout Plot ..........................................106 


\section{CHAPTER I}

\section{INTRODUCTION}

Black youth are suspended and expelled from United States public schools at a rate three times that of their White counterparts (U.S. Department of Education, Office for Civil Rights [OCR], 2014). Additionally, Black students are 3.8 times more likely than White students to be suspended from school one or more times (OCR, 2016).

Among Black males, $83 \%$ are suspended at least once during their P-12 public school educational experience for subjective infractions such as disrespect, willful defiance, and insubordination (Glass, 2014). Approximately 2 out of 10 Black males are predicted to make it through their P-12 education experience without being suspended (Glass, 2014). Equally noteworthy, Black females are six times more likely to be suspended than White females (OCR, 2014). Black females are also considered the fastest growing population in the U.S. juvenile justice system (Crenshaw, Ocen, \& Nanda, 2015).

To put this into perspective, according to Smith and Harper (2015), 1.2 million Black students in the U.S. were suspended from K-12 public schools over the course of an academic year. Although the aforementioned statistic is staggering, it is even more pronounced when coupled with the statistic that 1 out of 3 Black males is projected to be incarcerated during his lifetime (Smith \& Harper, 2015). This connection between school pushout (e.g., suspension and expulsion) and incarceration for Black youth and other youth representing historically marginalized or vulnerable populations (e.g., racially minoritized, children with disabilities, and youth identifying as Lesbian, Gay, Bisexual, 
Transgendered, and Queer [LGBTQ]) is often referred to as the school-to-prison pipeline (STPP; Heitzeg, 2009; Nelson, 2014).

The STPP, fueled by the increase in prison privatization and the proliferation of zero tolerance policies implemented in urban schools, has had a significantly injurious influence on Black youth (Alexander, 2012; Losen \& Skiba, 2010). School pushout, which is categorized by school administrators' tendencies to disproportionately utilize exclusionary practices (i.e., suspensions, expulsions, and school arrests) with Black students, has notably impacted the academic trajectory for Black youth (Noguera, 2003; Skiba \& Knesting, 2001). Literature supports findings that disproportionate school suspensions of Black students are directly associated with dropout rates and poor academic performance (Ali \& Dufresne, 2008; Heitzeg, 2014; Losen \& Skiba, 2010; Skiba \& Rausch, 2006).

The often-reported inability of teachers and administrators to work with youth, specifically Black youth, to resolve minor infractions (e.g., excessive noise, loitering, disrespect, and defiance), often contributes to the criminalization of Black youths' behaviors and subsequent school pushout (i.e., suspensions and expulsions; Charnofsky, 1971; OCR, 2016). The process of pushing Black students out of schools in efforts to raise test scores and alleviate student misconduct in classrooms (Skiba, 2000) fuels the STPP by contributing to academic and school disengagement (Caton, 2012). Black youth are inevitably behind in their studies after the suspension lifts, and upon their return, they are more likely to be frustrated due to the lack of support from teachers (Tenenbaum \& Ruck, 2007). Additionally, there are often issues concerning unresolved conflict and perceived stigma attached to school pushout, which further aid in creating a negative 
educational experience for Black youth (Quin \& Hemphill, 2014).

School pushout precipitates further academic disengagement and may result in internalization of school pushout labels (Quin \& Hemphill, 2014). Such labels can also impact perceived future outlook (Noguera, 2003). In this dissertation study, future outlook refers to expectancies about the future based on the internalized (i.e., self-worth and hopelessness) and externalized (i.e., graduation, incarceration, and employment opportunities) value of self. School pushout directly impacts the future outlook of Black youth as the internalized and externalized value of self have the potential to be altered by school pushout stigma (Quin \& Hemphill, 2014). As students experience school pushout, they may interpret that pushout as rejection, and they are likely to return to school with the feelings of rejection attached to their psyche. School pushout is linked to an increased likelihood to drop out (i.e., leave after pushout) and decreased acquisition of higher educational goals (Toldson, McGee, \& Lemmons, 2014). In addition to the more conspicuous factors such as dropout and incarceration, deleterious effects of school pushout also include inconspicuous factors. Decreased self-worth and increased hopelessness are outcomes of school pushout for many Black youth (Toldson et al., 2014).

The correlation between school pushout and negative future outlook (i.e., decreased self-worth and increased hopelessness) is of grave concern to many parents of Black youth. Because the STPP has been identified as a systemic issue that directly impacts Black youth in the education system, the STPP needs to be addressed from multiple levels as parents, teachers, administrators, and advocates have a vested interest in examining protective factors for their children. Protective factors that pertain to 
parenting and home environment could potentially benefit parents of Black youth who are seeking solutions to assist their children in having a positive future outlook (i.e., increased self-worth and decreased hopelessness) despite the racially disparate discipline practices that their children often experience in schools.

\section{Statement of the Problem}

Historically, empirical data have supported the notion that Black youth, especially Black males, have been disproportionately disciplined in schools (Gregory, 1997; Mendez \& Knoff, 2003; Noguera, 2003; OCR, 2014, 2016; Skiba et al., 2000). The discourse and research around school pushout has evolved over time to include the disproportionate impact of school pushout on Black females as well; however, school pushout of Black females has been significantly understudied (Crenshaw, Ocen, \& Nanda, 2015). The research foci of school pushout of Black youth have also changed with time. Traditionally, the examination of school pushout of Black males and females focused on risk factors at the individual level (i.e., examination of student behavior at the microsystem level), but recently the impetus has shifted to investigate protective factors and system-level risk factors (i.e., examination of school climate at the microsystem level; American Psychological Association [APA], 2008; Theriot, Craun, \& Dupper, 2010). System-level school pushout research includes a focus on school variables that contribute to the disparate implementation and enactment of discipline policies (e.g., zero tolerance policies; Church et al., 2012; Toldson et al., 2014). Given the epidemic of Black youth being pushed out of schools, it is imperative that protective factors are being examined from various levels of ecological systems (Bronfenbrenner, 1977). For example, the exosystem level includes the heightened implementation of zero tolerance 
policies in schools with predominantly Black students. Therefore, exploring school pushout protective factors at the exosystem level is logical and could be useful in addressing school pushout concerns.

\section{School Pushout and Race}

School pushout has systemically and disproportionately impacted historically marginalized populations—-specifically Black youth, and school pushout is mainly attributed to the implementation of zero tolerance policies in schools across the nation. Zero tolerance school policies, which were formed based on "a global concept that sets limits to perceived problem behavior" (Verdugo, 2002, p. 52), were implemented in schools in the 1990's as a direct response to fears of gang and drug activity (APA, 2008). As previously stated, zero tolerance policies were institutionalized in schools in response to concerns about violence in schools and later spurred by the Gun Free Schools Act of 1994 (GFSA, 2012).

The primary catalyst for the propagation of zero tolerance school policies was the Columbine High School massacre. The Columbine High School massacre in Columbine, Colorado was a national tragedy that occurred in 1999 in which two White male students at the suburban high school shot and killed 12 students and one teacher, injured 21 others, and then committed suicide (Fuentes, 2014). Although the aforementioned incident happened at a suburban school that served predominantly White students, the increased implementation and policing of zero tolerance school policies were disproportionately established and implemented at urban schools, which primarily serve Black students (Ayers, Dohrn, \& Ayers, 2001; Noguera, 2003; Verdugo, 2002).

The Children's Defense Fund provided the first analysis of OCR data reporting 
racial disproportionality in school suspensions in 1974 (Skiba \& Peterson, 2000). The data revealed that Black youth were 2-3 times more likely to be suspended than White youth. Over four decades later, the OCR data continues to support the racially disparate trend, with Black youth being 3.8 times as likely to receive one or more out-of-school suspensions than White youth.

Disproportionate school pushout rates for Black students are evidenced across the pre-K-12 spectrum (Gilliam, 2005; Mendez \& Knoff, 2003; Losen \& Martinez, 2013). Although school pushout rates are more disparate at schools located in lower income neighborhoods, the disproportionate racial trends are consistent irrespective of socioeconomic status, with some suburban districts reporting more school pushout racial disparities (Skiba \& Rausch, 2006). System-level factors concerning Black youth school pushout rates, such as implicit racial bias among teachers and administrators are increasingly examined within research to explore what readily appears as systemic or institutional racism (Oates, 2003; Tenenbaum \& Ruck, 2007; van den Bergh, Denessen, Hornstra, Voeten, \& Holland, 2010).

\section{School Pushout and Gender}

Much of the literature and research on youth who have been victimized by the STPP focuses on the discrepancies in race, and at times, gender. Empirical evidence supports the notion that Black males are the most discriminated against compared to their White counterparts (Smith \& Harper, 2015; Toldson et al., 2014). Black males are more likely to be perceived as being older and less innocent than their White peers (Goff, Jackson, Di Leone, Culotta, \& DiTomasso, 2014). The OCR reported that among K-12 students, $18 \%$ of Black males received one or more out-of-school suspensions during an 
academic year, while White males received $5 \%$ of one or more out-of-school suspensions.

Generally, males are more likely than females to be referred to the office for delinquent behavior (Skiba, Michael, Nardo, \& Peterson, 2002; Wallace et al., 2008). However, within extant literature, findings have reported Black females as being disproportionately subjected to the same punitive practices as Black males when compared to their female and male peers of other racial backgrounds (Losen \& Skiba, 2010). Disaggregated school pushout data and intra-gender comparisons reveal that Black females are a cohort of concern (Crenshaw et al., 2015; Mendez \& Knoff, 2003). In fact, among K-12 students, $10 \%$ of Black females received one or more out-of-school suspensions, while $2 \%$ of White females received one or more out-of-school suspensions (OCR, 2016). Additionally, Black females have also been identified as experiencing more school pushout than males of other races (Crenshaw et al., 2015; Finn \& Servoss, 2014; Losen \& Martinez, 2013). Such racial discrepancies are mainly attributed to implicit racial biases existing among teachers and administrators (Gilliam, Maupin, Reyes, Accavitti, \& Shic, 2016; Smith \& Harper, 2015).

Research also reflects gender-biased reporting of findings. Some researchers report disproportionate school pushout rates for Black males and females, but selectively frame the discourse in a way that solely addresses Black males or pronounces Black male school pushout over Black female school pushout (Finn \& Servoss, 2014; Losen \& Martinez, 2013). Such oversight, irrespective of intent, has resulted in a school pushout narrative that has not historically given credence to the racial and gender oppressions that impact Black females (Crenshaw et al., 2015; Morris, 2016). 


\section{School Pushout and Future Outlook}

In this dissertation study, future outlook has been defined as the internalized and externalized value of self and serves as a measure of self-worth and hopelessness.

Historically, researchers have mainly examined future outlook as a risk factor for school pushout likelihood (Kuperminc, Leadbeater, Emmons, \& Blatt, 1997; Taylor, Davis-

Kean, \& Malanchuk, 2007); however, the examination of school pushout as a risk factor for negative future outlook has been understudied. Literature supports the association between external factors, such as school climate perceptions among youth, which can potentially impact immediate future outlook (i.e., behavioral outcomes; Hoge, Smit, \& Hanson, 1990; Kuperminc et al., 1997).

The association between school climate perceptions and behavioral outcomes has implications for the nature of the relation between school pushout and future outlook, as negative school climate perceptions concerning school pushout can impact a youth's sense of belonging and self (Hoge et al., 1990; Kuperminc et al., 1997). Researchers, who have examined the association between school pushout and future outlook for Black youth, suggest an inverse (i.e., negative) relation between school pushout and future outlook (Taylor et al., 2007; Toldson et al., 2014). Research also reveals the potential for internalization of school pushout stigma among Black youth, which can impact future outlook (Quin \& Hemphill, 2007; Laura, 2014).

\section{School Pushout and Future Outlook: Exploring Parental Warmth as a Moderator}

School pushout and future outlook among Black youth can be influenced and impacted by various systems (e.g., government, education, and community); however, assigning responsibility for addressing STPP entry points (e.g., school pushout) 
oftentimes presents as a nebulous task. Some elect to find various ways to address the issue by placing the onus on youth to change or be more resilient, while others choose to focus on changing various elements of other systems. Meanwhile, many parents and youth advocates are seeking ways to protect or safeguard Black youth from the potentially devastating impact of school pushout (Laura, 2014; Morris, 2016).

Parental warmth will be explored in this dissertation study as a protective factor. Parental warmth will be explored in order to examine its potential moderating effects between school pushout and future outlook of Black youth. Given the myriad of systemic issues that surround the STPP, the researcher elected to study parental warmth as a protective factor to explore potential opportunities for parents to support their children when they experience school pushout.

Parental warmth reflects parents' general tendencies to be supportive, affectionate, and sensitive to the child's needs (Lamborn et al., 1999). Direct correlations between parental warmth and school pushout have not been widely studied; however, parental warmth has historically been studied as a protective factor for negative youth behavior (Brookmeyer, Henrich, \& Schwab-Stone, 2005; Simons et al., 2006). Studies have revealed that parental involvement is significantly correlated with frequency of disciplinary referrals (Toldson et al., 2014). Other findings suggest that parental warmth has been inversely related to delinquency and disciplinary referrals among Black males (Simons et al., 2006; Toldson et al., 2014). Unfortunately, similar correlations have not been widely investigated among Black females. Studies identify parental warmth as a protective factor against violence among adolescents (Brookmeyer, Henrich, \& SchwabStone, 2005; Stoddard, Henly, Sieving, \& Bolland, 2011). Similarly associations 
between parental warmth and delinquency and gang involvement have also been examined (Church et al., 2012; Walker-Barnes \& Mason, 2004).

Although there are no studies showing a relation between school pushout and parental warmth, similar constructs such as parental involvement or parenting style provide a pathway for the potential associations between student behavior and parental warmth (Baumrind, 1967; Khaleque \& Ronner, 2002). The relation between school pushout and parental warmth also has implications for the future outlook of Black youth. There is a need for research that intentionally examines the relation between school pushout and parental warmth, and more importantly, the impact that parental warmth has on school pushout.

A growing body of literature supports the relation between parenting behaviors and an adolescent's sense of self (Izzo, Weiss, Shanahan, \& Rodriguez-Brown, 2000; Kim \& Cicchetti, 2004; Laible, 2007). In particular, parental warmth has been positively linked to social and emotional adjustment among youth (Savage, 2014). A vast body of seminal research supports parental warmth and developmental gains among youth (Ainsworth, 1979; Bandura 1977; Baumrind, 1967; Bowlby, 1969). Mainly, child adaptation and adjustment are positively correlated with parental warmth (Chen, Liu, \& Li, 2000; Khaleque \& Rohner, 2002; Toldson et al., 2014).

In this dissertation study, the relations between school pushout, future outlook, and parental warmth among Black youth are being examined. Presently, there is minimal empirical research regarding the exploration of significant linkage between parental warmth, school pushout, and future outlook among Black youth; however, recent studies have established correlations between parental warmth and behavioral and psychological 
issues (Quin \& Hemphill, 2007; Stoddard et al., 2011; Toldson et al., 2014; Van

Voorhees et al., 2008). Such studies may have implications for this dissertation study.

\section{Conceptual Framework}

Extant research regarding the STPP generally highlights stultifying risk factors (Christle, Jolivette, \& Nelson, 2005; Toldson et al., 2014). The focus on risk factors is necessary in understanding the scope of the problem and the ways in which students are targeted as victims of the STPP; however, increased attention to risk factors perpetuates the systemic issues surrounding the STPP, and consequently, supports a deficit approach to solutions (Smith \& Harper, 2015). Protective factors addressed in STPP literature are much less prevalent than risk factors, and the ecological systems or levels of influence in which these factors would be beneficial are limited (Christle et al., 2005; Toldson et al., 2014).

\section{Bronfenbrenner's Ecological Model}

Bronfenbrenner's Ecological Model will be used in this study to address the systemic impact of the STPP. Only a portion of the STPP will be examined in this dissertation study. The dissertation study is designed to investigate the nature of characteristics or variables observed at the microsystem, mesosystem, and macrosystem levels as outlined in Bronfenbrenner's (1977) Ecological model. Scholarly works have acutely focused on the mesosystem level (e.g., interactions between school and community) concerning risk and protective factors (Christle et al., 2005; Nelson \& Eckstein, 2008; Wald \& Losen, 2003). In light of the increased attention given to risk and protective factors at the mesosystem level, this work will deliberately investigate potential risk and protective factors within the contexts of the microsystem (e.g., parental 
warmth) and the macrosystem (e.g., future outlook) in conjunction with the mesosystem (e.g., school pushout; Bronfenbrenner, 1977). Bronfenbrenner's Ecological Model is depicted in Figure 1.

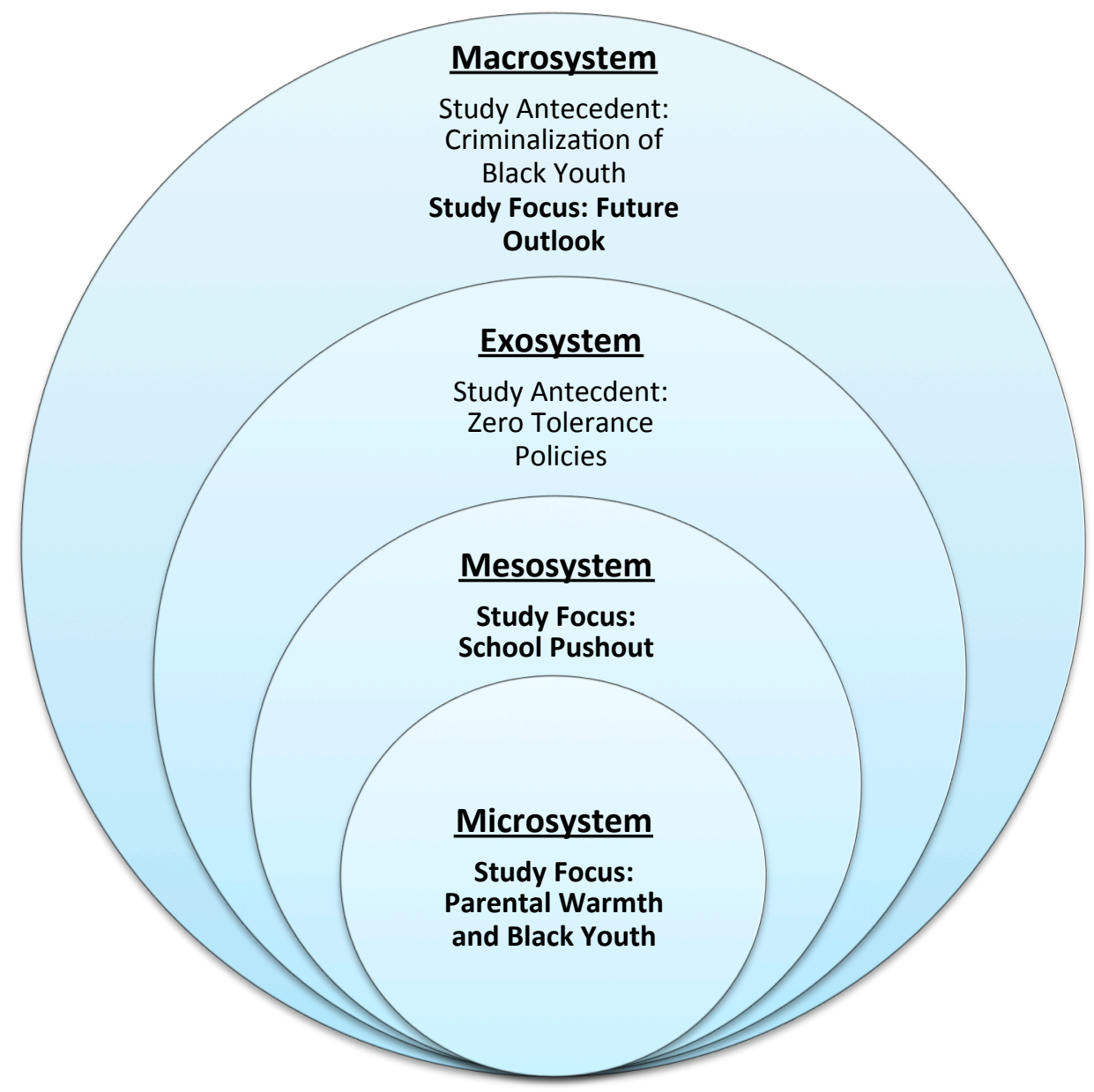

Figure 1. Bronfenbrenner's (1977) Ecological Model with Dissertation Study Foci.

\section{Racial Encounter Coping Appraisal and Socialization Theory (RECAST)}

Racial/ethnic socialization is commonly utilized by parents of Black youth in an effort to prepare their offspring for inevitable future racial discrimination (Adams-Bass, Bentley-Edwards, \& Stevenson, 2014). Parents use racial socialization to familiarize their children with the historical context of racial constructs and associated injustices (Adams- 
Bass et al., 2014). Racial/ethnic socialization must be considered in this dissertation study based on (a) the acknowledgement of the racial context undergirding the constructs of school pushout, (b) the connection that racial socialization has to framing future outlook for Black youth, and (c) the study of parental warmth as a construct. Racial Encounter Coping Appraisal and Socialization Theory (RECAST) is the specific theory employed to conceptualize the racial/ethnic aspects of this study (Adams-Bass et al., 2014). RECAST is a racial/ethnic socialization theory purporting that racial socialization assists youth in determining both positive and negative connotations affiliated with various indirect and direct images and messages regarding Black people (Adams-Bass et al., 2014).

\section{Purpose of the Study}

The purpose of this dissertation study was to examine the relation between school pushout and future outlook for Black youth, and to explore parental warmth as a potential protective factor by examining the relations among parental warmth, school pushout, and future outlook. School pushout was operationalized as suspensions and expulsions, and the examination of responses to measures of hopelessness and self-worth operationalized future outlook. This dissertation study was a cross-sectional analysis of a pre-existing dataset collected from the Mobile Youth Survey (MYS; Bolland, 2007), over the span of fourteen years in Mobile and Prichard, Alabama. The MYS was selected because all of

the constructs of interest were contained within the dataset particularly Black youth living in economically marginalized communities. The MYS was used to obtain annual data from multiple cohorts in a longitudinal study based in two poverty-stricken communities in Alabama (Bolland, 2007). 
This dissertation study was designed to gather information regarding the differences in Black youth who experience school pushout, namely, the likelihood of hopelessness, personal assessment of self-worth, and experience of parental warmth. The results of this study provide a description of the characteristics that existed for Black youth who experienced school pushout compared to those who did not experience suspensions and expulsions. In an effort to provide more solution-based thinking to an ever-increasing deficit-focused approach to the STPP, this dissertation study focused on (a) highlighting trends in a select sample of Black American youth regarding school pushout (i.e., school suspensions and expulsions) and future outlook (i.e., hopelessness and self-worth; Toldson et al., 2014), and (b) examining parental warmth as a possible protective factor that could potentially inform therapeutic prevention and intervention.

\section{Research Questions and Hypotheses}

The research questions and hypotheses explored in this dissertation study were based on cross-sectional analyses of the MYS, a pre-existing longitudinal dataset that captured the constructs of interest (i.e., suspensions, expulsions, hopelessness, self-worth, parental warmth, and gender; Bolland, 2007) among Black youth.

\section{Research Questions}

This dissertation study was designed to answer the following questions:

(RQ 1) What is the relation between school pushout (as measured by suspensions and expulsions) and future outlook (as measured by hopelessness and self-worth) among Black youth? 
(RQ 2) Does parental warmth moderate the relation between school pushout (as measured by suspensions and expulsions) and future outlook (as measured by hopelessness and self-worth) among Black youth?

(RQ 3) Does age and gender impact the relation among school pushout (as measured by suspensions and expulsions), future outlook (as measured by hopelessness and self-worth), and parental warmth amongst Black youth?

\section{Research Hypotheses}

The following hypotheses were constructed in light of the research questions of the dissertation study and reviewed literature:

H1(a): There will be a direct relation between self-reported school pushout (as measured by suspensions and expulsions) and hopelessness among Black youth.

H1(b): There will be an inverse relation between self-reported school pushout (as measured by suspensions and expulsions) and self-worth among Black youth.

H2: Parental warmth will moderate the relation between self-reported school pushout (as measured by suspensions and expulsions) and future outlook (as measured by hopelessness and self-worth).

H3: Age and gender will impact the relation among school pushout (as measured by suspensions and expulsions), future outlook (as measured by hopelessness and self-worth), and parental warmth amongst Black youth.

\section{Significance of the Study}

The dissertation study contributes to the breadth of knowledge regarding the impact of school pushout on future outlook for Black youth. Data obtained from the study provide parents, administrators, teachers, and students with information that 
captures the association between school pushout and future outlook, and highlights the impact that parental warmth has on the relation between school pushout and future outlook. The predictor variables (i.e., suspensions and expulsions), criterion variables (i.e., hopelessness and self-worth), and moderator variable (i.e., parental warmth) that were investigated in this dissertation study were not conjointly studied in extant school pushout literature (Farrington, 1989; Kasser, Koestner, \& Lekes, 2002; Tolson et al. 2014). The constructs introduced in this dissertation study were identified in an effort to respond to the gap in literature.

\section{Assumptions}

This dissertation study used data from the MYS study (Bolland, 2007) and is based on the following assumptions:

1. The relevance of the study is critical given the persistence of the STPP and the need for identification of potential risk- and, namely, protective factors.

2. The MYS study assumes the sample represents Black youth living in impoverished neighborhoods (Bolland, 2007).

3. Participants were encouraged by the statement of confidentiality and anonymity and candidly answered the survey items (Bolland, 2007).

4. A final assumption includes recognition of the utilization of subscales as potentially valid measures of study constructs.

\section{Limitations}

Limitations for this dissertation study, in light of using MYS study data, are included in the following summary: 
- In order to reduce participant burden, some of the constructs were measured using subscales instead of including all items contained within a particular scale; however, researchers reported validity and reliability for all subscales.

- The nature in which the data were collected should be considered due to the study's reliance on self-report measures. Research suggests that participants of self-report surveys are subject to social desirability bias, especially given the nature of some of the topics addressed in this study (e.g., hopelessness, selfworth; Arnold \& Feldman, 1981).

- Another limitation is the potential presence of confounding variables, which could more readily explicate the descriptive characteristics observed in the sample of interest.

\section{Delimitations}

Due to the nature of this study, specifically the analysis of a pre-existing dataset, the boundaries of this study were previously determined.

- Age: The majority of participants in the original MYS study consisted of youth (i.e., ages 9-19). The dissertation study investigated Black youth (ages 11-17).

- Geographical Area: The MYS study was conducted within the Mobile Metropolitan Statistical Area in Mobile and Prichard, Alabama (Bolland, 2007). This dissertation study only included youth who represent the Metropolitan Statistical Area in Mobile and Prichard, Alabama.

- Race: The majority of participants in the original MYS study consisted of youth who identified as Black. This dissertation study only investigated Black youth.

- School Pushout: The MYS study collected data for school suspensions and 
expulsions; therefore, school arrests were not included in the dissertation study.

- Socioeconomic Status: The majority of participants in the original MYS study are youth who resided in areas deemed as impoverished (i.e., the lowest median household income). This dissertation study only consisted of youth who resided in impoverished neighborhoods.

- Suspensions: The MYS study collected data for out-of-school suspensions, therefore, in-school suspensions were not included in this dissertation study.

\section{Definition of Terms}

1. Drop out/dropout: In this dissertation study, drop out or dropout refers to a student opting to permanently leave school after experiencing school pushout (Nielsen, 1986; Van Dorn, Bowen, \& Blau, 2006). The stigmatizing nomenclature related to dropping out or dropout has been used to reference adolescents' choice to abandon their academic experience; however, contextually, and for the purposes of this dissertation study, school pushout is viewed as an antecedent to, and in many circumstances, synonymous with school dropout (Nielsen, 1986; Van Dorn, Bowen, \& Blau, 2006). Within this dissertation study, terminology such as dropping out and dropout is solely used in order to remain in accordance with how the phenomenon is captured in extant research.

2. Expulsions: indicates being expelled from school (Charnofsky, 1971). Expulsion is generally defined as "the complete and permanent removal of a child from an entire educational system" (Gilliam \& Shahar, 2006, p. 228).

3. Future outlook: refers to expectancies toward the future based on internalized and externalized value of self. In this dissertation study, future outlook is operationalized 
as measures of self-worth and hopelessness from youth's self-report.

4. Gender: refers to gender identity (Bolland, 2004). Please note that since the terms of male and female were used to capture gender in the MYS study, the same terms are utilized throughout the dissertation study. Although the sociologically-appropriate terms for gender are boy and girl, the terms denoting sexual orientation, male and female, are utilized for consistency purposes.

5. Hopelessness: refers to negative expectancies toward oneself and toward the future (Kazdin, French, Unis, Esveldt-Dawson, \& Sherick, 1983; Stotland, 1969).

6. Parental warmth: reflects parents' general tendencies to be supportive, affectionate and sensitive to the child's needs (Lamborn et al., 1991).

7. School pushout: reflects reference to suspensions from school and expulsions out of school (Charnofsky, 1971). School pushout constitutes pushing students out of schools by way of (a) suspensions, (b) expulsions, or (c) in-school arrests. School pushout has also been referenced as exclusion. In this study, school pushout refers to out-of-school suspensions and expulsions.

8. School-to-prison pipeline (STPP): refers to the "growing pattern of tracking students out of educational institutions, primarily via zero tolerance policies, and directly and/or indirectly, into the juvenile and adult criminal justice systems" (Heitzeg, 2009, p.1). Although the STPP is a term that describes the general matriculation of students from educational marginalization to incarceration, this dissertation study focuses on data emphasizing the STPP's nature and design specifically for Black youth.

9. Self-worth: refers to how much one values oneself as a person (Harter, 1982).

10. Suspensions: refers to suspensions from school (i.e., out-of-school suspensions; 
Charnofsky, 1971). Suspensions are the most frequently utilized disciplinary approach in public schools (Gilliam \& Shahar, 2006).

11. Youth: refers to children or students 17 years of age or younger.

12. Zero tolerance: indicates "a global concept that sets limits to perceived problem behavior" (Verdugo, 2002, p. 52)

13. Zero tolerance policies: Zero tolerance policies were implemented in schools in the 1990's as a direct response to fears of gang and drug activity (APA, 2008) and further proliferated as a result of the The Gun Free Schools Act (GFSA) of 1994 and the Columbine High School massacre in 1999.

\section{Organization of the Dissertation}

Chapter I provided an introduction to the study and emphasized the stultifying effects of school pushout on Black youth, including hopelessness and diminished selfworth. Parental warmth was also introduced as a variable of interest, namely due to its significant linkage to social and emotional adjustment of youth. Research questions and hypotheses were presented along with assumptions and limitations of the study.

This dissertation includes an exploration of the relations between the various constructs of the study in Chapter II, to include: (a) the relation between school pushout and hopelessness; (b) the relation between school pushout and self-worth; (c) the impact of parental warmth on the aforementioned relations; and (d) potential gender effects regarding the aforementioned relations. The specific methodological approach and research design utilized to examine the research questions and to capture desired outcomes are outlined in Chapter III. The results of the dissertation study and findings are explicated in Chapter IV. A discussion of the dissertation study findings, 
implications for research, practice, and advocacy, and a conclusion to the dissertation study are presented in Chapter V. 


\section{CHAPTER II}

\section{LITERATURE REVIEW}

This dissertation study will examine the relation between school pushout (i.e., suspensions and expulsions) and future outlook (i.e., hopelessness and self-worth) among Black youth. Parental warmth and gender will also be explored for associations with school pushout and future outlook. This chapter is intentionally organized to (a) elucidate the school-to-prison pipeline and its relevance to this dissertation study, (b) provide a review of extant literature regarding the study constructs, and (c) provide a review of the theoretical frameworks that contextualize this dissertation study.

\section{Elucidating the School-to-Prison Pipeline: Relevance to the Dissertation Study}

Two fifth-grade females were suspended from school for four days because their teacher saw them with nasal spray during recess — a violation of the school's zero tolerance policy for drugs (Suspension Stories, 2015). A 14-year-old male received inschool suspension for hugging his best friend - a violation of the school's zero tolerance

policy for public displays of affection (Suspension Stories, 2015). A $7^{\text {th }}$ grader received a 180-day suspension from school due to a yawn that resulted in the student inadvertently making contact with a teacher who walked up behind the student as she stretched (Suspension Stories, 2015). The previously mentioned suspensions serve as exemplars of the relation between zero tolerance school policies and school pushout 


\section{Zero Tolerance School Policies}

Although, zero tolerance school policies have not been universally defined (Heitzeg, 2014; Skiba \& Knesting, 2001), defining zero tolerance can potentially clarify such policies in schools. Zero tolerance can be defined as "a global concept that sets limits to perceived problem behavior" (Verdugo, 2002, p. 52). Zero tolerance policies, were initially constructed by the U.S. Customs Agency in order to target and discourage drug trade, but eventually precipitated revisions to national school policy (Verdugo, 2002).

In the 1980 's, an increase in violence in urban schools was reported by mass media along with fearmongering concerning superpredators (i.e., a term created to describe feral and depraved youth; Muschert, 2007). The superpredator myth, spurred by the media, served to evoke fear and panic in mainstream America that the rise of youth who had no impulse control would result in the murders of countless innocent people (Muschert, 2007). Zero tolerance policies were implemented in schools in the 1990's as a direct response to fears of gang and drug activity (American Psychological Association [APA], 2008).

The Gun Free Schools Act (GFSA) of 1994 solidified the enactment of zero tolerance policy at the federal level by mandating school administrators to expel students for a minimum of one year for bringing a gun to school, and subsequent amendments expanded the regulations to include objects that may be used as weapons (GFSA, 2012). Zero tolerance policies were fermented by mass shootings such as the Columbine High School massacre in 1999 (Fuentes, 2014). After said tragedy, states were free to interpret and implement the nationally mandated policies at their discretion based on the GFSA, 
and zero tolerance school policies were further promulgated (Webb \& Kritsonis, 2006). Zero tolerance school policy implementation has been unstandardized, unregulated, and for many years, unchallenged (Webb \& Krtisonis, 2006).

Zero tolerance policies were widely implemented in inner city or urban schools as compared to rural and suburban schools (Verdugo, 2002). Explicitly stated, zero tolerance policies were focused narrowly in schools with a high enrollment of students from historically marginalized populations, namely Black youth (Ayers et al., 2001). Although zero tolerance policies were initially enacted to deter violence in schools, the policies were extended to punish violent and non-violent behaviors with the same ideology, exclusion as restitution (Heitzeg, 2014; Skiba \& Knesting, 2001).

The criminalization of minor acts of misconduct and normative youthful behavior, along with the disparate implementation of zero tolerance policies in urban schools, have greatly impacted Black youth (Noguera, 2003). The criminalization of minor infractions present in schools (Balfanz \& Fox, 2014) mirrors the history of criminalization of minor offenses in the nation's criminal system. The nation's criminalization paradigm has resulted in racial disproportionalities and the gross overrepresentation of incarcerated Black males (Alexander, 2012).

As states have increasingly outsourced prisons to private corporations, the incarceration of individuals, specifically Black men, has also increased at an alarming rate (Alexander, 2012; Smith \& Harper, 2015). Prison privatization realigns the intent of imprisonment to for-profit business, which drastically differs from the often-commonly held belief that the American carceral system is designed to reform prisoners and protect society (Alexander, 2012). The STPP should be examined with the understanding of its 
association with prison privatization. An explicit connection between the STPP and prison privatization is the increased demand for prisoners (i.e., employees) to fill the prisons in order for the prison corporation to make a profit, which consequently relates to the increased incarceration of Black males and females and increased school pushout rates of Black males and females (Alexander, 2012; Morris, 2016; Smith \& Harper, 2015). The argument could be made that the connection between school pushout rates for Black males and females and incarceration rates for Black males and females is coincidental or by chance; however the correlations are undeniable (Alexander, 2012; Balfanz \& Fox, 2014; Losen \& Martinez, 2013; Smith \& Harper, 2015).

Finn and Servoss (2014) explored the systemic nature of school pushout and its connection to the surrounding community or neighborhood as they analyzed three national surveys of $10^{\text {th }}$ grade students $(N=8,775)$ and students' respective schools $(N=$ 500). Study findings revealed that out-of-school suspensions were implemented at a higher rate in schools located in higher-crime neighborhoods. Losen and Martinez (2013) also reported similar findings with their designation of hotspot schools. Hotspot schools were defined within their report as secondary schools that suspended $25 \%$ or more of their student population. In the academic year, 2009-2010, researchers reported 2,624 secondary schools, nationwide, as hotspots.

Balfanz and Fox (2014) also reported demographic disparities in the usage of suspensions. In their longitudinal cohort study of $9^{\text {th }}$ graders $(N=181,897)$, researchers reported increased suspensions among minority and high poverty populations. Among students representing the aforementioned populations, findings revealed (a) increased suspensions, (b) increased frequency of suspensions, (c) increased duration of 
suspensions, and (d) increased likelihood of receiving suspensions for minor offenses. Counterintuitively, some urban school districts use zero tolerance policies to justify school suspensions for such discipline issues as absenteeism (i.e., truancy). In fact, legislators in the state of Maryland, deemed it necessary to establish a law that prohibited schools from suspending a student for truancy (Glass, 2014). Although suspensions for truancy are still lawful in most states, empirical evidence does not support the rationale for suspending students as a corrective action for poor attendance (Heitzeg, 2014; Losen \& Martinez, 2013).

Increased police presence in many urban schools is also a result of zero tolerance policies and youth criminalization paradigms. School policing is a growing law enforcement field (Hirschfield, 2008) and many school districts are investing more money to increase police presence (i.e., school resource officers [SROs]) than they are for mental health support personnel. Losen and Martinez (2013) suggested that youth advocates challenge school districts by asking those with "large investments in school policing and high security whether they have adequate numbers of school counselors, mental health support, and sufficient training resources for teachers" (p. 5).

Zero tolerance policies are upheld under the premise that such policies protect children and keep schools safe; however, there are no empirical studies supporting a direct correlation between zero tolerance policies and safer schools, nor does empirical evidence support the claim that zero tolerance policies reduce misconduct (APA, 2008; Losen \& Skiba, 2010). Findings show that the majority of suspensions are issued for non-violent behaviors, and possession of a weapon is rarely reported as the reason for suspensions (Mendez \& Knoff, 2003). In fact, the American Psychological Association 
Zero Tolerance Task Force reported that there might be an inverse relationship between schools' suspension and expulsion rates and school climate (APA 2008).

The Zero Tolerance Task Force (APA, 2008) was charged with examining research related to the academic and behavioral outcomes of zero tolerance polices. The task force investigated the following five assumptions of zero tolerance policies:

1. "School violence is at a crisis level and increasing, thus necessitating forceful, no-nonsense strategies for violence prevention" (p. 853).

2. "Through the provision of mandated punishment for certain offenses, zero tolerance increases the consistency of school discipline and thereby the clarity of the disciplinary message to students" (p.853).

3. "Removal of students who violate school rules will create a school climate more conducive to learning for those students who remain" (p. 854).

4. "The swift and certain punishments of zero tolerance have a deterrent effect upon students, thus improving overall student behavior and discipline" (p. 854).

5. "Parents overwhelmingly support the implementation of zero tolerance policies to ensure the safety of schools, and students feel safer knowing that transgressions will be dealt with in no uncertain terms" (p. 854).

The findings from this evidentiary review suggested that the assumptions are not valid, and in fact, data contradict the assumptions.

According to a report issued by the United States Government Accountability Office (2016), the deleterious effects of zero tolerance policies on Black youth include, but are not limited to (a) school pushout (i.e., suspension, expulsion, and law enforcement 
referrals), (b) loss of classroom time, (c) unimproved behavior, (d) less likely to graduate, (e) more likely to repeat a grade, (f) drop out of school, and (g) become involved in the juvenile justice system. Forced entry into the juvenile justice system frequently results in further discrimination, victimization, and criminalization of Black youth (Ali \& Dufresne, 2008; Caton, 2012). In addition to the aforementioned conspicuous effects, there are other inconspicuous effects, such as negative future outlook (i.e., decreased selfworth and increased hopelessness), and the stigma of being bad (Gregory \& Thompson, 2010; Laura, 2014). Many Black youth who experience school pushout, as a result of zero tolerance policies, are labeled and continue to be subjected to school pushout or classroom pushout (i.e., pushed out of mainstream classes into special education classes; Gregory, 1997; Nelson, 2014; Noguera, 2003).

As a result of zero tolerance policies, school pushout stigma often continues to impact many Black students post high-school graduation, as they seek college admission. When some Black youth apply for college, they are often subjected to significant negative consequences based on their high school disciplinary records (Center for Community Alternatives [CCA], 2015). A student's high school suspensions or expulsions could potentially preclude them from being considered a viable candidate for college acceptance (CCA, 2015).

In a recent report, the CCA (2015) found that approximately $75 \%$ of colleges and universities request high school disciplinary records. Of those higher education institutions requesting such information, $90 \%$ of them use the collected data to determine admission decisions. Colleges and universities that request disciplinary records for applicants also use the information to determine if students should be admitted with 
provisions (e.g., probationary period or housing restrictions). As a result, Black students may not gain college access due to their previous suspensions and/or expulsions.

Alternatively, some Black students with school pushout history may gain acceptance into a college and, consequently, receive substandard treatment based on previous high school misconduct (CCA, 2015).

In summary, although zero tolerance policies have not been effective in keeping schools safe (APA, 2008), the implementation and exacerbation of such policies have been effective in keeping Black youth out of mainstream classes, talented and gifted programs, advanced placement courses, and institutions of higher education, and thusly, decreasing opportunities for them to advance academically, emotionally, and economically (CCA, 2015; Losen \& Skiba, 2010). While no evidence supports the rationale for the implementation of zero tolerance policies, they continue to pervade urban schools and disparately impact Black youth (Ayers et al., 2001; Fuentes, 2014). The direct impact of zero tolerance polices on Black youth is school exclusion, or school pushout — a direct effort to remove or exclude youth from schools, mainly via suspensions and expulsions.

\section{School Pushout}

Oftentimes, teachers and administrators view some Black students as incorrigible, and as a result, Black students are disproportionately not welcomed at school (Heitzeg, 2014). School pushout constitutes pushing students out of schools by way of (a) suspensions, (b) expulsions, or (c) in-school arrests. School pushout has also been referenced as exclusion. For the intents and purposes of this dissertation study, school pushout will only refer to suspensions and expulsions. Suspensions refer to out-of-school 
suspensions, while expulsions refer to students no longer being enrolled at their respective schools.

\section{Suspensions}

Suspensions are the most frequently utilized disciplinary approach in public schools (Gilliam \& Shahar, 2006). The frequency and duration of suspensions are generally set by administrators and vary based on state, district, local, and school-specific standards. When students are suspended from school, they are excluded from their regularly scheduled academic programs by receiving either in-school or out-of-school suspensions. In-school suspensions entail disengaging or removing students from their regular academic classes and temporarily reassigning them to a designated space other than their classrooms. In contrast, out-of-school suspensions involve the outright exclusion from classrooms and the school. As Skiba (2000) states, "suspension often becomes a pushout tool to encourage low achieving students and those viewed as 'troublemakers' to leave school before graduation” (p.13). Consequently, suspensions frequently serve as the entry point for the school-to-prison pipeline (STPP), which is a system that provides youth, specifically Black youth, with ominous outcomes (Skiba, 2000).

\section{Expulsions}

Expulsion is generally defined as "the complete and permanent removal of a child from an entire educational system" (Gilliam \& Shahar, 2006, p. 228). Expulsion serves as one of the more drastic forms of exclusionary practice and marks the end of that particular educational system's responsibility to provide educational, behavioral, and emotional support for the student who has been expelled (Gilliam \& Shahar, 2006). 
Based on OCR data, expulsions are less likely to be enforced when compared to suspensions, and Black students are more likely to be expelled than their counterparts (OCR, 2014, 2016). In some instances, regardless of a student's ability to seek a reconnection with his/her school after an expulsion, he/she will no longer be welcomed in that particular school and possibly rejected from other schools in the surrounding district (Losen \& Skiba, 2010). In addition to suspensions, expulsions also serve as an entry point for the STPP and also critically impact student outcomes (Losen \& Skiba, 2010; Skiba, 2000).

\section{School Pushout and STPP}

Risk factors for school pushout have historically included: (a) special education status, (b) male gender identification, (c) low socioeconomic status, and (d) students of color, and more recently (e) youth identifying as Lesbian, Gay, Bisexual, Transgender, and Queer (LGBTQ; Nelson, 2014; Theriot, Craun, \& Dupper, 2010). A robust body of literature supports findings that excessive school suspensions of students of color are directly tied to dropout rates, as students who are suspended are more likely to exhibit poor academic performance (Ali \& Dufresne, 2008; Skiba \& Rausch, 2006) and ultimately, drop out of school (Heitzeg, 2014; Losen \& Skiba, 2010). Traditionally, stigmatizing nomenclature such as dropping out or dropout has been used to describe the tendency of adolescents to abandon their academic experience. Within the context of understanding the STPP, it is apparent that in many cases youth are not willingly choosing to drop out or pull out as some literature suggests, but they are actually being pushed out (Nielsen, 1986; Van Dorn, Bowen, \& Blau, 2006). Therefore, the terminology (e.g., dropping out and dropout) is primarily used within this literature 
review in an effort to explicate the most research-relevant renderings of the phenomena.

Suspension rates are directly correlated with dropout rates as a result of many suspended students becoming engaged with delinquent behavior and encountering academic challenges due to time out of class (Krezmien et al., 2014; Losen \& Skiba, 2010). As students are suspended and academically disengaged, they may internalize the labels of being pushed out and develop a negative outlook on education, and ultimately, life (Noguera, 2003). Researchers proffer that such school detachment experiences may serve as an indicator for Black youths' perceived future outlook (Balfanz \& Fox, 2014; Losen \& Martinez, 2013; Toldson, McGee, \& Lemmons, 2014). Toldson et al. (2014) found an inverse relationship between discipline referrals and future outlook among Black males (i.e., $8^{\text {th }}$ and $10^{\text {th }}$ graders; $n=703$ ).

Other researchers have confirmed similar findings (Balfanz \& Fox, 2014; Losen \& Martinez, 2013; Wald \& Losen, 2003). Balfanz and Fox (2014) reported disturbing findings that associated the increased likelihood of a student dropping out with out-ofschool suspension experiences. In a longitudinal cohort study $(N=181,897$ ninth graders), researchers found that a student who has been suspended only one time in ninth grade is twice as likely to drop out of school (32\%) than a ninth-grade student who was not suspended (16\%). Such findings have implications for students who are classified as repeat offenders as well as those who are typically viewed as obedient, but are suspended for an isolated event (Balfanz \& Fox, 2014).

Some school districts use correctional programs like disciplinary alternative schools as an alternative to expulsion and an attempted deterrent for dropping out. Typically, school districts offer alternative schooling as a final attempt to provide 
students an education within a confined and segregated institution; however, the educational experience differs from mainstream education mainly due to its closer connection to juvenile detention centers (Vanderhaar, Munoz, \& Petrosko, 2014). In a longitudinal study conducted by Vanderhaar et al. (2014) in the Jefferson County Public Schools district in Kentucky (i.e., a school district designated as one of the districts having the largest number of hotspot secondary schools in the U.S.; Losen \& Martinez, 2013), researchers found that approximately 1 out of 10 students $(N=7668$ third-graders $)$ during an academic year were placed in disciplinary alternative schools. Racial disproportionality was salient in disciplinary alternative school placement for students with approximately $13 \%$ of Black students $(n=2715)$ being placed compared to approximately $4 \%$ of White students $(n=4638)$. The study also revealed high rates for re-entry or recidivism after the first placement, which has implications for the entrenched practice of utilizing disciplinary alternative schools as a corrective alternative for students.

School pushout is associated with (a) decreased attendance rates, (b) increased course failure, and (c) school disengagement (Balfanz \& Fox, 2014). The aforementioned conditions often precipitate participation in antisocial behaviors (Morrison, 2001). Students are more likely to drop out of school when they are excluded from their academic environments and frequently experience a diminished sense of belonging at school and unsupervised time at home during a suspension or expulsion (Morrison, 2001; Wald \& Losen, 2003). The lack of supervision coupled with increased opportunities to engage in deviant behavior also increase the likelihood that students will encounter the criminal system as well. Therefore, disengagement (i.e., suspensions, 
expulsions, dropping out) from the educational system indirectly becomes an antecedent to engagement with the carceral system (Wald \& Losen, 2003).

Dropout rates are positively correlated with incarceration rates. For example, statistics state that approximately $68 \%$ of state prisoners dropped out of school (Martin \& Halperin, 2006; Wald \& Losen, 2003). The significant relationship between suspensions and school dropout activity, with youth being twice as likely to dropout after experiencing one suspension (Balfanz \& Fox, 2014; Krezmien, Leone, \& Wilson, 2014; Schiff \& Bazemore, 2012), combined with the association between dropout and incarceration rates (Fuentes, 2014; Heitzeg, 2014; Wald \& Losen, 2003) coalesce into the STPP (Christle, Jolivette, \& Nelson, 2005; Heitzeg, 2009).

The STPP, as previously discussed, can be defined as the "growing pattern of tracking students out of educational institutions, primarily via zero tolerance policies, and directly and/or indirectly, into the juvenile and adult criminal justice systems" (Heitzeg, 2009, p.1). This dissertation study focuses on an entry point into the STPP by investigating the impact of school pushout on future outlook (i.e., hopelessness and selfworth) for Black youth, as it is evidenced in literature that school pushout and future outlook are associated with the likelihood of dropout (Martin \& Halperin, 2006; Skiba, 2000). Subsequently, dropout gives rise to incarceration, and school pushout predisposes Black youth to feelings of hopelessness and desires to drop out of school, which are intricately linked to incarceration (Skiba, 2000).

A startling report from the U.S. Department of Education (2016) that links national spending on schools and prisons, states "over the past three decades, state and local government expenditures on prisons and jails have increased about three times as 
fast as spending on elementary and secondary education" (p. 1). Likewise, the patterns and policies of mass incarceration outlined by Alexander (2012) in The New Jim Crow, which are seemingly colorblind, often lead to racialized outcomes - praxis congruent with the nature and results of zero tolerance policy implementation. The pipeline from schools to prisons is dubiously formed by exclusionary principles and practices. In other words, the exclusionary nature of discipline praxes for schools and prisons are comparable. As Dolovich (2011) states, "The logic of exclusion and control is first and foremost the logic of imprisonment” (p. 267).

To further clarify, the STPP captures the matriculation of historically marginalized youth from schools to prisons by tracking patterns of (a) school pushout rates, (b) dropout rates, and (c) incarceration rates. However, this dissertation study examined (a) school pushout rates, in regards to the various factors that are generally associated with the STPP. The other components of the STPP (i.e., dropout and incarceration) were not examined in this dissertation study, but such components are valuable and necessitate consideration in light of linkages with future outlook.

The stultifying rhetoric surrounding the STPP has inhibited many practitioners and researchers from (a) taking ownership of implicit biases, (b) working to create a more supportive classroom and school culture to assist in keeping Black youth academically engaged in schools and hopeful about their futures and (c) conducting research that avoids victim blaming and seeks to highlight protective factors, and (d) advocating for Black youth who are victimized by the STPP (Losen \& Skiba, 2010; Smith \& Harper, 2015; Toldson et al., 2014; van den Bergh et al., 2010). Consequently, practitioners and researchers need to further explore and explicate the implications of school pushout for 
Black youth and the STPP. Furthermore, in addition to implementing culturallyresponsive teaching (Ladson-Billings, 1995) and research practices, advocacy for Black youth must also be prioritized and corroborated among practitioners and researchers.

\section{School Pushout and Race}

Of the 2.8 million students who received one or more out-of-school suspensions during the 2013-2014 academic year, 1.1 million students were Black (Office for Civil Rights [OCR], 2016). The extant racial discrepancies in school suspensions have been identified and documented in recent successive national reports by the OCR (2014, 2016). As cited by Skiba and Peterson (2000), the Children's Defense Fund first analyzed OCR data and reported racial disproportionality in school suspensions in 1974. Findings suggested that African-American youth were two to three times more likely to be suspended than White youth. The disparate trend identified over 40 years ago, is, essentially still relevant today. According to the most recent statistics reported by the OCR (2016), Black youth (i.e., K-12 students) are 3.8 times as likely to receive one or more out-of-school suspensions than their White peers.

Black youth are also expelled from school at disproportionate rates; Black youth are approximately two times as likely as their White counterparts to experience expulsions without educational services (OCR, 2016). Black youth are also disproportionately referred to law enforcement or arrested in school (OCR, 2014; Osher et al., 2015). Schools in the United States disparately discipline Black youth and utilize exclusionary discipline practices resulting in Black youth being pushed out of schools (Osher et al., 2015). 
Black youth are often subjected to school pushout even before they enter the K-12 educational system. Data indicate Black youth as young as 3-years-old and 4-years-old are being pushed out of preschools across the nation. In a nationwide study conducted by the Yale University Child Study Center, researchers examined approximately 4,000 preschools and found racial disparities in expulsions of preschoolers (Gilliam, 2005). Expulsion rates among preschoolers were found to be highest among African-American youth, who were twice as likely to be expelled as European-American youth (Gilliam, 2005).

According to a report issued by the OCR (2016), nearly a decade after Gilliam's national study examining preschool expulsions, Black youth attending public preschools represented $19 \%$ of preschool enrollment, but accounted for $47 \%$ of preschool children receiving one or more out-of-school suspensions. It has become such an epidemic that some states like New Jersey have implemented laws that ban suspensions and expulsions of preschoolers (New Jersey, n.d.). Other school systems have decided to ban suspension or expulsion of young students based on the nature of the infraction. For instance, Minneapolis public schools banned suspensions of young students (i.e., preschool through first grade students) for nonviolent misconduct (Matos, 2014).

Black youth are often referred to the office for minor behavior violations that are considered subjective (e.g., excessive noise or disrespect; Skiba et al., 2002). Comparatively, White youth are more likely to receive referrals for objective infractions (i.e., aggressiveness or violence; Skiba et al., 2002). In addition to being frequently suspended for subjective misconduct, Black youth are also more likely to be punished than their White peers when committing the same infractions (Mendez \& Knoff, 2003; 
Wallace, Goodkind, Wallace, \& Bachman, 2008). A seminal study that examined trends in racial, ethnic, and gender differences in school discipline among a large sample of high school students $(N=73,539)$ revealed that Black students were slightly more likely than their White peers to be referred to the office for discipline issues, and two to five more times likely to be suspended or expelled (Wallace et al., 2008). Researchers reported that while suspension rates decreased over time for most racial/ethnic groups, these rates increased for Black youth. The study also revealed that racial discrepancies in school discipline were not attributed to socioeconomic status, as socioeconomic status was considered as a potential risk factor for school pushout.

In another confirmatory study, which examined annual office referrals for problem behaviors among 364 elementary and middle schools, Skiba et al. (2011) reported that African-American elementary students were 2.19 times more likely to receive office referrals than their White peers. African-American middle school students were 3.78 times more likely to be referred to the office than White students. Skiba and Rausch (2006) state, "Although rates of absolute suspension appear to be highest in poor urban districts, disparities between Black and White suspension rates appear to be as great or greater in higher resourced suburban districts” (p. 91). Such evidence leads scholars to believe that the racial discrepancies surrounding school pushout are due to factors that extend beyond socioeconomic status or the demographic makeup of the school (Skiba et al., 2002; Wallace et al., 2008).

For many years, school exclusion or pushout research focused on individual student behavior as risk factors. Although demographic factors still need to be examined, recent research has pivoted toward examining school level risk factors in lieu of student 
characteristics (APA, 2008; Theriot et al., 2010). Factors regarding school learning climate and teacher-student relationship have been most widely studied (Hughes \& Kwok, 2007; Khalifa, Gooden, \& Davis, 2016; Skiba, Michael, Nardo, \& Peterson, 2002). Other school level factors have also been explored such as teacher job satisfaction (Gilliam \& Shahar, 2006). Gilliam and Shahar (2006) found that the likelihood of suspensions was associated with teacher job satisfaction, as suspensions were more likely when teacher job satisfaction was low. They also reported minimal expulsions when teacher stressors were low.

A robust body of literature supports the importance of teacher-student relationship on student academic and behavioral adjustment (Hughes \& Kwok, 2007; Skiba et. al, 2002; Tenenbaum \& Ruck, 2007). The impact of teacher-student racial congruence has also been widely studied to examine implicit racial bias to determine if teachers' perceptions of Black students are influenced by anti-Black bias (Oates, 2003; Toldson \& Ebanks, 2014). Research supports that anti-Black bias among White teachers does negatively impact their respective relationships with Black students (Oates, 2003; Tenenbaum \& Ruck, 2007; Toldson \& Ebanks, 2014). Research regarding the perfunctory elements of the teacher-student dynamic, such as daily communication and interaction, reveals racial discrepancies in treatment (Skiba et al., 2002; Tenenbaum \& Ruck, 2007; van den Bergh, Denessen, Hornstra, Voeten, \& Holland, 2010; Toldson \& Ebanks, 2014). These racial biases may have implications regarding teachers' tendencies to disproportionately write discipline referrals for Black youth—an action, which often leads to suspensions and expulsions. 
In a recent study conducted by the Yale University Child Study Center, researchers showed videos of a diverse group of students interacting within a classroom to 132 educators (Gilliam et al., 2016). The educators were told to expect some misconduct in the classroom as they watched the video; however, there were no actual misbehaviors demonstrated in the video. Researchers tracked eye movement of the educators as they viewed the video in anticipation of misbehaviors. Gilliam et al. (2016) found that educators were more likely to look at Black boys in expectation of misconduct. Such studies further elucidate the impact that implicit racial bias has on the suspension and expulsion of Black youth.

Implicit racial bias is not only limited to White teachers: Black teachers are subject to acting on unconscious anti-Black biases as well. Recent maltreatment of Black youth in schools include one of the most publicized occurrences - the 2015 incident at Spring Valley High in Columbia, South Carolina, in which a Black teacher complicity watched as a White School Resource Officer (SRO) slammed a Black adolescent female to the ground for not complying with the SRO's demands (Craven, 2015). Although the Spring Valley High incident is as a single occurrence, the incident, as well as other less publicized incidents, illuminates the existence of implicit biases among teachers and administrators irrespective of race.

While there is a substantial body of literature that emphasizes the systemic racial roots of disparate disciplinary practices (e.g., suspensions, expulsions, and arrests) exercised against Black youth (Skiba et al., 2002; Toldson et al., 2014; Wald \& Losen, 2003), some scholars have purported that school pushout of Black youth (i.e., racial discipline gap) is attributed to factors other than implicit bias or racial antipathy (Kinsler, 
2011; Wright, Morgan, Coyne, Beaver, \& Barnes, 2014). For instance, Kinsler (2011) studied the Black-White school discipline gap among a sample of North Carolina students, teachers, and principals. His findings suggest that the discrepancy in exclusionary discipline is not significant within schools, but is only a factor when comparing across schools (Kinsler, 2011). In other words, he purports that a Black student and a White student would receive congruent penalties for similar violations if those students attended the same school (Kinsler, 2011).

Kinsler also noted that White and Black teachers and administrators did not exhibit any racial bias regarding student treatment since both White and Black educators treated Black youth the same within the context of his study. However, such a statement denies implicit racial bias and the impact it can have on Black and White educators' perspectives toward Black youth. Although he states that such a finding does not mean that bias was not present, the findings in the study cannot be supported while simultaneously deemphasizing the significance of implicit racial biases (Kinsler, 2011).

In another study that examined discrepancies in school suspensions based on race, Wright et al. (2014), replicated previous studies and confirmed racial gap findings between Black and White students; however, in a secondary analysis, the researchers stated that prior problem behavior of the student accounts for the racial gap. In other words, according to the study, a student's previous misconduct solely explains the racial gap. The fallacy within this study is the assumption that a student's previous misconduct was predicated upon the student's characteristics without considering the teacher's implicit racial bias. The researchers utilized teacher reports on the Social Skills Rating Scale (SSRS; Gresham \& Elliott, 1990) to assess students' prior problem behavior. The 
teachers were asked to rate students' social skills and behaviors during their K-3 public school experience (excluding second grade; Wright et al., 2014). Therefore, the targeted measure, prior problem behavior, was calculated based on earlier reports of students' behavior reported by teachers (Wright et al., 2014), which confound the study's findings.

The widely accepted body of research supporting racial discipline gaps identifies antecedents as (a) the existence of racial bias among teachers writing disciplinary referrals (van den Bergh et al., 2010) and (b) students' likelihood to experience multiple suspensions after the first suspension (Losen \& Skiba, 2010). The deleterious impact of school pushout on youth, namely Black youth, is pronounced in empirical literature (Losen \& Skiba, 2010; Toldson et al., 2014).

\section{School Pushout and Gender}

Generally, males are more likely than females to experience school pushout (Skiba et al., 2002; Wallace et al., 2008). In a study that examined gender difference trends in school discipline among U.S. high school students (i.e., $10^{\text {th }}$ graders in approximately 420 public and private schools per year) between 1991 and 2005, intraracial comparisons (i.e., comparisons within race) revealed that males $(n=35,896)$ are more likely than females $(n=37,643)$ of the same race/ethnicity to be suspended or expelled (Wallace et al., 2008). In a study that examined disciplinary data for 11,001 middle school students in 19 different middle schools, Skiba et al. (2002) found that males were more likely to be referred to the office for a range of infractions (e.g., minor infractions, fighting, threat, vandalism), while females were only more likely to receive office referrals for truancy. 
Wallace et al. (2008) found that the same gender trend was not consistent across races (i.e., inter-racial comparisons, such that males of any race were referred more than females of any race), as Black males experienced the most school pushout and Black females encountered more pushout than White males and females. Such findings have exposed a steady trend, as the OCR (2016) reported that among K-12 students, $18 \%$ of Black males, $10 \%$ of Black females, $5 \%$ of White males, and $2 \%$ of White females received one or more out-of-school suspensions. The inconsistent gender discrepancies concerning race, when race and gender interact, have been duly noted (Finn \& Servosa, 2014, Losen \& Martinez, 2013; OCR, 2014, 2016; Wallace et al., 2008).

As previously stated, Black youth are 3.8 times as likely as White youth to be suspended one or more times (OCR, 2016) and three times more likely to be suspended or expelled from their respective schools (OCR, 2014). In addition to disproportionate school pushout rates based on race, gender disparities exist as well. Gender disparities for Black youth concerning school pushout commence prior to the K-12 experience, as captured in the previously referenced Yale University study; the study's findings support the notion that preschool marks the inception of school pushout praxis within the education system for many Black students (Gilliam, 2005). In this national study examining preschool expulsions, preschool boys were reported as being 4.5 times more likely to be expelled than preschool girls. Among Black youth; however, the gender disparity was more pronounced than any other ethnicity represented in the study, as expulsions of Black preschool boys accounted for approximately $90 \%$ of the expulsions among Black preschoolers. 
The gender disparity trends also apply to out-of-school suspensions. According to the U.S. Department of Education (2014), 20\% of Black males received an out-of-school suspension, while more than $12 \%$ of Black females were suspended from school. Despite the implementation of federal laws, such as Title IX and the Gender Equity in Education Act of 1993, which were designed to prevent gender discrimination in public education, school pushout gender discrimination is prevalent (Gregory, 1997; Skiba et al., 2002; Wallace et al., 2008).

Research examining the school pushout phenomenon among Black youth has traditionally focused on Black males since males generally experience school pushout at a higher rate than Black females. In a seminal article that examined summary data of approximately 25 million elementary and secondary students, published by the U.S. Department of Education Office for Civil Rights, Gregory (1997) reported findings that revealed schools' responses to Black males' misbehavior (i.e., problem behaviors). The study investigated the likelihood of schools to respond to Black males' misbehavior by utilizing (a) corporal punishment, (b) suspension from school, and (c) placement in Special Education for the Behaviorally Disordered. Results indicated that Black males, in comparison to White females, were approximately 16 times more likely to receive corporal punishment, 6 times more likely to be suspended, and 5 times more likely to be labeled with a behavior disorder and placed in Special Education (Gregory, 1997). Gregory's conclusion, which has been supported by other researchers, is that students essentially have three strikes if they are (a) poor, (b) Black, and (c) male (Mendez \& Knoff, 2003; Noguera, 2003; Skiba et al., 2002). 
Researchers such as Mendez and Knoff (2003) reported the same findings of Black males who are living in poor conditions being suspended from school at much higher rates than any other subgroup. In a demographic analysis of a large school district (i.e., $N=142$ schools), Mendez and Knoff (2003) reported that poor African-American males in special education received the highest suspension rates. They also noted that out-of-school suspensions in the primary and middle grades serve as a predictor of future suspension and precipitates grade retention, and ultimately, school failure (Losen \& Skiba, 2010; Mendez \& Knoff, 2003). The aforementioned association between primary and middle grade suspensions as a predictor of future suspension is significant as Black males are often perceived as being older and less innocent than their White peers (Goff et al., 2014). Almost 20 years after Gregory's seminal analysis, the OCR data (2016) continues to support findings of Black males being subjected to the highest rates of school pushout.

The dominating discourse in the previously mentioned studies and other subsequent studies (Mendez \& Knoff, 2003; Noguera, 2003; Skiba et al., 2002) focused on the dubious differences between Black males and youth represented in other cohorts. Fewer studies have emphasized the disproportionate school pushout rates of both Black males and Black females when compared to females and males representing other races. In other words, the comparison within race and between genders (i.e., Black males vs. Black females) has deemphasized the overrepresentation of Black females' school pushout experiences evidenced when examining between races and within genders (i.e., Black females vs. White females) or between races and between genders (i.e., Black females vs. White males). 
The previously mentioned study by Mendez and Knoff (2003) provides an example of the tendency of researchers to report gender discrepancies while simultaneously minimizing the overrepresentation of Black female school pushout. In the longitudinal study of approximately 142 elementary, middle, and secondary schools, Mendez and Knoff (2003) reported that Black males and females were disproportionately represented in suspension data across the K-12 spectrum compared to their peers. The researchers noted that although Black females were overrepresented, Black males were drastically overrepresented compared to their counterparts. The emphasis that is put on Black male school pushout sometimes overshadows the pushout disproportionality witnessed among Black females when compared to other cohorts (Crenshaw et al., 2015). In light of the intransigent trend of disparate treatment of Black males in schools, Black females' experiences have often been understudied, and consequently, undervalued (Crenshaw et al., 2015; Morris, 2016). Due to researchers typically examining Black females as a sub-group for Black youth or a comparison group for White females in school pushout data analyses, school pushout and extant disparities that Black females experience have often been overlooked. As school pushout rates for Black females are steadily increasing, it is imperative that researchers examine gender disparities among Black youth when studying school pushout, instead of solely focusing on intra-gender comparisons (Crenshaw et al., 2015).

Black females represented $8 \%$ of enrolled students in K-12 schools during the 2013-2014 academic year, nationwide, but they represented 14\% of students who received one or more suspensions (OCR, 2016). The statistics for Black preschool girls are more disparate than those reported for K-12 students, as Black girls represented 20\% 
of female preschool students, but $54 \%$ of female preschool children receiving one or more suspensions (OCR, 2016). Black females experience school pushout more frequently than their White female counterparts with recent reports indicating that Black females are six times more likely to experience school pushout than White females (OCR, 2014). Research reveals that Black females are also more likely to be suspended and expelled than White males (OCR, 2016; Wallace et al., 2008). As cited by Crenshaw et al. (2015), Black females have been documented as representing the fastest growing demographic in the juvenile justice system.

In her seminal book, Pushout: The Criminalization of Black Girls in Schools (2016), Morris presents narratives of Black girls' school pushout experiences. Through qualitative methodology, Black females shared the various ways in which they were pushed out of schools while feeling (a) undervalued, (b) overlooked, (c) misunderstood, (d) unsecure by the presence of SROs, (e) unsupported by teachers and counselors, and (f) parentified. School pushout of Black females can result in a unique set of outcomes that males do not normally experience, namely, (a) pregnancy, (b) financial reliance on males involved in criminal activity, and (c) child sex trafficking (George, 2015). Data on school pushout and its impact on Black youth are not lacking, but a deficiency in genderdisaggregated studies exists (Crenshaw et al., 2015; Morris, 2016).

Some researchers have deliberately disaggregated and emphasized gender data for Black youth without infusing gender bias. For example, Finn and Servoss (2014) in their nationwide study of $10^{\text {th }}$ graders $(N=8,775)$, reported “Overall, males were more likely to be suspended than were females, an effect above and beyond that explained by differences in behavior. There was little or no difference in the suspension of Black 
males and females ...” (p. 2). The researchers strategically highlighted the similarly disparate pushout of Black males and females. Losen and Martinez (2013) also reported that among secondary students representing 5,908 schools nationwide, Black females "were suspended at a higher rate $(18.3 \%)$ than secondary school males from all other racial/ethnic groups" (p. 3).

Theriot et. al's (2010) multilevel evaluation of school pushout (i.e., school exclusion) factors among middle and high school students $(N=9,706)$ representing a school district in the southeastern region of the U.S. revealed that the interaction of race, gender, and socioeconomic status did not significantly predict school pushout. However, researchers reported that poverty, previous suspensions, and severity of last infraction were significant predictors of school pushout. These findings have implications for the interaction effects of gender in conjunction with other school pushout predictors.

\section{School Pushout and Future Outlook}

While many Black youth experience school pushout, their personal stories are often unsolicited, and consequently, undocumented. Few researchers have sought to capture the impact of school pushout on the future outlook of Black youth. Attempts to assess school pushout outcomes often provide statistical analyses of externalized future outlook factors such as graduation, incarceration, and employment opportunities. However, outcomes on internalized future outlook such as hopelessness and self-worth are not widely studied.

According to Krezmien et al. (2014), the main school factors associated with school pushout are poverty, minority student representation, low teacher expectations, and school mobility. As students are pushed out of schools, they inevitably become more 
disengaged from school and educational attainment, as most school pushout practices (i.e., suspensions, expulsions, and arrests) do not involve provision of educational support for students during their time away from school (Losen \& Skiba, 2010). Students returning from suspensions are expected to return to their classes and reengage in academic rigor as if nothing occurred (Losen \& Skiba, 2010; Tenenbaum \& Ruck, 2007). They are inevitably behind in their studies after the suspension lifts, and upon their return, they are more likely to be frustrated due to the possible lack of support from teachers (Tenenbaum \& Ruck, 2007), experience of unresolved conflict, and perceived stigma attached to the suspension (Quin \& Hemphill, 2014).

In a secondary analysis study of $8^{\text {th }}$ and $10^{\text {th }}$-grade males $(N=4,164)$, Toldson et al. (2014) examined a statistical relationship between hopelessness and disciplinary referrals among Black males $(n=703)$. The study revealed a positive relationship between experienced disciplinary referrals and feelings of hopelessness for Black males (Toldson et al., 2014). As previously intimated, while research focused on Black females' experiences regarding exclusionary discipline and future outlook is limited, the Center for Intersectionality and Social Policy Studies garnered insightful data while conducting focus groups with primarily Black females $(n=17)$ in New York and Boston (Crenshaw et al., 2015). Black females shared the unique challenges and burdens they face that impact their school experiences, and ultimately, their future outlook, such as caretaking responsibilities, sexual victimization, bullying, financial hardship, complex trauma, disdain for school, and lack of support from school personnel.

The relationship between school pushout and self-worth has not been extensively investigated. Research concerning school pushout and self-worth has traditionally 
focused on investigating self-worth as a predictor of student behaviors and cognitions that are generally associated with school pushout antecedents, such as aggression (Taylor, Davis-Kean, \& Malanchuk, 2007) or stress (Kliewer \& Sandler, 1992). Positive selfworth has been identified as a potential protective factor from student's experience of stress (Kliewer \& Sandler, 1992). The association between positive self-worth and the way that students experience stress has implications for how a student could potentially deal with school pushout stress.

Thus, the examination of the relationship between school pushout and self-worth could potentially assist in identifying protective factors for Black youth and the schools charged with educating and supporting Black youth. For example, in a recent study examining the relationship between suspensions and academic engagement, a statistical relationship between positive self-worth and disciplinary referrals among Black males (i.e., $8^{\text {th }}$ and $10^{\text {th }}$ graders; $n=703$ ) was reported (Toldson et al., 2014). Among Black males, positive self-worth diminished with the increase of disciplinary referrals among Black males (Toldson et al., 2014).

Research regarding coping processes and perceptions among Black youth also adds to the examination of associations between school pushout and self-worth. Religion, spirituality, and cultural pride were identified as factors contributing to a healthy sense of self among Black adolescent males. The same findings were not significant for Black females ( $N=562$ Black adolescents; Spencer, Fegley, \& Harpalani, 2003). School climate perceptions have also been associated with emotional and behavioral outcomes. In a study examining middle school students $(N=499)$, researchers found that school climate perception impacted students' emotional and 
behavioral outcomes, whereas, boys' emotional outcomes and girls' behavioral outcomes were more greatly impacted (Kuperminc, Leadbeater, Emmons, \& Blatt, 1997).

A longitudinal study examining self-worth (i.e., self-esteem) changes in middle school students $(N=322)$ also included similar findings with reports that school climate and teacher evaluations significantly impacted self-worth (Hoge, Smit, \& Hanson, 1990). In an analysis of cross-sectional data from the National Longitudinal Study of Adolescent Health, researchers reported the significance of school impact (i.e., adolescents' relationship to school) regarding between-level variance of depressive symptoms in adolescents $(N=16,172$; Dunn, Milliren, Evans, Subramanian, \& Richmond, 2015). The same finding was not significant for the impact of neighborhoods. Such studies support the notion that school pushout can impact youths' sense of self (Khalifa, Gooden, \& Davis, 2016; Spencer, Fegley, \& Harpalani, 2003).

\section{School Pushout and Parental Warmth}

Parenting in relation to school pushout has generally been studied investigating parenting as a predictor for unfavorable conduct. For instance, Fleming, Mason, Thompson, Haggerty, and Gross (2015) found that parent self-report of healthy parenting was associated with a lower likelihood of school suspensions. The same findings were not consistent when child report of healthy parenting was examined. Parental warmth has also been associated with youths' adaptive problem solving and stress relief (McIntyre \& Dusek, 1995). Typically, researchers do not specifically examine parental warmth and school pushout as constructs of interest with parental warmth serving as an outcome variable and school pushout as a predictor variable. In contrast, parental warmth is often treated as a predictor variable for youth behavior. 
For instance, parental warmth has been identified as a protective factor against violence for adolescents; this finding transcends race and gender (Brookmeyer, Henrich, \& Schwab-Stone, 2005; Stoddard et al., 2011). Vazsonyi, Pickering, and Bolland (2006) conveyed findings that among Black youth (i.e., ages 9-19; $N=2,867$ ) residing in lowincome areas, parental warmth and consistent discipline served as protective factors for health compromising behaviors and acts of violence. In another study examining the same population, higher levels of parental warmth led to decreased delinquency among Black youth (Church et al., 2012). Similar findings of parental warmth serving as a moderator for the relationship between gang involvement and problem behavior were also reported among a sample of $9^{\text {th }}$ grade students $(N=300$; Walker-Barnes \& Mason, 2004).

A construct that is very closely linked to parental warmth, parental involvement, has been studied in conjunction with school pushout. Parental involvement was reported as a factor with significant relation to disciplinary referrals among $8^{\text {th }}$ and $10^{\text {th }}$ grade Black males $(n=703)$, with higher levels of parental involvement corresponding with lower levels of disciplinary referrals (Toldson et al., 2014). Findings regarding the linkage between parental support and violent delinquency among Black males were also documented, with parental support operating as a moderator of the relation between racial discrimination and violent delinquency (Simons et al., 2006).

Although there are no studies showing a direct linkage between school pushout and parental warmth, the studies highlighted in this section provide context for the connection that exists between student behavior and parental warmth, which has implications for the impact of school pushout on Black youth. There is a need for 
research that intentionally examines the relation between pushout and parental warmth, and more importantly, the impact that parental warmth has on pushout, specifically for Black youth.

\section{School Pushout and Future Outlook: Exploring Parental Warmth as a Moderator}

As researchers and youth advocates seek to discover school pushout and STPP protective factors, the examination of parent-child relationships are noteworthy. The relationship between parents and children has been examined for many years (Baumrind, 1967; Khaleque \& Ronner, 2002). Many scholars have researched the various developmental gains that children experience within healthy parent-child relationships (Ainsworth, 1979; Bandura 1977; Baumrind, 1967; Bowlby, 1969).

The parent-child relationship has been linked with child and adolescent adaptation. Such developmental gains and adaptation could potentially assist Black youth in maintaining a positive future outlook despite school pushout treatment. Research reveals that cross-culturally, perceived parental acceptance-rejection is associated with a child's psychological adaptation or adjustment (Khaleque \& Rohner, 2002).

In a longitudinal study that investigated parental warmth and child adjustment among 12 year-old youth, researchers found that maternal warmth impacted emotional adjustment, and paternal warmth was linked with predicting social and school achievement (Chen, Liu, \& Li, 2000). The study was a follow-up to Khaleque and Rohner's (2002) seminal meta-analytic study, where researchers found that a child's perceived parental warmth or affection resulted in greater psychological adjustment, while perceived parental hostility or aggression resulted in psychological maladjustment. 
Such findings present implications for the impact that parental warmth could potentially have on future outlook of Black youth subjected to school pushout.

Correlations between parental warmth and child hopelessness have been understudied; however, empirical evidence supports associations between parental warmth and depressive symptoms. In a longitudinal study examining predictive factors of new onset depressive episode among over 4,000 adolescents, results indicated that African American youth with a low-income status were at greater risk of onset of a depressive episode than their peers (Van Voorhees et al., 2008). This same study reported parental warmth as a protective factor for depressive episodes (Van Voorhees et al., 2008). Other studies also report similar findings regarding parental warmth's association with depressive symptoms for adolescents (Huang \& Guo, 2009).

Taliaferro and Muehlenkamp (2014) conducted a study with approximately 70,000 adolescents in grades 9-12 that examined parent connectedness as a protective factor for hopelessness (e.g., suicide and suicidal ideation). The study investigated youth among three groups: (1) those who had attempted suicide, (2) those who had experienced suicidal ideations, and (3) those who had not considered suicide within the past year. Among the three groups, hopelessness and depressive symptoms were identified as risk factors for youth who had attempted suicide or thought about attempting suicide. Youth who had not contemplated suicide did not express hopelessness (Taliaferro \& Muehlenkamp, 2014). Parent connectedness was identified as a protective factor among all three groups (Taliaferro \& Muehlenkamp, 2014). In light of the deleterious outcomes of school pushout, parental warmth or connectedness could potentially moderate the effects and serve as a protective factor. 
Parental warmth has been associated with a child's motivation level and enjoyment of life (Baumrind, 1971). Such factors, as motivation and enjoyment of life, are seemingly associated with hopelessness and could be categorized as correlates. Therefore, it can be assumed that parental warmth and hopelessness are negatively related. Such an association could have positive implications for increased perceived parental warmth for Black youth who have experienced school pushout.

As previously mentioned, the nature of parent-child relationships have been linked to youth self-esteem and self-worth for many years. Baumrind (1971) specifically researched the impact of parenting styles on self-esteem. Her research revealed that parenting that is child-centered and tempered with a balance between control and acceptance (i.e., authoritative) is perceived as warm and nurturing. In contrast, parentcentered parenting that is controlling with absolute conformity expectations (i.e., authoritarian) is not perceived as being affectionate or warm. She also categorized permissive parenting as child-centered parenting without any control or standards. Children experiencing parental warmth (i.e., have authoritative parents) tend to be more driven, assertive, independent, communicative, friendly, and enjoy life. Dornbusch, Ritter, Leiderman, Roberts, and Fraleigh (1987) also confirmed similar findings in a study with over 7,000 adolescents. Researchers reported that parental warmth (i.e., authoritative parenting) was positively associated with grades. In contrast, authoritarian and permissive parenting were negatively associated with grades.

In a study that examined Black adolescents' $(N=339$ ninth graders) externalizing behavior and the mediating effects of parental monitoring on said behavior and academic outcomes, researchers found that parental monitoring predicted low externalizing 
behavior (Lopez-Tamayo, Robinson, Lambert, Jason, \& Ialongo, 2016. Data from this study also supported the finding that low externalizing behavior predicts better academic outcomes. Researchers reported that the findings were consistent regardless of neighborhood disadvantage (Lopez-Tamayo et al., 2016).

Deutsch, Crockett, Wolff, and Russell (2012) explored mediating effects of maternal support and parental control by analyzing data among 8,250 Black and White adolescents (i.e., grades 7-11). The study examined associations between maternal support, parental control, delinquent behavior, and association with deviant peers within various neighborhood contexts (i.e., based on economic hardship). Researchers found a direct effect of maternal support on delinquency and parental control was negatively related to association with deviant peers. Higher maternal support was correlated with less association with deviant peers, which also correlated with lower likelihood of engagement in delinquent behaviors. Deutsch et al. (2012) reported that parental control was higher among youth who resided in higher-risk neighborhoods, regardless of race, which suggests that parental control may be used as a protective factor for youth as parents seek to protect adolescents. In other words, increased prevalence of parental control or an authoritarian style of parenting for youth living in higher-risk neighborhoods may be due to neighborhood context (Cantillon, 2006).

Parental warmth has also been examined to determine associations between parental warmth and self-esteem. An investigation of parental warmth and self-esteem can be found in the work of Buri et al. (1988). Researchers found a positive correlation between parental warmth (i.e., authoritativeness) and self-esteem and a negative correlation between parental hostility (i.e., authoritarianism) and self-esteem. The 
investigation of the linkage between parenting styles and self-esteem has implications for school pushout research that examines the relationship between parental warmth and selfworth among Black youth.

Parental warmth has been linked with high-achieving, low-income youth's (Murry \& Brody, 1999), self-esteem (Doyle \& Markiewicz, 2004), and psychological adjustment (Khaleque \& Rohner, 2002). In a meta-analytic study examining the impact of parental acceptance on psychological adjustment among youth (i.e., ages 9-18), the results indicated that youth's perceived paternal acceptance seemed to have a significantly stronger association with psychological adjustment than maternal acceptance (Khaleque \& Rohner, 2012).

In a study that utilized the Mobile Youth Survey, parental warmth was positively associated with self-worth for Black youth (Church et al., 2012). This study also disaggregated parental warmth data and revealed differences in the perceived impact of maternal and paternal relationships on Black youth's self-worth. Although maternal and paternal warmth were both found to have a positive correlation with adolescent's selfworth, the same gender parent's warmth had a greater impact on self-worth (Church et al., 2012). The impact of parental warmth on Black adolescents' sense of self-worth has also been found to change over time depending on the gender of the parent and adolescent (Jaggers et al., 2015). Regardless of the gender of the parent, research supports the notion that having at least one caring adult in a youth's life increases the likelihood that said youth will develop a healthy, caring, and productive sense of self (Murphey, Bandy, Schmitz, \& Moore, 2013; Scales \& Leffert, 1999). 


\section{Summary of Study Constructs and Identified Gaps in the Literature}

In light of historical findings that Black males—and more recently—Black females are experiencing high rates of pushout compared to their White counterparts, school pushout studies that include disaggregated data for Black youth without infusing gender-biased reporting would also add to the body of literature. Both Black males and Black females are subjected to disparate school pushout practices, and therefore, it is critical that both populations receive equal attention.

There is a need for research that thoroughly explores school pushout and future outlook among Black youth across age groups. Specifically, empirical research that examines gender-disaggregated findings for school pushout and future outlook experienced by Black males and Black females at various ages are scarce. More studies that report Black youth's perspective concerning school pushout and the impact of such experiences on their psychological development would fill the extant gap in literature.

Additionally, there is a need for research that explores the relation between school pushout and parental warmth. Research that examines the effects of parental warmth on school pushout and, conversely, the impact that school pushout has on parental warmth, would also contribute to the literature. In addition, the associations between parental warmth and future outlook also require further investigation. Researchers are encouraged to design studies that examine the relation between parental warmth and hopelessness among Black youth.

\section{Conceptual Framework}

The theoretical foundations that will frame this study are Bronfenbrenner's Ecological Model (1977) and Racial Encounter Coping Appraisal and Socialization 
Theory (RECAST; Adams-Bass, Bentley-Edwards, \& Stevenson, 2014).

Bronfenbrenner's Ecological Model serves as a proxy for the study's ecological foci (e.g., self, parents, and schools), while RECAST contextualizes the various study constructs addressing race/ethnicity (Adams-Bass et al., 2014).

Extant research regarding school pushout and the STPP overwhelmingly emphasizes deficit-based risk factors (Christle, Jolivette, \& Nelson, 2005; Toldson et al., 2014). Although, the proliferation of risk factor research assists in scaling the parameters of the problem and the ways in which students are victimized by school pushout tactics, the continued emphasis on risk factors augments the implicit biases that feed the STPP (Smith \& Harper, 2015). The result of such an approach to research supports a deficit model approach to solutions (Smith \& Harper, 2015). Contrariwise, protective factor literature surrounding the STPP is scarce, and the ecological systems in which these factors are evaluated are limited (Christle et al., 2005; Toldson et al., 2014).

\section{Bronfenbrenner's Ecological Model}

Bronfenbrenner's Ecological Model will be used in this study to address the systemic impact of the STPP. The various system levels included in Bronfenbrenner's Ecological Model are increasingly nested inside of the succeeding system and are as follows: microsystem, mesosystem, exosystem, and macrosystem. This particular study is primarily designed to investigate the nature of characteristics or variables observed at various ecological system levels according to Bronfenbrenner's (1977) Ecological model. Scholarly works have myopically focused on the mesosystem level (e.g., interactions between school and community) concerning risk and protective factors (Christle et al., 2005; Nelson \& Eckstein, 2008; Wald \& Losen, 2003). In light of the increased attention 
given to risk and protective factors at the mesosystem level, this work deliberately places emphasis on investigating potential risk and protective factors within the context of the microsystem (e.g., relation between youth and home; Bronfenbrenner, 1977).

The various study constructs and antecedents that will be examined at each level of Bronfenbrenner's Ecological Model are as follows. At the microsystem level, Black youth and parental warmth will be examined, while school pushout will be explored at the mesosystem level. At the exosystem level (i.e., an extenstion of the mesosystem level containing influential elements on the person's environment), zero tolerance policies are recognized as a study antecedent. Criminalization of Black youth is also recognized as a study antecedent at the macrosystem level (i.e., referring to general prototypes that impact the culture or subculture) and future outlook will be examined as a study focus at this level as well.

This dissertation study was generated under the premise of the initial driving questions of the researcher: (a) In light of the STPP, how do the beginning stages of the STPP relate to the future outlook of Black youth (from the youth's perspective)? and (b) In light of the STPP, aside from advocating for their children, what can parents do to assist their children until the STPP is dismantled? These questions provide perspective regarding the ways in which this study is situated and also buffers any misconstructions of the study's intent. To further elucidate intentions of this study, any discoveries regarding the relation between parental warmth and school pushout or future outlook are focused on providing evidentiary data to support parents of Black youth and are not to be used to conflate findings with victim or parent blaming. 


\section{Racial Encounter Coping Appraisal and Socialization Theory (RECAST)}

Racial/ethnic socialization is most readily utilized by parents of Black youth in an effort to prepare their offspring for inevitable future racial encounters and discrimination (Bentley-Edwards, Thomas, \& Stevenson, 2013). Parents use racial socialization to familiarize their children with the historical context of racial constructs and associated race-based injustices (Adams-Bass, Bentley-Edwards, \& Stevenson, 2014). Examples of such racial injustices that parents of Black youth might prepare their sons and daughters for are (a) negative public perceptions and media images of blackness and Black people, (b) social pressures to assimilate to the hegemonic Eurocentric culture that often dominates and dictates their ability to occupy certain spaces with confidence, and (c) the unfair, unjust, and racist treatment of Black youth and generally-speaking, Black people, by some authority figures who have taken oaths to protect and serve them but could potentially have proclivities to dehumanize, harm, and kill them (Goff et al., 2014).

Racial/ethnic socialization must be considered in this study based on (a) the acknowledgement of the racial context undergirding the constructs of school pushout (i.e., suspensions and expulsions), (b) the connection that racial socialization has to framing future outlook (i.e., hopelessness and self-worth) for Black youth, and (c) the study of parental warmth as a construct. Racial Encounter Coping Appraisal and Socialization Theory (RECAST; Adams-Bass et al., 2014) is the specific theory employed to conceptualize the racial/ethnic aspects of this study. RECAST is a racial/ethnic socialization theory suggesting that racial socialization assists youth in determining both positive and negative connotations affiliated with various indirect and direct images and messages regarding Black people (Adams-Bass et al., 2014; Spencer et 
al., 2003).

In acknowledgement of the racial context surrounding school pushout, Black youth may or may not be familiar with the discrepancies that exist regarding exclusionary disciplinary policies at their respective schools. Likewise, parents of Black youth may not be aware of the existing pushout tactics that profoundly impact their children. The RECAST provides context in which to frame this study, as it enlightens both students and parents of the racial considerations that are prevalent in the disciplinary practices of many schools and encourages parents to prepare their children regarding the harsh realities of a system that is designed to significantly penalize and exclude them.

The RECAST also serves as a proxy for the connection that racial socialization has to framing future outlook (i.e., hopelessness and self-worth) for Black youth. The theory suggests that racial socialization assists youth in building critical agency concerning how Black people are treated by teaching them to assess both positive and negative implications of public messages and actions (Adams-Bass et al., 2014). Such development and critical consciousness regarding school pushout could potentially impact their future outlook-(a) negative expectancies toward oneself and toward the future (i.e., hopelessness; Stotland, 1969) and (b) how much they value themselves as a person (i.e., self-worth; Harter, 1982).

The study of parental warmth as a construct also warrants the usage of the RECAST. RECAST is a racial/ethnic socialization theory proposing that racial socialization aids youth in conceptualizing the world and racial/ethnic elements of the world that inadvertently and advertently impact them as Black youth (Adams-Bass et al., 2014; Bentley-Edwards et al., 2013). Parents who exhibit more parental warmth may be 
more inclined to prepare their children for the harsh realities surrounding the STPP, and that preparation and discourse of race implications could potentially impact their child's future outlook.

\section{Chapter Summary}

This chapter commenced with information regarding the foreground of the study, the STPP. The chapter continued with a contextualized review of the literature pertaining to the study. The chapter concluded by situating the study within a conceptual framework that included Bronfenbrenner's Ecological Model and the RECAST. The next chapter will provide a detailed review of the methodology selected for this dissertation study. 


\section{CHAPTER III}

\section{METHODOLOGY}

The purpose of this dissertation study was to examine the relation between school pushout and future outlook for Black youth, and to explore the potential moderating effect of parental warmth on the relationship between school pushout and future outlook. The examination of school pushout and future outlook among Black youth contributed to school-to-prison pipeline research, while the exploration of parental warmth served as an addition to parental advocacy research. This dissertation study was designed as one of the first quantitative studies to concurrently examine the associations of (a) school pushout (i.e., suspensions and expulsions), (b) future outlook (i.e., hopelessness and selfworth, (c) parental warmth, (d) age effects, and (e) gender-effects, among Black youth. Within this dissertation study, school pushout was defined and measured by examining suspensions and expulsions, and both variables were treated as predictor variables in the study. Future outlook was defined and measured by hopelessness and self-worth, and both variables were treated as criterion variables in this study. Parental warmth was defined by parents' general tendencies to be supportive, affectionate, and sensitive to the child's needs (Lamborn et al., 1991) and were measured by child report of parental warmth. Parental warmth was examined as a moderator variable. Gender effects among the study constructs were also explored.

The Mobile Youth Survey (MYS; Bolland, 2007), a pre-existing longitudinal dataset comprised of multiple cohorts of primarily Black youth, was used in this 
dissertation study. The MYS dataset distinctively captured the dissertation study constructs among the population of interest, Black female and male students. This chapter explicates the research design, instrumentation, data collection procedures, and data analysis that will be used to examine the research questions.

\section{Research Design}

The dissertation study employed a cross-sectional research design, as variables are examined at one particular point in time by exploring data within one wave (i.e., year of 2011) of the MYS database. The variables of interest for this dissertation study, which include, school pushout, future outlook, and parental warmth among Black youth were uniquely captured by a pre-existing dataset. As previously stated, the MYS database was designated as an ideal database for this dissertation study based on the dataset including all of the constructs of interest among a primarily Black youth sample.

The MYS database also offered contextual benefits due to the original study being administered within community settings. This dissertation study employed a crosssectional analysis of a subset of the data derived from the MYS, a multiple cohort longitudinal community-based study of primarily Black youth in the cities of Mobile and Prichard Alabama (Bolland, 2007). The last wave of the MYS study (i.e., the year of 2011) was utilized for this dissertation study.

The last wave of the MYS study was selected in order to (a) capture the most recent school pushout data reported by youth in the study, (b) capture more school pushout history of each participant, (c) consider the implications of the proliferation of zero tolerance policies in schools from 1998-2011, and (d) recognize that this dissertation study contributes to the growing body of school pushout empirical literature by using the 
most recent data reported by youth in the MYS study. The MYS specifically allows for an exploration of the questions posed in this dissertation study due to its measurement of school pushout (i.e., suspensions and expulsions), future outlook (i.e., hopelessness and self-worth), and parental warmth within the context of race and gender. Researchers conducted the MYS over a period of 14 years (i.e., from the years 1998 to 2011).

Annually, youth participated in the multiple cohort research designed study, as researchers retained existing cohorts and recruited new participants. Primarily Black American adolescents between the ages of 10-18 from identified neighborhoods with low median incomes were eligible to participate in the original study. This dissertation study was designed to garner information concerning how school pushout relates to future outlook and parental warmth interactions among Black female and male students.

\section{Research Questions}

This dissertation study was designed to answer the following questions:

(RQ 1) What is the relation between school pushout (as measured by suspensions and expulsions) and future outlook (as measured by hopelessness and self-worth) among Black youth?

(RQ 2) Does parental warmth moderate the relation between school pushout (as measured by suspensions and expulsions) and future outlook (as measured by hopelessness and self-worth) among Black youth?

(RQ 3) Does age and gender impact the relation among school pushout (as measured by suspensions and expulsions), future outlook (as measured by hopelessness and self-worth), and parental warmth amongst Black youth? 


\section{Research Hypotheses}

The following hypotheses were constructed in light of the research questions of this dissertation study and reviewed literature:

H1(a): There will be a direct relation between self-reported school pushout (as measured by suspensions and expulsions) and hopelessness among Black youth.

H1(b): There will be an inverse relation between self-reported school pushout (as measured by suspensions and expulsions) and self-worth among Black youth.

H2: Parental warmth will moderate the relation between self-reported school pushout (as measured by suspensions and expulsions) and future outlook (as measured by hopelessness and self-worth).

H3: $\quad$ Age and gender will impact the relation among school pushout (as measured by suspensions and expulsions), future outlook (as measured by hopelessness and self-worth), and parental warmth amongst Black youth.

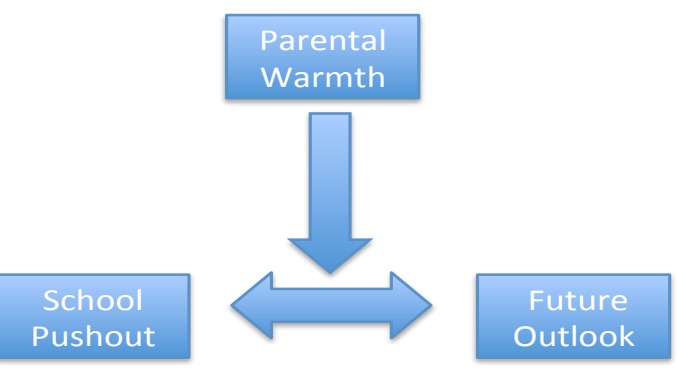

Figure 2. Conceptual Model for the Dissertation Study. 


\section{Participants}

This dissertation study utilized a pre-existing database from the original MYS, which is an annual data collection over the course of 14 years (i.e., from the years 1998 to 2011). The original MYS dataset represented multiple cohorts. The survey was administered to youth within the communities of Mobile and Prichard, Alabama. Approximately $98 \%$ of youth represented within the parent study were Black youthages 10-18 — who were from neighborhoods identified as low median income areas.

Specific neighborhoods in both communities were identified as participant recruitment areas. The 13 neighborhoods identified for the study were selected based on median household incomes within the Mobile Metropolitan Statistical Area (MSA) reported on the 1990 United States Census (Jargowsky, 1997). Neighborhoods within the Mobile MSA with the lowest median household incomes were selected (Bolland, 2004). The original study sought to capture the experiences of youth living in areas of concentrated poverty.

This dissertation study examined a limited range of approximately 12,000 adolescents who participated in the MYS study. The limited range for this dissertation study included female and male participants who (a) self-identify as Black, (b) are ages 11-17, (c) identify as having a parent or someone who is like a mother or father to them, and (d) have complete data on the variables of interest for the last wave of the MYS study, in the year of 2011. Therefore, participant data from the original study were excluded from this dissertation study if (a) participants did not identify as Black, (b) participants were younger than 11 or older than 17 , (c) participants did not report having a mother or father figure, or (d) complete participant data for all study variables were not 
reported in the last wave of the MYS study. The age range of 11-17 was selected by the researcher based on the determination that self-worth is not a concept that can be conceived by youth prior to the age of 11 (Stoddard et al., 2011), and it is also noteworthy that by the age of 10, Black males are generally perceived as being older and more guilty or accountable (Goff et al., 2014). The age of 17 was selected as the cutoff based on the determination that youth are considered adults in the criminal system at the age of 18 .

\section{Procedure}

Given that this study is based on a pre-existing dataset, explication of the procedure for the original study is detailed in this section. The sampling method for the MYS involved both active and passive recruitment strategies. The 13 neighborhoods represented in the MYS study were identified based on low median household income status. According to the 1990 census, Mobile, Alabama was identified as the third most

poverty-stricken MSA in the nation (Jargowsky, 1997). For the MYS, households in said neighborhoods qualified if they had adolescents (i.e., 10-18 year-olds; Bolland, 2004) living in the residence. Half of the public housing neighborhoods and half of the nonpublic housing neighborhoods were randomly selected as active recruitment households. By default, the other neighborhoods were identified as passive recruitment households (Bolland, 2004). The various strategies employed were contingent upon the categorizations of active recruitment households or passive recruitment households (Bolland, 2004).

The active recruitment household strategy consisted of researchers knocking on doors of the identified homes and explaining the study to determine if adolescents (i.e., 
10-18 year-olds) were interested in participating. If the adolescents accepted the invitation to participate, parental consent was obtained, and group survey administration times were set (Bolland, 2007). Group surveys were administered at a local community agency (e.g., community centers, churches, and schools; Bolland, 2004).

The passive recruitment household strategy consisted of posting flyers about the survey in the designated neighborhoods inviting neighborhood adolescents (i.e., 10-18 year-olds) to participate. Interested adolescents or household residents responded by calling the phone number provided on the flyer or by expressing interest at one of the select community agencies (Bolland, 2004). Researchers responded to inquiries received by phone and in person by employing the same procedures used for the active recruitment households (i.e., home visit to explain the study, obtain parental consent, and schedule group survey administration appointment; Bolland, 2007). Recruitment commenced in 1998, and researchers continued to use the aforementioned strategies for participant recruitment and retention for the duration of the study. New participants were actively and passively recruited each year from the designated MYS neighborhoods, and previous participants, who had relocated to other neighborhoods, were also tracked and invited to continue their participation in the MYS study (Bolland, 2007).

The MYS was administered in a group setting (i.e., approximately 10-20 participants) at a designated community center (e.g., Boys and Girls Club), church, or school (Bolland, 2007). Participants were screened for the following prior to each administration (a) verification of previous contact information obtained during recruitment by stating the name, birth date, and address that researchers had on file; (b) 
confirmation of parental consent; and (c) assurance that the participant was not taking the survey more than once in a given year (Bolland, 2004).

After participants were cleared to participate, they would join the other MYS participants to take the survey (Bolland, 2007). Researchers read the assent statement aloud to participants and garnered participant assent by asking adolescents to print their name, birth date, address, and date of administration on the cover page of the survey (Bolland, 2004). The researchers collected the cover pages and proceeded to administer the survey (Bolland, 2004). Researchers typically read the survey items aloud and required participants to mark their responses (Bolland, 2004). Adolescents requiring more time or attention to complete the survey were given the option of individually working with a survey team member (Bolland, 2004). The survey administration time was approximately one hour (Bolland, 2004). Upon completion of the survey, respondents received an incentive of $\$ 10$ (during the years of 1998-2004) or $\$ 15$ (during the years of 2005-2011; Bolland, 2007).

Several attempts were made and opportunities were extended in order to ensure that participants were able to participate in the study (Bolland, 2007). Alternative dates and locations were offered to adolescents who were unable to make the regularly scheduled appointments (Bolland, 2007). Survey team members scheduled in-home administrations if participants missed their neighborhood administration times or if they relocated to a district outside of the MYS designated neighborhoods (Bolland, 2007). The aforementioned protocol was tactically used to administer the home surveys as well (Bolland, 2007). Survey team members typically did not read the survey aloud if other members were present in the home during the time of administration; otherwise, the 
questions were read to the respondents, and the respondents recorded their answers (Bolland, 2007). The aforesaid MYS data collection procedures were implemented in 1998 and remained consistent throughout the duration of the study until 2011 when the study concluded (Bolland, 2007).

\section{Instrumentation}

This dissertation study included school pushout—which was measured by suspensions and expulsions, future outlook - which was measured by hopelessness and self-worth, parental warmth, and demographic items (i.e., race, gender, and age). This dissertation study aimed to (a) examine the association between school pushout, future outlook, and parental warmth for Black youth and (b) describe any gender differences regarding the study's variables. The MYS database was selected due to the dataset capturing all of the constructs of interest among a primarily Black youth sample.

The MYS dataset (Bolland, 2004) consisted of multiple scales and subscales measuring constructs addressing development (e.g., hopelessness, self-worth, identity style), behavior (e.g., substance use, weapon use, suicide), environmental context (e.g., parental warmth, security, household structure), beliefs and attitudes (e.g., cynicism, inevitability of violence, attitudes about romantic relationships), and psychosocial variables (e.g., callousness, traumatic stress, worry). The specific constructs and measures utilized in this dissertation study are detailed below.

\section{Demographic Questionnaire}

Race. Race was determined based on participant responses on the MYS to a single-item question regarding race, which prompted youth participants to describe themselves. (1) Are you [B]lack/African American? (2) Are you [W] hite? (3) Are you 
Hispanic/Latino? (4) Are you mixed race and/or Creole? For each question, participants were provided with an $(A)$ yes or $(B)$ no response. Only participants who identify as Black/African American were included in this dissertation study.

Gender. Gender was determined based on participant responses on the MYS to a single-item question regarding gender on the survey: Are you male or female (a boy or a girl)? Respondents were provided with forced choices, (A) Male (boy) or (B) Female (girl). Male and female participants were included in this dissertation study.

Age. Age was measured by year. Age was determined based on participant responses on the MYS to the question regarding age on the survey: How old are you now? Respondents were provided with choices to select the letter that corresponded with their age (i.e., between 9 and 19).

\section{School Pushout}

In this dissertation study, school pushout was measured based on suspensions and expulsions experienced by youth participants. Suspensions and expulsions were recorded based on youth self-report data. Suspensions and expulsions were reported annually in the MYS as follows.

Suspensions. Suspensions were measured utilizing the following question: Have you ever been suspended from school? Participants were permitted a yes or no response. Responses of no (i.e., no suspensions reported) were recorded as 0 , while responses of yes (i.e., suspensions reported) were recorded as 1 .

Expulsions. Expulsions were measured using the following question: Have you ever been expelled from school? Participants were permitted a yes or no response. 
Responses of no (i.e., no expulsions reported) were recorded as 0 , while responses of yes (i.e., expulsions reported) were recorded as 1.

\section{Future Outlook}

In this dissertation study, future outlook was measured based on participant responses on scales that measure hopelessness and self-worth. Hopelessness and selfworth were assessed annually in the MYS as follows:

Hopelessness. Hopelessness, a criterion variable in this dissertation study, was used to describe future outlook and was measured based on the Brief Hopelessness Scale (Bolland, McCallum, Lian, Bailey, \& Rowan, 2001) created for the MYS study. The Brief Hopelessness Scale is a 6-item measure consisting of 5 items adapted from The Hopelessness Scale for Children (Kazdin et al., 1983) along with a researcher-created item: I do not expect to live a very long life. The Brief Hopelessness Scale measures hopelessness as a dynamic construct (i.e., negative expectancies toward oneself and toward the future; Stotland, 1969). Some of the other sample items included in this scale were: (1) I might as well give up because I can't make things better for myself, and (2) There's no use in really trying to really get something I want, because I probably won't get it. The items were measured with a dichotomous response, agree/disagree. Hopelessness was treated as a continuous variable as a range of scores will be created based on participants' responses to each question. Cronbach's alpha for the Brief Hopelessness Scale for participants in this sample ranges from .72-.84 (Jaggers et al., 2015; Stoddard et al., 2011).

Self-worth. Self-worth was also used to assess future outlook. Specifically, selfworth was measured using a 9-item summative scale derived from the original 28 -item 
Perceived Competence Scale for Children (Harter, 1982). The 9-item scale included items that assess (a) being happy with self, (b) being sure of self; (c) feeling good about personal actions; and (d) belief in personal good-naturedness (Harter, 1982). The items in this scale included dichotomous responses such as, (1) I am usually unhappy with myself, or I am usually happy with myself and (2) I like the kind of person I am, or I don't like the kind of person I am. Cronbach's alpha for the summative scale was 0.67, which is lower than the original Perceived Competence Scale's reliability, 0.85 (Church et al., 2012). The full scale was not used in order to reduce participant burden. Self-worth was treated as a continuous variable with a range of scores (i.e., 0-9) created based on participants' responses to each item.

\section{Parental Warmth}

Parental warmth reflected parents' general tendencies to be supportive, affectionate, and sensitive to the child's needs (Lamborn et al., 1991). Parental warmth was measured using 12 researcher-created items with six items measuring maternal warmth and six items measuring paternal warmth. These items were derived from scales produced by Dornbusch et al. (1985), Lamborn et al. (1991), Patterson and StouthamerLoeber, (1984), and Rodgers, (1966). Items evoked youth participants' opinions regarding their respective parents' support, affection, and sensitivity to their children's needs (Dornbusch et al., 1985; Patterson \& Stouthamer-Loeber, 1984; Rodgers, 1966).

Sample items included, We do fun things together, and She spends time just talking to me. Item response options were multiple choice in design, offering the following responses for questions focused on the mother's warmth: agree, disagree, or I don't have anyone who is like a mother to me. The following responses were offered as 
options for questions focused on the father's warmth: agree, disagree, or I don't have anyone who is like a father to me.

The maternal warmth section of the survey included the directive, Please tell us about the person who is most like a mother to you. The paternal warmth section included the directive, Please tell us about the person who is most like a father to you. The instructions preceding the section on parental warmth questions, in general, also included the following statement: People live in different kinds of families. Some kids live with their mother or their father. Others live with people who are like a mother of a father to them. Each section, maternal and paternal, were scored by summing the item responses for each section, resulting in a range between 0 and 6 . The Cronbach's alphas for maternal and paternal warmth were .80 and .82, respectively (Jaggers et al., 2015).

Parental warmth was scored based on the highest score of parental warmth (i.e., maternal or paternal warmth) reported by each youth participant, as the researcher was interested in exploring the benefits of a parent's warmth (or a figure viewed as a parent by the youth) in accordance with literature that supports the significance of having at least one caring adult in a youth's life (Murphey et al., 2013; Scales \& Leffert, 1999). Such an examination does not require or aim to determine the differences between maternal and paternal warmth; therefore, the maximum score of maternal or paternal warmth will be used for each participant reporting a maternal and paternal figure. For participants who reported only one parental warmth score, the reported score for either maternal or paternal warmth was used. Parental warmth was treated as a continuous variable as a range of scores were created based on participants' responses to each question. 


\section{Procedural Benefits and Limitations}

The procedural benefits of the original MYS study were (a) the procedures used were consistent throughout the scope of the longitudinal study (Bolland, 2007); (b) the procedures were ethically implemented (Bolland, 2007); and (c) the procedures accounted for participant retention (Bolland, 2007).

Procedural limitations of the original MYS study included (a) the amount of time that elapsed between participants' survey administration was not accounted for beyond guaranteeing that the participant had not taken the survey more than once in any given year (Bolland, 2007); and (b) the procedure did not include assessing the reading level of the participant when the survey was not read aloud (Bolland, 2004).

\section{Benefits and Limitations of the Dissertation Study}

Benefits of this dissertation study included (a) homogeneity of the sample, (b) empirical evidence regarding the study variables among Black youth, (c) disaggregated data by gender, (d) study variables were examined in a community context, (e) data obtained from a longitudinal dataset, (f) data obtained by youth selfreport, and (g) the study captures the intersection of study variables. The intentional focus on Black youth for the dissertation study necessitated the usage of a homogenous sample. This dissertation study examined the relations among school pushout, future outlook, and parental warmth regarding Black youth, while also exploring the impact of gender on the relations of study variables. Although the study variables have been studied individually and in conjunction with other variables, this is the first study that examined all of the study variables collectively. School pushout data such as suspensions and expulsions are often captured by administrators within the context of schools, but this 
dissertation study offers a different perspective, as this study examined school pushout data reported by youth in a community setting.

Limitations of the study included (a) the homogeneity of the sample, (b) the usage of subscales or newly created scales to measure variables of interest, (c) the period of time chosen for analysis, and (d) data obtained by youth self-report. The homogeneity of the sample was previously mentioned as a benefit of this dissertation study, but it is also engenders a limitation. Due to the sample being comprised of Black youth in Mobile, Alabama and surrounding communities, the generalizability of potential findings to other demographics is limited.

Subscales of instruments were used to measure variables and somewhat low alphas were reported on some measures, which may have limited the reliability of the respective instruments and corresponding constructs measured. The cross-sectional design of the study focused on a particular period of time (i.e., the last wave of the MYS, year 2011), and therefore, results were limited to the experiences of Black youth during that specific period of time and not necessarily indicative of their experiences at another point in time during the study. Although data obtained by youth self-report was a benefit in this study, it was also a limitation based on the lack of clarity regarding the interpretation of suspended in the question used to determine suspension data: Have you ever been suspended from school? Since youth self-report was utilized to capture suspension data, it was not clear if youth participants interpreted the question as out-ofschool suspensions or in-school suspensions. However, data obtained from the suspension question was useful in assessing school pushout, as the students were inevitably removed from their regular classroom environment and their regular learning 
experience was deferred, regardless of the students' interpretation of suspended within the survey item.

\section{Data Analysis}

Descriptive and inferential statistics were employed in this dissertation study in order to effectively address the study research questions and study hypotheses. As previously stated, data from the last wave of the MYS study, from the year, 2011 were used to answer the research questions and test the study hypotheses. The specific methodological techniques that were utilized to analyze the data are as follows (Figure 3).

The first hypothesis, H1(a), tested for a direct relation between self-reported school pushout (as measured by suspensions and expulsions) and hopelessness among Black youth, while H1(b) will test for an inverse relation between self-reported school pushout and self-worth. This hypothesis was tested using simple linear regression analysis. The model examined school pushout (i.e., suspensions or expulsions) as the predictor variable and future outlook (i.e., hopelessness and self-worth) as the criterion variable.

The second hypothesis, $\mathrm{H} 2$, tested parental warmth as a moderator for the relation between school pushout (as measured by suspensions and expulsions) and future outlook (as measured by hopelessness and self-worth) among Black youth. This hypothesis was tested using moderated multiple regression analysis. The model examined parental warmth as the moderator variable, school pushout (i.e., suspensions or expulsions) as the predictor variable, and future outlook (i.e., hopelessness and self-worth) as the criterion variable. 
The third hypothesis, $\mathrm{H} 3$, tested the impact of age and gender on the relation among, school pushout (as measured by suspensions and expulsions), future outlook (as measured by hopelessness and self-worth), and parental warmth amongst Black youth. This hypothesis was tested by examination of the moderated multiple regression analysis and running separate regression analyses for both genders (i.e., male and female) and all ages of participants (i.e., 13,14,15, 16, and 17). Due to the utility of a pre-existing dataset to assess this dissertation study, the analyses were conducted utilizing the Statistical Package for the Social Sciences ([SPSS], 2010), a statistical analysis software package. 
H1(a): There will be a direct relation between self-reported school pushout (as measured by suspensions and expulsions) and hopelessness among Black youth.

H1(b): There will be an inverse relation between self-reported school pushout (as measured by suspensions and expulsions) and self-worth among Black youth.

H2: Parental warmth will moderate the relation between self-reported school pushout (as measured by suspensions and expulsions) and future outlook (as measured by hopelessness and self-worth) among Black youth.

H3: Age and gender will impact the relation among school pushout (as measured by suspensions and expulsions), future outlook (as measured by hopelessness and self-worth), and parental warmth among Black youth.
Simple Linear Regression Analysis (OLS) Predictor Variable: School Pushout Criterion Variable: Hopelessness

Simple Linear Regression Analysis (OLS) Predictor Variable: School Pushout Criterion Variable: Self-worth

Moderated Multiple Regression Analysis Predictor Variable: School Pushout Criterion Variable: Future Outlook Moderator Variable: Parental Warmth

Separate Regression Analyses for both genders (i.e., male and female) and all ages (i.e., 11, 12, 13, 14, 15, 16, and 17) added to the Moderated Multiple Regression Analysis

Figure 3. Data Analysis

\section{Chapter Summary}

This chapter commenced with the research design and methodology. The chapter also outlined study variables, participant information, sampling and data collection procedures, instrumentation, procedural benefits and limitations, overall benefits and limitations of the study, and projected data analysis. The subsequent chapters present findings of the study, discuss implications of the findings, and provide a conclusion to the study. 


\section{CHAPTER IV}

\section{RESULTS}

The purpose of this dissertation study was to focus on the relation between school pushout and future outlook for Black youth. Secondarily, the study explored parental warmth as a potential protective factor by examining the relation among parental warmth, school pushout, and future outlook. Age and gender effects were also examined as a function of the relations between school pushout, future outlook, and parental warmth.

In addition to the results, this section includes the specific data analytic procedures that were followed to address each research question and to test the corresponding hypothesis. Sample demographics, analyses of the research questions, and testing of the respective hypotheses are outlined in this chapter.

\section{Sample Demographics}

The sample for this study consisted of 1,728 Black youth who completed the last wave of the Mobile Youth Survey (MYS) during 2011. The sample included all Black youth who had complete data for (a) school pushout (i.e. suspensions and expulsions), (b) future outlook (i.e., hopelessness and self-worth), (c) parental warmth, (d) age (i.e., 1318), and (e) gender. The sample $(N=1728)$ included $862(50 \%)$ females and $866(50 \%)$ males ages 13-17 years old. Approximately 1465 (85\%) of the sample reported experiencing school pushout. 


\section{Data Cleaning and Coding}

The data were cleaned to ensure that all participants included within the final study sample had complete data for each variable (i.e., school pushout, hopelessness, self-worth, parental warmth, age, gender, and race). The original dataset for the MYS included 12,387 participants, ages 9-19. The original datatset was reduced and limited to participant data reported in the last wave of the MYS (i.e., year 2011). After limiting the dataset to the last wave of the MYS with participants who had data for all study variables, the study sample consisted of 2,245 participants, ages 11-17. In accordance with the research design for this dissertation study, the dataset was initially delimited to 11-17 year-olds. However, the sample was further limited to 1,728 participants, ages 13-17, after the relation between age and school pushout was examined for dependencies. Thus, the resultant final study sample was 1728 .

Other data cleaning included the examination of categorical data. For example, categorical data such as gender and school pushout were evaluated by checking frequencies. Because older youth would be more likely to experience school pushout, the relation between age and school pushout was explored for dependencies. In other words, due to older youth having more exposure to the school system, they would be more likely to have experienced school pushout than younger youth.

Chi-squared tests were utilized to examine the age level of school pushout dependency. Three contingency tables of frequencies were generated (see Tables 1-3). In Table 1, the chi-square contingency table of frequencies is listed for ages 11-17, where the percentage of participants who experienced school pushout differed by age, $X^{2}(6, N$ $=2245)=139.98, p=.01$. 
Table 1

Chi-Square Contingency Table of Frequencies (Ages 11-17)

\begin{tabular}{cc}
\hline Age & School Pushout \\
\hline 11 & $7 \%$ \\
12 & $8 \%$ \\
13 & $14 \%$ \\
14 & $11 \%$ \\
15 & $12 \%$ \\
16 & $13 \%$ \\
17 & $15 \%$ \\
\hline
\end{tabular}

In Table 2, when age 11 was eliminated from the dataset, the percentage of participants who experienced school pushout still differed by age, $X^{2}(5, N=1977)=40.30, p=.01$. However, when the sample was reduced to 13-17-year-olds (i.e., by removing 11- and 12-year-old participants from the dataset), the percentage of participants who experienced school pushout no longer significantly differed by age, $X^{2}(4, N=1728)=2.88, p=.58$ (Table 3). Eleven and 12 year-olds made up half of the sample that had not experienced school pushout. It was determined that the observed dependency was eliminated at age 13; therefore, all regression models consisted of responses submitted by 13-17 year-olds. Table 2

Chi-Square Contingency Table of Frequencies (Ages 12-17)

\begin{tabular}{cc}
\hline Age & School Pushout \\
\hline 12 & $9 \%$ \\
13 & $16 \%$ \\
14 & $13 \%$ \\
15 & $14 \%$ \\
16 & $14 \%$ \\
17 & $17 \%$ \\
\hline
\end{tabular}


Table 3

Chi-Square Contingency Table of Frequencies (Ages 13-17)

\begin{tabular}{cc}
\hline Age & School Pushout \\
\hline 13 & $18 \%$ \\
14 & $15 \%$ \\
15 & $16 \%$ \\
16 & $16 \%$ \\
17 & $20 \%$ \\
\hline
\end{tabular}

Hopelessness scores ranged from 0-6, where 0 represented less hopelessness and 6 represented higher hopelessness. Self-worth scores ranged from 0-9, where 0 represented less self-worth and 9 represented higher self-worth. Prior to running the analyses for each research question, four items were coded: (a) school pushout was coded based on participants' responses to items assessing suspension and expulsion history, (b) the maximum parental warmth scores were coded based on the highest score reported between maternal and paternal warmth, (c) age was centered at 13, and (d) gender was dummy coded as 0 for males and 1 for females. More specifically, school pushout was coded by dichotomizing two self-report items regarding suspensions and expulsions. If adolescents reported either of these, they were coded as a 1, while if they experienced neither of them they were coded as a 0 . Adolescents with missing data on either of the two items were removed from the data set previously during data cleaning. That is, if respondents reported that they never experienced a suspension, but they did not respond to the item assessing expulsion, participant data were removed from the dataset.

The same approach was used if respondents reported that they never experienced an expulsion, but they did not respond to the item assessing suspension. The researcher chose to eliminate participant data in those circumstances in order to avoid including 
youth who could have experienced school pushout, but failed to report it. The newly coded scores were utilized to examine school pushout in all regression models.

Maximum parental warmth was determined by selecting cases if parental warmth was reported for at least one parent. The maximum score reported for either maternal warmth or paternal warmth was then selected for each participant by coding a new variable and selecting maternal warmth as the maximum parental warmth score if the maternal warmth score was greater than the paternal warmth score. Conversely, if paternal warmth was greater than maternal warmth, the maximum parental warmth score was coded as the paternal warmth score. In cases where the maternal and paternal warmth scores were equal, either score was retained. Parental warmth scores ranged from $0-6$, with 0 representing low parental warmth and 6 representing high warmth. The newly coded maximum warmth score was utilized to examine parental warmth in all regression models.

Age was centered at 13, therefore, age was transformed and coded into a new variable. The old and new variables for age were transformed as follows, $13=0,14=1$, $15=2,16=3,17=4$. The centered age was utilized to examine age in all regression models.

Assumptions of linear regression: (a) normality, (b) linearity, (c) reliability of measurement, and (d) homoscedasticity were tested for the study variables used in the analyses. Variables were normally distributed, as indicated by P-P plots and visual assessment. Linear relationships existed between the dependent and independent variables, which were confirmed by examining residual plots. The assumption of reliability of measurement was met with Cronbach's alphas of measures ranging between 
approximately .70 and .90 . Finally, the assumption of homoscedasticity was tested and met by examining plots of the standardized errors by the regression standardized predicted value.

\section{Data Analytic Procedures}

The first research question, (RQ 1) What is the relation between school pushout (as measured by suspensions and expulsions) and future outlook (as measured by hopelessness and self-worth) among Black youth?, was tested using simple regression. Two separate regression models were utilized to test the hypotheses. School pushout variable was entered as the independent variable in both models while hopelessness was entered as the dependent variable for the first model and self-worth was entered as the dependent variable for the second model.

The second research question, (RQ 2) Does parental warmth moderate the relation between school pushout (as measured by suspensions and expulsions) and future outlook (as measured by hopelessness and self-worth) among Black youth?, was analyzed using multiple regression. Two moderated multiple regression models were estimated to test the respective hypothesis. The first model included hopelessness as the dependent variable with school pushout as a fixed factor and maximum parental warmth entered as an independent variable. The second model included self-worth as the dependent variable with school pushout and maximum parental warmth entered as independent variables.

The third research question, (RQ 3) Does age and gender impact the relation among school pushout (as measured by suspensions and expulsions), future outlook (as measured by hopelessness and self-worth), and parental warmth amongst Black youth?, 
was examined using two moderated multiple regression models with age entered as a continuous independent variable and gender entered as a fixed factor. One model included hopelessness as the dependent variable, while the other model included selfworth as the dependent variable. All other variables were the same for both models with school pushout and gender entered as fixed factors and age and parental warmth entered as continuous factors. The General Linear Model (GLM) univariate analysis was utilized to run all regression models in the Statistical Package for the Social Sciences (SPSS), Version 22.0.

\section{Results}

The results for the dissertation study are described in this section. Descriptive statistics and frequencies were reviewed for continuous and categorical study variables. The analytic procedures and results associated with each research question and hypothesis are presented in the following section.

\section{Descriptive Statistics and Frequencies}

Descriptive statistics (Table 4) and frequencies (Tables 5-10) for the study variables are reported in this section. The sample $(N=1728)$ consisted of $50 \%(n=866)$ (Black males and 50\% $(n=862)$ Black females. The sample was fairly evenly distributed across age with approximately $20 \%(n=345)$ of the sample being represented at each age (i.e., $13,14,15,16,17)$. An estimated 75\% $(n=1296)$ reported low hopelessness (i.e., ratings of 0 or 1), while self-worth was reported at varying levels, with approximately $85 \%(n=1572)$ of the sample responding with a mid to high rating (i.e., ratings between 5-9). An estimated $90 \%(n=1555)$ of the sample reported experiencing high levels of parental warmth (i.e., ratings of 5 or 6 ). 
Table 4

Descriptive Statistics Table for Study Variables

\begin{tabular}{lccccc}
\hline Variables & N & Min & Max & Mean & SD \\
\hline Warmth & 1728 & 0 & 6 & 5.60 & 0.88 \\
Hopelessness & 1728 & 0 & 6 & 0.90 & 1.55 \\
Self-worth & 1728 & 0 & 9 & 6.69 & 1.98 \\
& & & & & \\
\hline
\end{tabular}

Approximately $85 \%(n=1465)$ of the sample reported experiencing school pushout (Table 5). The sample representation for Black youth who had experienced school pushout ( $n=1465)$ was much larger than Black youth who had not experienced school pushout $(n=263)$. The sample size discrepancy is not unusual given the likelihood that more Black youth, ages 13-17, would have experienced school pushout than those who had not experienced school pushout.

Table 5

Frequency (School Pushout)

\begin{tabular}{lcc}
\hline Pushout & Total & Frequency \\
\hline & & \\
No pushout & 263 & $15 \%$ \\
Pushout & 1465 & $85 \%$ \\
\hline
\end{tabular}

Table 6

Frequency (Hopelessness)

\begin{tabular}{ccc}
\hline Scores & Total & Frequency \\
\hline 0 & 1138 & $66 \%$ \\
$1-1.9$ & 182 & $10 \%$ \\
$2-2.9$ & 136 & $8 \%$ \\
$3-3.9$ & 125 & $7 \%$ \\
$4-4.9$ & 56 & $3 \%$ \\
$5-5.9$ & 40 & $2 \%$ \\
6 & 51 & $3 \%$ \\
\hline
\end{tabular}


Table 7

Frequency (Self-worth)

\begin{tabular}{ccc}
\hline Scores & Total & Frequency \\
\hline 0 & 5 & $0 \%$ \\
$1-1.99$ & 20 & $1 \%$ \\
$2-2.99$ & 37 & $2 \%$ \\
$3-3.99$ & 81 & $5 \%$ \\
$4-4.99$ & 119 & $7 \%$ \\
$5-5.99$ & 166 & $10 \%$ \\
$6-6.99$ & 241 & $13 \%$ \\
$7-7.99$ & 343 & $20 \%$ \\
$8-8.99$ & 361 & $20 \%$ \\
9 & 355 & $21 \%$ \\
\hline
\end{tabular}

Table 8

Frequency (Parental Warmth)

\begin{tabular}{ccc}
\hline Scores & Total & Frequency \\
\hline 0 & 7 & $0 \%$ \\
$1-1.99$ & 4 & $0 \%$ \\
$2-2.99$ & 22 & $1 \%$ \\
$3-3.99$ & 32 & $2 \%$ \\
$4-4.99$ & 91 & $5 \%$ \\
$5-5.99$ & 253 & $14 \%$ \\
6 & 1319 & $76 \%$ \\
\hline
\end{tabular}


Table 9

Frequency (Age)

\begin{tabular}{ccc}
\hline Age & Total & Frequency \\
\hline & & \\
13 & 361 & $21 \%$ \\
14 & 301 & $17 \%$ \\
15 & 317 & $18 \%$ \\
17 & 339 & $20 \%$ \\
\end{tabular}

Table 10

Frequency (Gender)

\begin{tabular}{lcc}
\hline Gender & Total & Frequency \\
\hline Male & & \\
Female & 866 & $50 \%$ \\
& 862 & $50 \%$ \\
\hline
\end{tabular}

\section{School Pushout and Hopelessness}

(RQ 1) What is the relation between school pushout (as measured by suspensions and expulsions) and future outlook (as measured by hopelessness and self-worth) among Black youth?

H1(a): There will be a direct relation between self-reported school pushout (as measured by suspensions and expulsions) and hopelessness among Black youth.

The relation between school pushout and hopelessness was estimated by calculating a simple linear regression. The hypothesis was supported by the estimated regression equation as there was a direct relation between self-reported school pushout and hopelessness, $\mathrm{b}=0.21, t(d f)=2.00, p=.05$, among the study participants (Table 11 ). School pushout related to more hopelessness, while no school pushout related to less 
hopelessness.

Table 11

School Pushout and Hopelessness Parameter Estimates

\begin{tabular}{lcccc} 
Variable & B & SE & t & Sig. \\
\hline Intercept & 0.73 & 0.10 & 7.59 & $<0.01$ \\
Pushout & 0.21 & 0.10 & 2.00 & $0.05^{*}$ \\
\hline Note:
\end{tabular}

Note: * $=$ significant at $p<0.05$

\section{School Pushout and Self-Worth}

(RQ 1) What is the relation between school pushout (as measured by suspensions and expulsions) and future outlook (as measured by hopelessness and self-worth) among Black youth?

H1(b): There will be an inverse relation between self-reported school pushout (as measured by suspensions and expulsions) and self-worth among Black youth.

The relation between school pushout and self-worth was estimated by calculating a simple linear regression. The hypothesis was supported by the estimated regression equation as there was a negative relation between self-reported school pushout and selfworth among the study participants, $\mathrm{b}=-0.92, t(d f)=-7.00, p<.001$ (Table 12). Youth who reported school pushout also reported lower self-worth than youth who had not experienced school pushout.

Table 12

School Pushout and Self-Worth Parameter Estimates

\begin{tabular}{lcccc}
\hline & & & & \\
Variable & $\mathrm{B}$ & $\mathrm{SE}$ & $\mathrm{t}$ & Sig. \\
\hline Intercept & 7.47 & .12 & 61.91 & $<.001$ \\
Pushout & -.92 & .13 & -7.00 & $<.001^{*}$ \\
\hline
\end{tabular}

Note: $*$ significant at $p<0.05$ 


\section{Parental Warmth, School Pushout, Hopelessness, and Self-Worth}

(RQ 2) Does parental warmth moderate the relation between school pushout (as measured by suspensions and expulsions) and future outlook (as measured by hopelessness and self-worth) among Black youth?

H2: Parental warmth will moderate the relation between self-reported school pushout (as measured by suspensions and expulsions) and future outlook (as measured by hopelessness and self-worth).

The relation between parental warmth, school pushout, hopelessness, and selfworth were estimated by calculating two separate moderated multiple regression models (i.e., separate models for hopelessness and self-worth). Although there was a significant main effect for parental warmth as high parental warmth related to less hopelessness and higher self-worth and low parental warmth related to more hopelessness and lower selfworth, $\mathrm{b}=-0.27, t(d f)=-2.42, p=.02$, parental warmth did not serve as a moderator for the relation between school pushout and future outlook. As reported in Tables 13 and 14, there was not a significant interaction effect between (a) parental warmth, school pushout, and hopelessness $\mathrm{b}=0.13, t(d f)=1.08, p=.28$ (Table 13), or (b) the relation between parental warmth, school pushout, and self-worth $\mathrm{b}=-0.11, t(d f)=-0.74, p=.46$ (Table 14). 
Table 13

Parental Warmth, School Pushout, and Hopelessness Parameter Estimates

\begin{tabular}{lcccc}
\hline Variable & $\mathrm{B}$ & $\mathrm{SE}$ & $\mathrm{t}$ & Sig. \\
\hline Intercept & 2.28 & .65 & 3.51 & $<0.01$ \\
Warmth & -.27 & .11 & -2.42 & $.02^{*}$ \\
Pushout & -.55 & .70 & -.79 & .43 \\
Warmth x Pushout & .13 & .12 & 1.08 & .28 \\
\hline
\end{tabular}

Note: * = significant at $p<0.05$

Table 14

Parental Warmth, School Pushout, and Self-worth Parameter Estimates

\begin{tabular}{lcccc}
\hline Variable & $\mathrm{B}$ & $\mathrm{SE}$ & $\mathrm{t}$ & Sig. \\
\hline Intercept & 5.56 & .82 & 6.80 & $<0.01$ \\
Warmth & .34 & .14 & 2.37 & $.02^{*}$ \\
Pushout & -.26 & .88 & -.29 & .77 \\
Warmth x Pushout & -.11 & .15 & -.74 & .46 \\
\hline
\end{tabular}

Note: * = significant at $p<0.05$

\section{Age and Gender Effects}

(RQ 3) Does age and gender impact the relation among school pushout (as measured by suspensions and expulsions), future outlook (as measured by hopelessness and self-worth), and parental warmth amongst Black youth?

H3: Age and gender will impact the relation among school pushout (as measured by suspensions and expulsions), future outlook (as measured by hopelessness and self-worth), and parental warmth amongst Black youth.

Age and gender were entered into two different models: (a) hopelessness model and (b) self-worth model. The results of both models reveal that age and gender impact the relation among school pushout, future outlook, and parental warmth. When age and gender were entered into both models, parental warmth was found to moderate the 
relation between school pushout and future outlook. Age and gender were added to the hopelessness model, which included school pushout, hopelessness, and parental warmth. Hopelessness was entered as the dependent variable. School pushout and gender were entered as fixed factors, while age and parental warmth were entered as continuous independent variables. Parental warmth was entered into the equation at specific data points (i.e., 0, 3, and 6) in order to explore parental warmth at various levels (i.e., low, mid, and high parental warmth).

Each main effect and every possible interaction effect were initially accounted for in the model. A backward elimination process was utilized to determine the best-fit model. All main effects and interaction effects are captured in Table 15, and plots were created from regression equations in order to better visualize the relations among the variables (Figures 4-7).

The full model for hopelessness included main effects for school pushout, $\mathrm{b}=$ $4.15, t(d f)=-2.99, p<0.01$, parental warmth, $\mathrm{b}=-1.00, t(d f)=-4.19, p<0.01$, age, $\mathrm{b}=-$ $1.40, t(d f)=-2.91, p<0.01$, and gender, $\mathrm{b}=-1.71, t(d f)=-3.17, p<0.01$. The school pushout effect suggests that youth who did not experience school pushout were more likely to report more hopelessness (Figures 6-7) than youth who did experience school pushout (Figures 4-5). The parental warmth effect demonstrates the indirect relation between parental warmth and hopelessness with high parental warmth corresponding to less hopelessness and low parental warmth corresponding to more hopelessness (Figures 4-7). Age had a significant effect on hopelessness as younger youth generally reported more hopelessness than older youth. The gender effect indicates that males were more 
likely to report more hopelessness than females. In other words, females were more hopeful than males (Figures 4-7).

There were also multiple interaction effects between the variables. The two-way interaction effects include (a) age and parental warmth, $\mathrm{b}=0.26, t(d f)=3.06, p<0.01$, (b) age and school pushout, $\mathrm{b}=1.44, t(d f)=2.83, p<0.01$, (c) gender and parental warmth, $\mathrm{b}=0.19, t(d f)=2.17, p=.03$, and (d) school pushout and parental warmth, $\mathrm{b}=$ $0.78, t(d f)=3.26, p<0.01$. There was also a three-way interaction between age, parental warmth, and school pushout, $\mathrm{b}=-0.27, t(d f)=-3.08, p<0.01$.

Overall, the age and parental warmth interaction demonstrates that for younger youth, the level of parental warmth has a more significant effect on the level of hopelessness when compared with older youth (Figures 6-7). There is an indirect relation between parental warmth and hopelessness such that higher parental warmth is related to less youth hopelessness. The interaction effect of age and school pushout reveal that youth who had not experienced school pushout reported a wider range of hopelessness and higher levels of hopelessness across age than youth who had experienced school pushout (Figures 4-7). The gender and parental warmth effect demonstrates that parental warmth has a more significant effect on hopelessness for females as compared to males. The relation between parental warmth and hopelessness is an inverse relation with less hopelessness associated with higher parental warmth (Figures 4-7). School pushout and parental warmth had a significant effect on hopelessness as youth who had not experienced school pushout reported more hopelessness irrespective of parental warmth level than youth who experienced school pushout (Figures 4-7). 
The three-way interaction between age, parental warmth, and school pushout demonstrated that younger youth who have experienced school pushout reported higher parental warmth than older youth who have experienced school pushout. Additionally, low parental warmth was more frequently reported by older youth who had experienced school pushout in comparison to younger youth who had experienced school pushout. Across age and gender, high parental warmth was associated with less hopelessness for youth irrespective of school pushout experience. The opposite trend emerged for youth who reported low parental warmth, with low parental warmth being associated with more reported hopelessness irrespective of school pushout experience. With gender and age added to the model, parental warmth moderated the relation between school pushout and hopelessness.

For youth who did not experience school pushout, the relation between parental warmth and hopelessness seemed to be more significant at younger ages (Figures 6-7). At age 16 for females (Figure 6) and age 17 for males (Figure 7), such differences between parental warmth, hoplessness, and age dissipate. Younger youth who had not experienced school pushout also reported more hopelessness when they experienced low or mid levels of parental warmth. 
Table 15

Full Hopelessness Model Parameter Estimates

\begin{tabular}{lcccc}
\hline Variable & $\mathrm{B}$ & $\mathrm{SE}$ & $\mathrm{t}$ & $\mathrm{Sig}$. \\
\hline Intercept & 6.65 & 1.39 & 4.79 & $<0.01$ \\
Age & -1.40 & .48 & -2.91 & $<0.01^{*}$ \\
Warmth & -1.00 & .24 & -4.19 & $<0.01^{*}$ \\
Pushout & -4.15 & 1.39 & -2.99 & $<0.01^{*}$ \\
Gender & -1.71 & .54 & -3.17 & $<0.01^{*}$ \\
Age x Gender & .03 & .05 & .56 & .58 \\
Age x Warmth & .26 & .08 & 3.06 & $<0.01^{*}$ \\
Age x Pushout & 1.44 & .51 & 2.83 & $<0.01^{*}$ \\
Gender x Warmth & .19 & .09 & 2.17 & $.03^{*}$ \\
Pushout x Gender & .15 & .22 & .70 & .49 \\
Pushout x Warmth & .78 & .24 & 3.26 & $<0.01^{*}$ \\
Age x Warmth x Pushout & -.27 & .09 & -3.08 & $<0.01^{*}$ \\
\hline
\end{tabular}

Note: * = significant at $p<0.05$

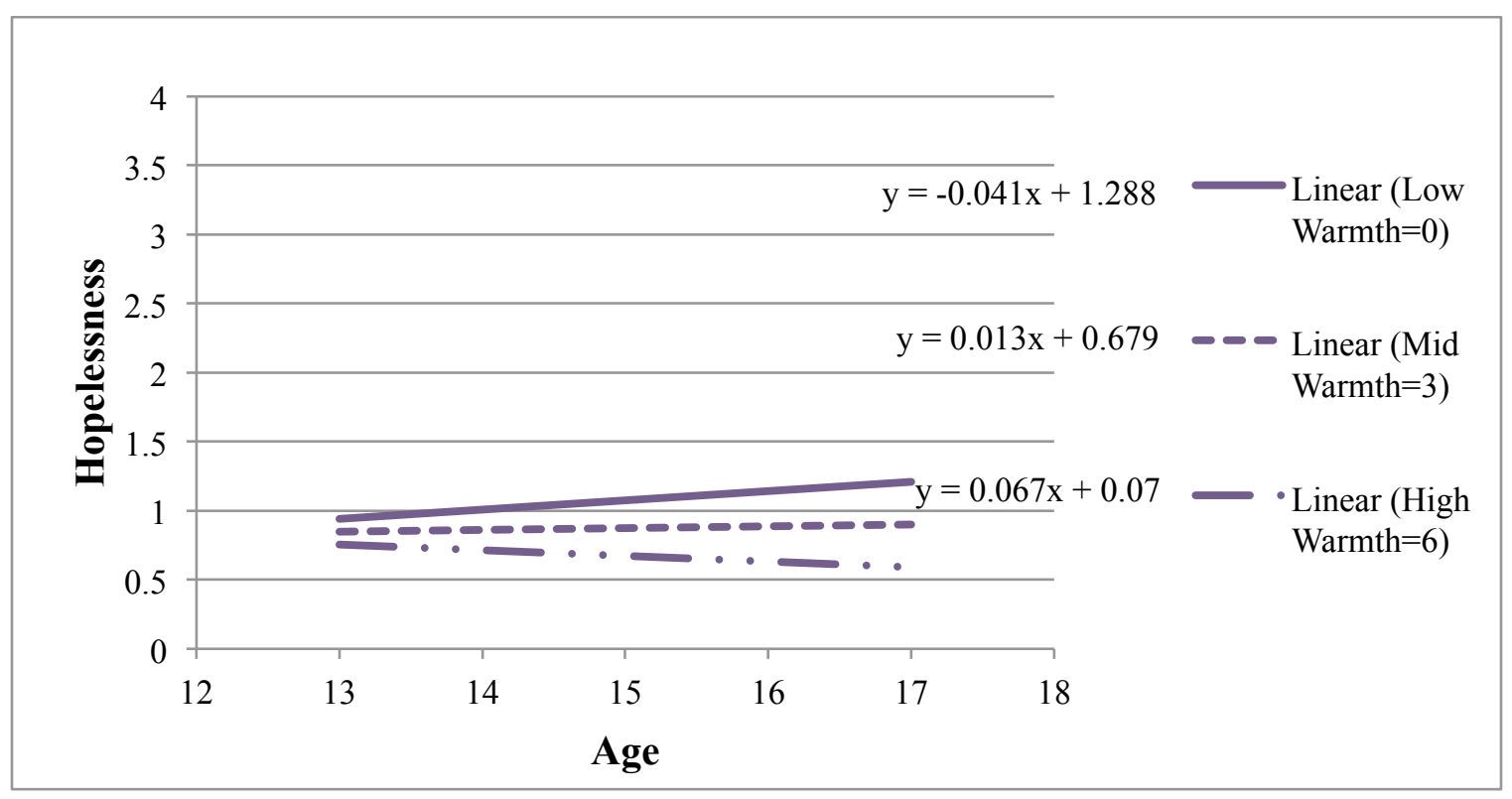

Figure 4. Full Hopelessness Model: Female School Pushout Plot. 


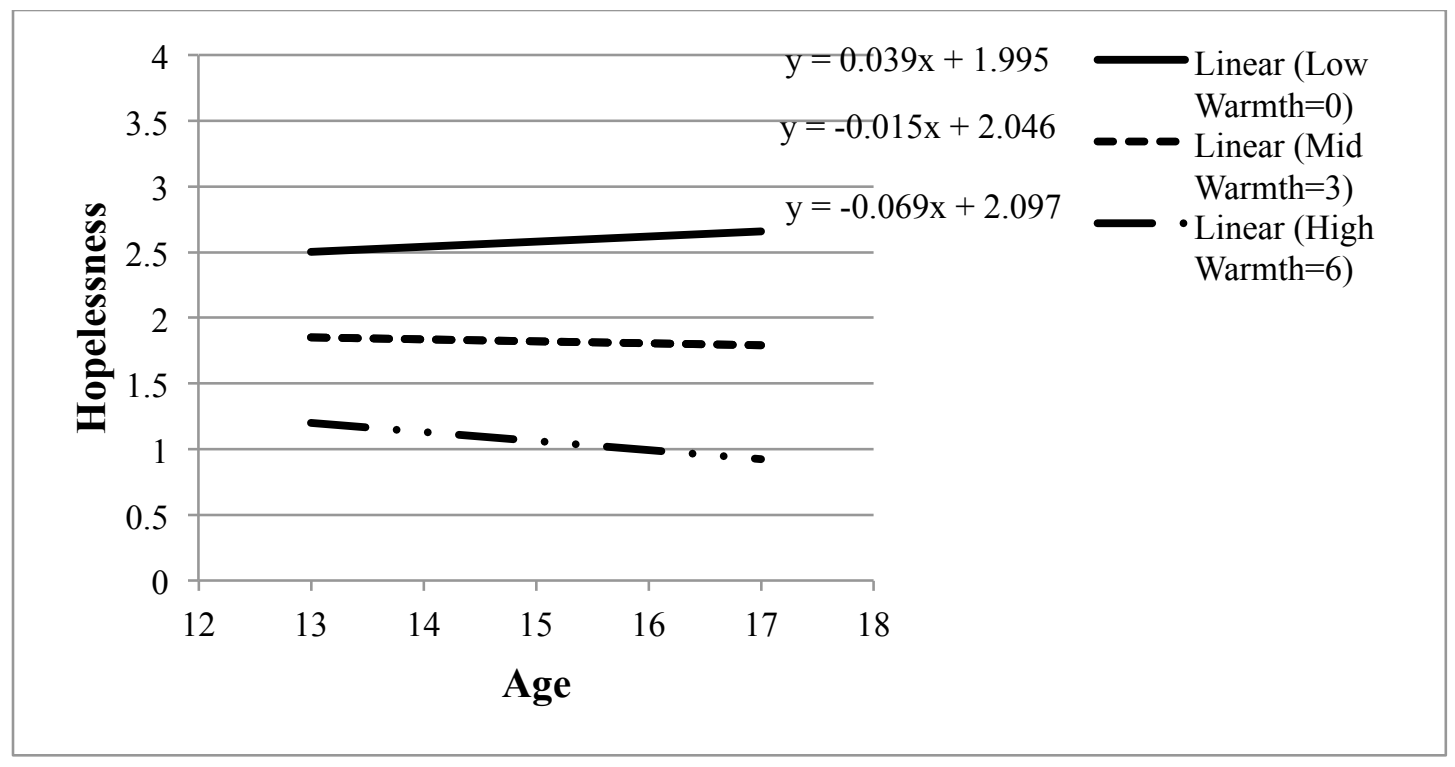

Figure 5. Full Hopelessness Model: Male School Pushout Plot.

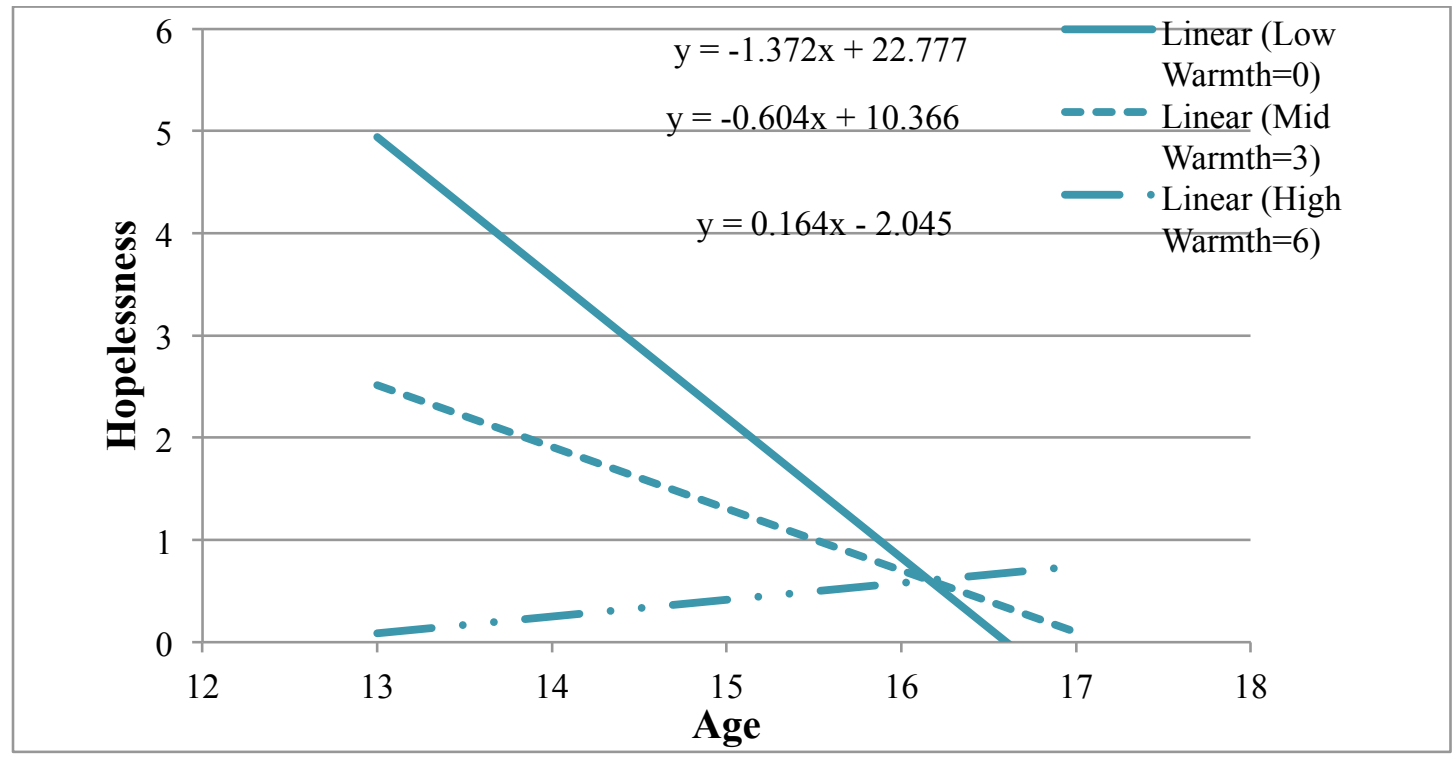

Figure 6. Full Hopelessness Model: Female No School Pushout Plot. 


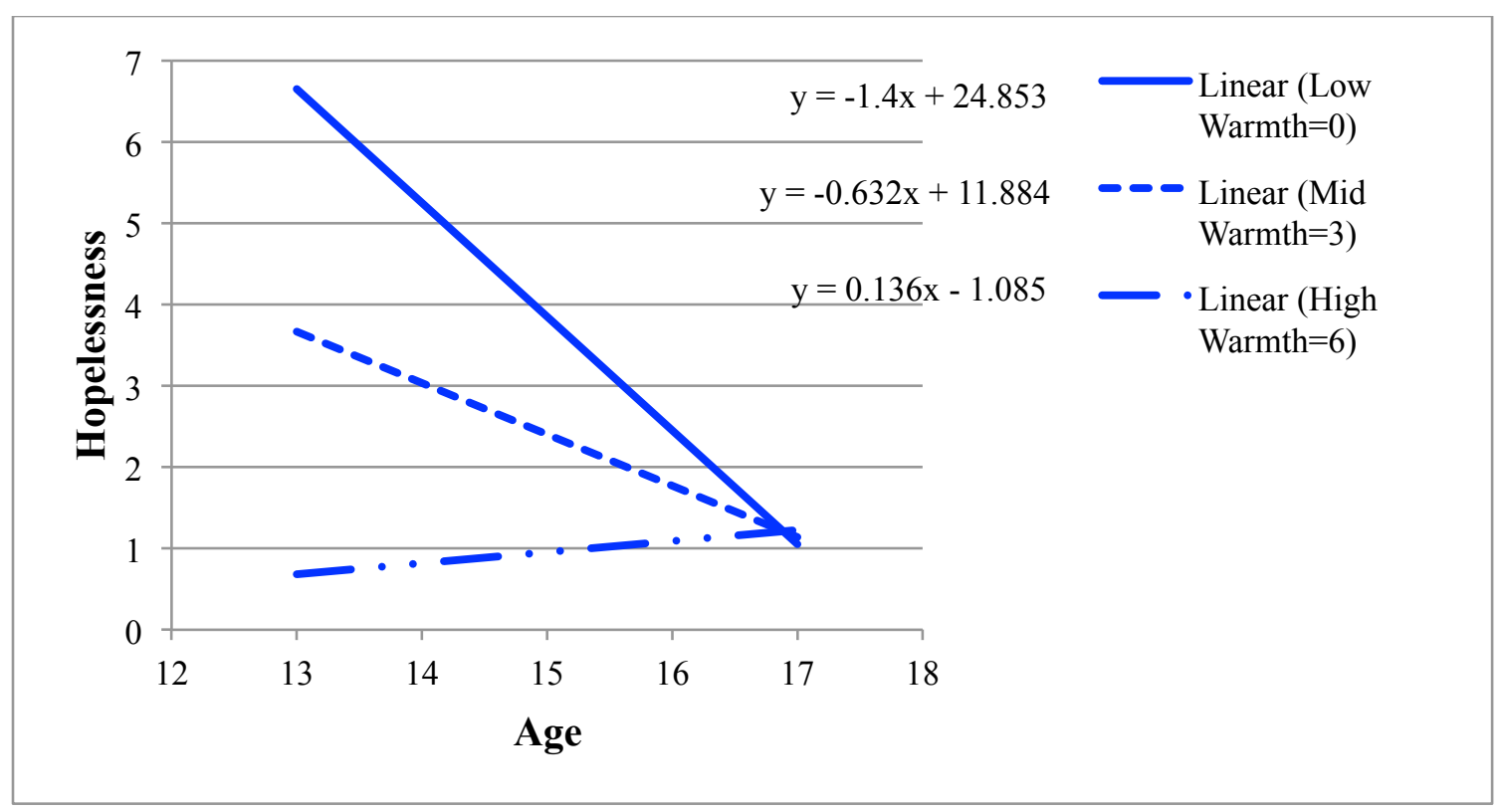

Figure 7. Full Hopelessness Model: Male No School Pushout Plot.

In the analysis for self-worth, age and gender were added to the model along with school pushout, self-worth, and parental warmth. Self-worth was entered as the dependent variable, school pushout and gender were entered as fixed factors, and age and parental warmth were entered as continuous independent variables. The same backward elimination process that was previously mentioned for the first model was employed for the second. Parameter estimates are displayed in Table 16.

The full model for self-worth included significant main effects and multiple interaction effects between the variables. There were significant main effects for age, $b=$ $2.52, t(d f)=2.25, p=.02$, parental warmth, $\mathrm{b}=1.73, t(d f)=2.69, p=.01$, and gender, $\mathrm{b}$ $=11.40, t(d f)=2.71, p=.01$. School pushout also represented a potential main effect in the model, $\mathrm{b}=7.46, t(d f)=1.92, p=.05$. In addition to the main effects, there were also crossover interaction effects between variables. 
Age had a significant effect on self-worth with older youth typically reporting higher levels of self-worth (Figures 8-11). The parental warmth effect on self-worth indicated that parental warmth predicts youth self-worth with higher parental warmth corresponding to higher levels of self-worth reported by youth. The gender effect revealed that Black females report higher self-worth than Black males. School pushout had a significant effect on self-worth with youth who had experienced school pushout reporting higher self-worth than youth who had not experienced school pushout.

Two-way interactions included significant effects between (a) age and gender, $b=$ $-4.13, t(d f)=-2.96, p<0.01,(\mathrm{~b})$ age and parental warmth, $\mathrm{b}=-0.45, t(d f)=-2.32, p=$ .02 , (c) age and school pushout, $\mathrm{b}=-2.54, t(d f)=-2.17, p=.03$, (d) parental warmth and gender, $\mathrm{b}=-2.00, t(d f)=-2.77, p=.01$, (e) school pushout and gender, $\mathrm{b}=-10.94, t(d f)$ $=-2.51, p=.01$, and (f) parental warmth and school pushout, $\mathrm{b}=-1.49, t(d f)=-2.24, p=$ .03 .

The age and gender interaction effect on self-worth demonstrated that younger females were more likely to report higher self-worth. Generally, age and parental warmth had a significant effect on self-worth with high parental warmth predicting high self-worth across age. The age and school pushout interaction effect revealed that selfworth was more consistent across age for youth who had experienced school pushout as compared to youth who had not experienced school pushout (Figures 8-11). Parental warmth and gender had a significant effect on self-worth demonstrating how parental warmth level had a significant positive effect on males' reported self-worth. School pushout and gender had a significant effect on self-worth with more consistency in selfworth report for males and females who had experienced school pushout, but a significant 
interaction effect is observed among the youth who had not experienced school pushout (Figures 10-11) with more variance in self-worth reported. The parental warmth and school pushout effect revealed that youth who experienced school pushuout had a positive relation between parental warmth and self-worth, whereas, youth who had not experienced school pushout had various levels of self-worth that were not directly related to parental warmth.

There were also three-way interaction effects between (a) age, parental warmth, and gender, $\mathrm{b}=0.76, t(d f)=3.13, p<0.01$, (b) age, school pushout, and gender, $\mathrm{b}=4.37$, $t(d f)=2.99, p<0.01,(\mathrm{c})$ age, parental warmth, and school pushout, $\mathrm{b}=0.47, t(d f)=$ $2.35, p=.02$, and (d) parental warmth, school pushout, and gender, $\mathrm{b}=1.91, t(d f)=2.55$, $p=.01$. A significant four-way interaction effect between age, parental warmth, school pushout, and gender, $\mathrm{b}=-0.78, t(d f)=-3.08, p<0.01$, was also reported. The interaction effects are reported in Table 16 and represented in the corresponding plots of the regression equations (Figures 8-11).

Overall, females and males who experienced school pushout reported higher selfworth with higher parental warmth scores and lower self-worth with lower parental warmth scores (Figures 8-9). Therefore, youth's feelings of overall self-worth was related to the level of parental warmth experienced by youth. The same trend of high self-worth experienced in conjunction with high parental warmth existed for youth who had not experienced school pushout. The trend was consistent across ages.

Self-worth increased across age for females and males regardless of school pushout experience with older youth reporting higher levels of self-worth than younger youth. As Figure 9 demonstrates, there was an exception to the previously stated trend 
with males who experienced school pushout and low parental warmth also reporting more consistent self-worth across age. Females typically reported higher self-worth than males regardless of school pushout experience. Generally, younger females who had not experienced school pushout reported higher self-worth at younger ages (Figure 10), while males who had not experienced school pushout reported higher self-worth at older ages (Figure 11).

At age 13, females self-worth was higher at lower levels of parental warmth for females who had not experienced school pushout (Figure 10). The trend for females changes at age 14 with self-worth increasing with higher levels of parental warmth. Older males who had not experienced school pushout reported more self-worth than younger males (Figure 11). While younger males who had not experienced school pushout reported higher self-worth scores with high levels of parental warmth. The trend seems to taper off with older males. With gender and age added to the model, parental warmth did moderate the relation between school pushout and self-worth. 
Table 16

Full Self-worth Model Parameter Estimates

\begin{tabular}{lcccc}
\hline & & & & \\
Variable & $\mathrm{B}$ & $\mathrm{SE}$ & $\mathrm{t}$ & Sig. \\
\hline Intercept & -2.64 & 3.79 & -.70 & .49 \\
Age & 2.52 & 1.12 & 2.25 & $.02^{*}$ \\
Warmth & 1.73 & .65 & 2.69 & $.01^{*}$ \\
Pushout & 7.46 & 3.88 & 1.92 & $.05^{*}$ \\
Gender & 11.40 & 4.21 & 2.71 & $.01^{*}$ \\
Age x Gender & -4.13 & 1.40 & -2.96 & $<0.01^{*}$ \\
Age x Warmth & -.45 & .19 & -2.32 & $.02^{*}$ \\
Age x Pushout & -2.54 & 1.17 & -2.17 & $.03^{*}$ \\
Warmth x Gender & -2.00 & .72 & -2.77 & $.01^{*}$ \\
Pushout x Gender & -10.94 & 4.36 & -2.51 & $.01^{*}$ \\
Warmth x Pushout & -1.49 & .66 & -2.24 & $.03^{*}$ \\
Age x Warmth x Gender & .76 & .24 & 3.13 & $<0.01^{*}$ \\
Age x Pushout x Gender & 4.37 & 1.46 & 2.99 & $<0.01^{*}$ \\
Age x Warmth x Pushout & .47 & .20 & 2.35 & $.02^{*}$ \\
Warmth x Pushout x Gender & 1.91 & .75 & 2.55 & $.01^{*}$ \\
Age x Warmth x Pushout x & & & & \\
Gender & -.78 & .25 & -3.08 & $<0.01^{*}$ \\
\hline Note: & & & &
\end{tabular}

Note: $*=$ significant at $p<0.05$ 


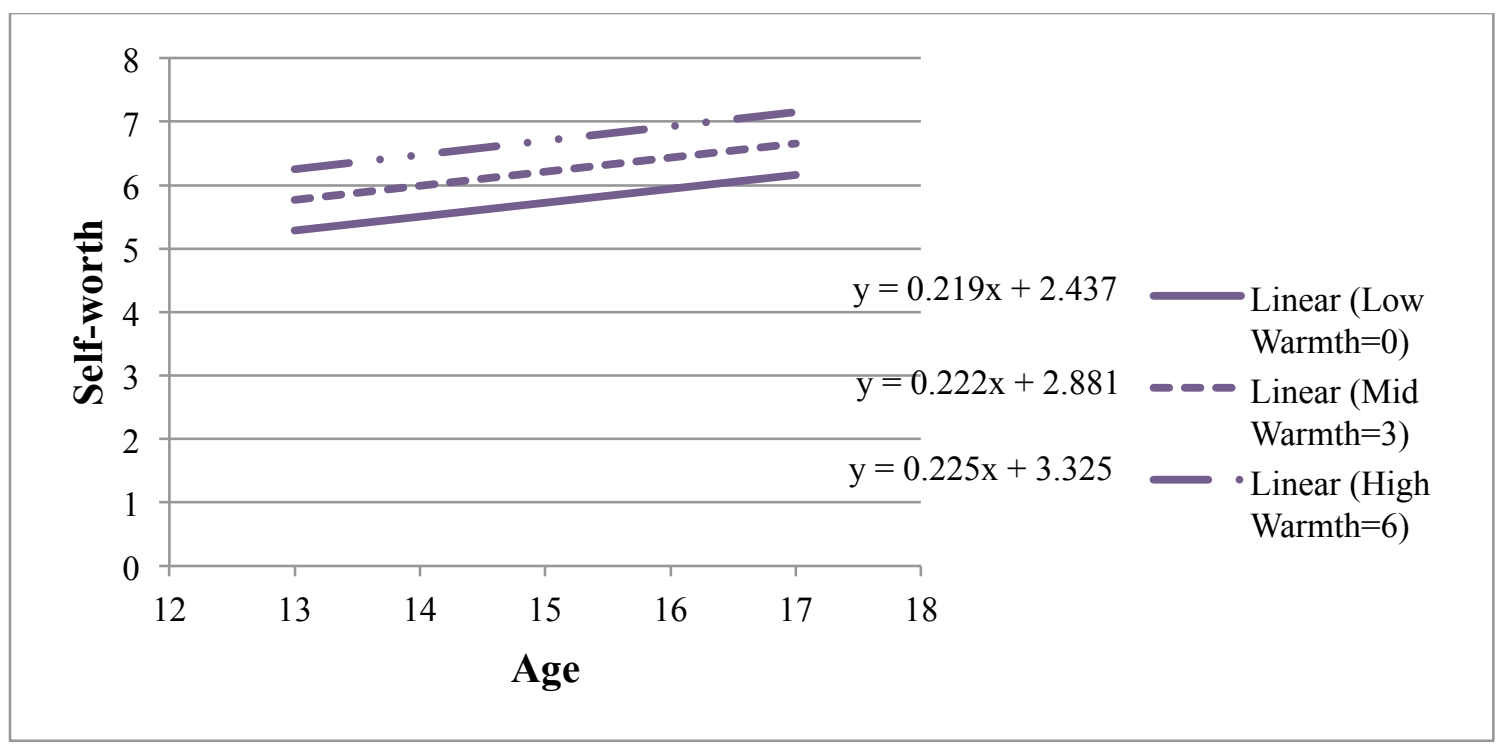

Figure 8. Full Self-Worth Model: Female School Pushout Plot.

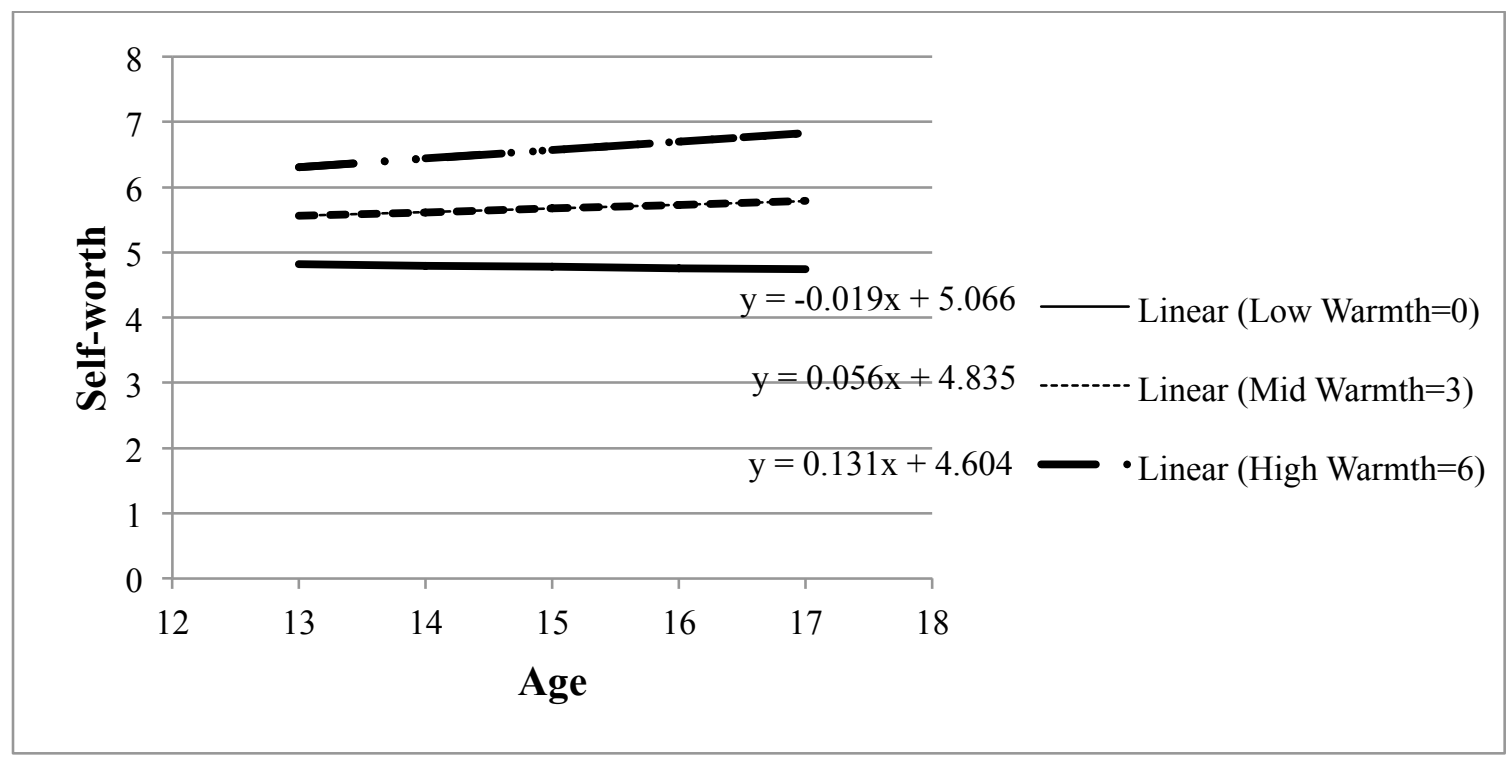

Figure 9. Full Self-Worth Model: Male School Pushout Plot. 


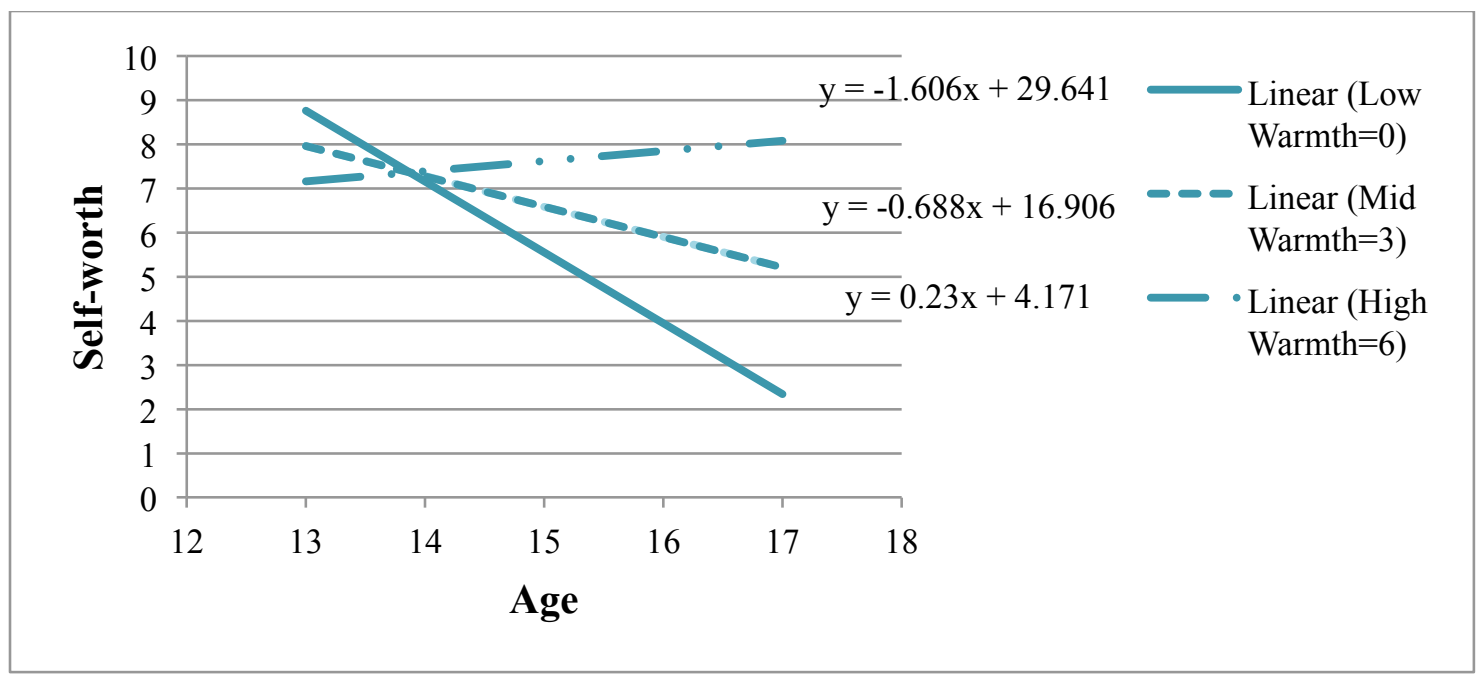

Figure 10. Full Self-Worth Model: Female No School Pushout Plot.

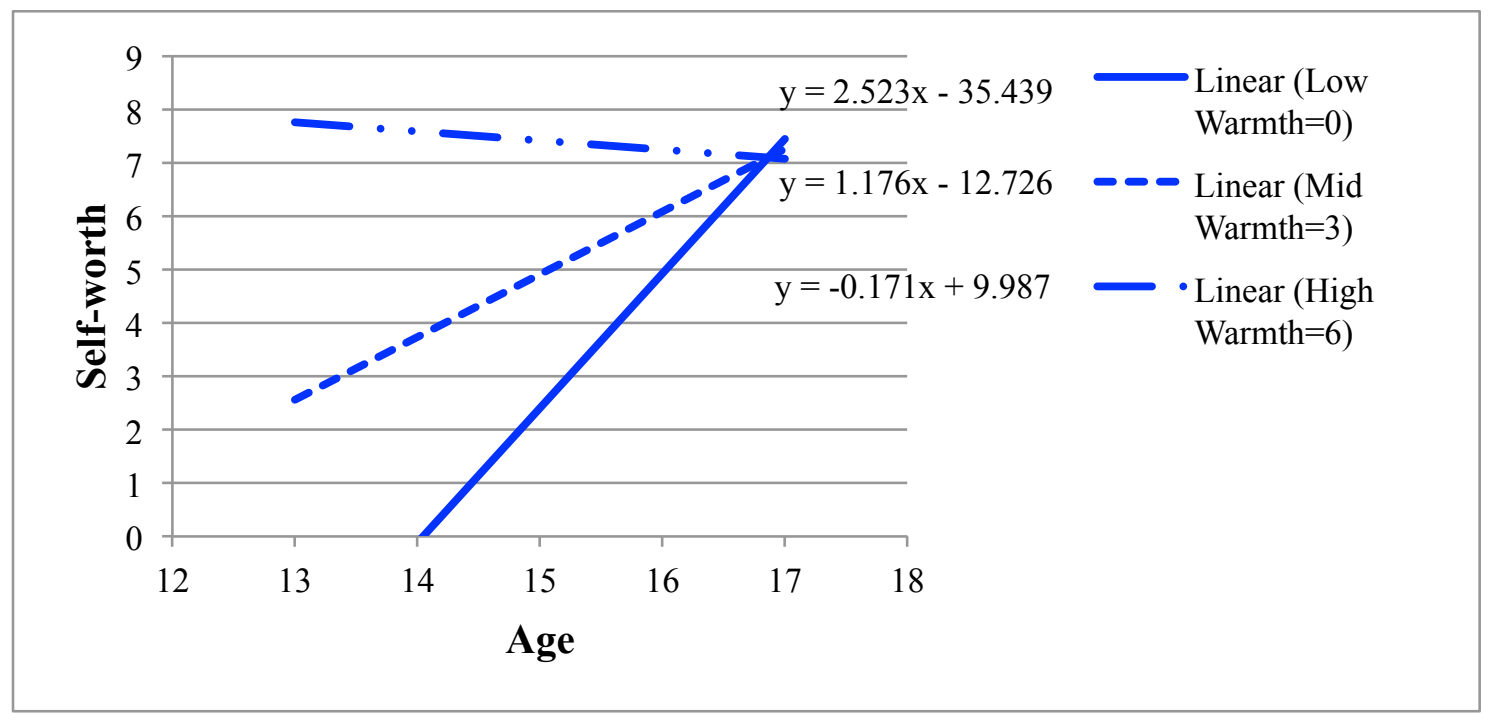

Figure 11. Full Self-Worth Model: Male No School Pushout Plot.

\section{Conclusion}

The research questions and the respective hypotheses were examined in this chapter. Data analytic procedures and results were shared along with accompanying plots to illustrate findings. The various significant main effects and interaction effects of 
each regression analysis were presented in the results. The findings revealed that school pushout was related to future outlook for Black youth, with school pushout corresponding to more hopelessness and less self-worth. Parental warmth did not moderate the relation between school pushout and future outlook for Black youth until age and gender were added to the model. The following chapter provides a discussion of the results and implications for further research. 


\section{CHAPTER V}

\section{DISCUSSION, IMPLICATIONS, AND CONCLUSION}

The purposes of this dissertation study were to (a) examine the relation between school pushout and future outlook for Black youth, (b) explore parental warmth as a protective factor - a moderator of the relation between school pushout and future outlook, and (c) determine if there were any age and gender effects in respect to the relations among school pushout, future outlook, and parental warmth. School pushout was operationalized as suspensions and expulsions, while future outlook was defined as expectancies toward the future based on internalized and externalized value of self and operationalized as an assessment of hopelessness and self-worth. Parental warmth was defined as parents' general tendencies to be supportive, affectionate and sensitive to the child's needs. The researcher's desire to investigate the entry point of the school-to-prison pipeline (STPP) and potential protective factors for Black youth inspired the examination of the relations among school pushout, future outlook, and parental warmth.

\section{Discussion}

Black youth, ages 13-17, who participated in the Mobile Youth Survey (MYS) during the last year of administration, 2011, constituted the sample $(N=1728)$ for this dissertation study. The sample was equally distributed based on gender with approximately 50\% $(n=862)$ Black female and 50\% $(n=866)$ Black male representation. The initial research design included youth from ages 11 to 17 within the 
sample; however, while examining school pushout frequencies, an age dependency was detected, such that youth were more likely to have experienced school pushout if they were older. The age dependency was no longer significant at age 13; thus, the sample was delimited to 13-17 year-olds.

The discovery regarding age dependency on school pushout is consistent with literature stating that Black youth are more likely to experience school pushout as they age (Skiba et al., 2011; Wallace et al., 2008). This trajectory has been identified by Skiba et al. (2011) for Black elementary and middle school youth as Black middleschoolers were more likely to receive office referrals than their White counterparts at a higher rate than Black elementary-aged youth when compared to their White counterparts. The same increasing trend has been identified at the high school level. Wallace et al. (2008) reported that suspension rates decreased over time for most racial groups, but among Black youth, the suspension rates increased over time.

The increased likelihood of Black youth experiencing school pushout as they grow older could be due to various reasons. An evidence-based consideration is the perception of Black youth as more blameworthy or accountable for their actions as they age. This consideration is supported by Goff et al.'s (2014) study, which revealed that in comparison to White males, Black males are viewed as being more culpable as they age. Approximately $85 \%(n=1465)$ of the sample reported experiencing school pushout. Although the statistics regarding racially disparate treatment of Black youth in schools are staggering with Black youth being 3.8 times more likely to be suspended than White youth (OCR, 2016), the discovery that $85 \%(n=1465)$ of the sample had experienced school pushout was sobering. The recognition that only $15 \%(n=263)$ of 
the Black youth in the sample of 1,728 youth responded that they had never been suspended or expelled gave credence to this study's purpose.

This dissertation study was designed to explore the relations among school pushout, future outlook, and parental warmth for Black youth. An investigation of the research questions and respective hypotheses revealed significant findings. The following sections include discussions of the results for each of the three research questions examined in this dissertation study.

\section{School Pushout and Future Outlook}

This dissertation study revealed findings that the relation between school pushout and future outlook among Black youth was significant with school pushout significantly predicting more hopelessness and lower self-worth. Therefore, the hypotheses that tested the relation between school pushout and future outlook were supported. The first hypothesis stated that there would be a direct relation between school pushout and hopelessness. The second hypothesis stated that there would be an inverse relation between school pushout and self-worth. Both of these hypotheses were supported.

The aforementioned findings regarding the relation between school pushout and future outlook are in accordance with those of Toldson et al. (2014), which supported (a) the direct relation between school disciplinary referrals and feelings of hopelessness, and (b) the inverse relation between school disciplinary referrals and positive self-worth among Black males. The findings of this dissertation study also support the work of Tenenbaum and Ruck (2007), which emphasized the direct relation between school pushout and youth frustrations. 
The inverse relation between school pushout and self-worth has implications for the internalized value of self for Black youth. These findings suggest that Black youth who are suspended or expelled from school, are likely to internalize the school pushout experience. These findings also support Quin and Hemphill's (2014) assertion that suspensions could be interpreted as rejection and youth may sense a perceived stigma associated with school pushout. Equally noteworthy was the unexpected finding that Black youth who had experienced school pushout exhibited less hopelessness (i.e., were more hopeful) across age than Black youth who had not experienced school pushout. Although this trend appears to be counterintuitive, it could be attributed to the notion that youth who have experienced school pushout or rejection are more likely to be hopeful in anticipation of something better to come.

\section{School Pushout, Future Outlook, and Parental Warmth}

The dissertation study revealed findings that although parental warmth had a significant effect on youth future outlook, the relation among school pushout, future outlook, and parental warmth amongst Black youth was not significant. Therefore, the hypothesis that parental warmth would moderate the relation between school pushout and future outlook was not supported. However, the examination of the relations among school pushout, future outlook, and parental warmth were significant when age and gender effects were considered.

Currently, there are not any studies that research the intersection of school pushout, hopelessness, self-worth, and youth-reported parental warmth. However, previous research has supported a positive relation between parental warmth and selfesteem (Buri et al., 1988; Doyle \& Markiewicz, 2004; Murry \& Brody, 1999), and 
parental warmth and psychological adjustment (Khaleque \& Rohner, 2002; Khaleque \& Rohner, 2012). There are also multiple studies that identify the importance of parental warmth in youth behavior prevention (Church et al., 2012; Stoddard et al., 2011; Toldson et al., 2014; Vazsonyi, Pickering, and Bolland, 2006; Walker-Barnes \& Mason, 2004). However, parental warmth has not been examined as a moderator between school pushout and future outlook for Black youth.

The findings from this dissertation study suggest that Black youth who experienced higher levels of parental warmth also reported higher self-worth and less hopelessness, while Black youth who experienced lower levels of parental warmth reported lower self-worth and more hopelessness. The finding that parental warmth moderated the relation between school pushout and future outlook for Black youth in this study when age and gender were considered encourages further investigation of parental warmth as a protective factor for Black youth who experience school pushout. In light of the dismal trend of Black youth being pushed out of schools in the United States (OCR, 2016), protective factors from various levels of ecological systems should be examined (Bronfenbrenner, 1977).

This dissertation study supports the identification of parental warmth as a protective factor for Black youth at the microsystem level, as parental warmth appears to moderate their future outlook. This discovery could potentially benefit parents of Black youth who are interested in identifying various ways to protect their children from the deleterious effects of school pushout, while awaiting the abolition of zero tolerance school policies and the dismantling of the STPP. Of equal acknowledgement for this discussion is the fifth system of Bronfenbrenner's Ecological Systems, the chronosystem, 
which addresses environmental and historical context. In regards to this dissertation study, the chronosystem includes the existence of historically racial discriminatory practices in the American school system (i.e., colonization of schools) that influence the current and projected trajectory of school experiences for Black youth. Thusly, from a sociohistorical context, the recognition of the disparate impact of education policies on communities of color is relevant and paramount as foreground to this discussion.

\section{Age and Gender Effects: School Pushout, Future Outlook, and Parental Warmth}

This dissertation study contributes to school pushout literature by providing an examination of an inclusive model consisting of school pushout, hopelessness, selfworth, parental warmth, age, and gender. The hypothesis, that age and gender would impact the relation among school pushout, future outlook, and parental warmth, was supported. As previously mentioned, the intersection of these variables have not been studied, therefore, the significant relations among school pushout, future outlook, parental warmth, age, and gender were unique.

Overall, pushout, parental warmth, age, and gender all had individual significant effects on future outlook. Various interaction effects between the various constructs were also evidenced in the study. Notably, an age and parental warmth interaction effect demonstrated that younger youth who experienced school pushout reported higher parental warmth than older youth who experienced school pushout. Older youth who experienced school pushout were also more likely to report lower parental warmth than younger youth who experienced school pushout. This finding regarding age and parental warmth could indicate that parents show less parental warmth to older children who have experienced school pushout when compared to younger children who have experienced 
school pushout. An additional consideration is that younger children who have experienced school pushout perceive more parental warmth from their parents than older children who have experienced school pushout.

Another emerging theme was that irrespective of age, females and males who experienced school pushout reported higher self-worth with higher parental warmth scores and lower self-worth with lower parental warmth scores. This finding suggests that youth's feelings of overall self-worth were related to the level of parental warmth experienced by youth as the same trend of high self-worth experienced in conjunction with high parental warmth existed for youth who had not experienced school pushout.

Additionally, a trend appeared that demonstrated that females who experienced school pushout were more hopeful than males who had experienced school pushout. However, as previously stated, Black females who experienced school pushout reported more hopelessness than Black females who had not experienced school pushout.

\section{School Pushout and Gender}

In the midst of an established school pushout literature base that focuses on Black male school pushout, oftentimes, the school pushout epidemic is not acknowledged among Black females (Morris, 2016). The findings of this dissertation study support Crenshaw et al.'s (2015) findings from her qualitative study with Black females, as they reported feelings of being undervalued, misunderstood, and overlooked. Specifically, this dissertation study revealed that Black females who experienced school pushout reported being more hopeless and having lower self-worth as compared to Black females who had not experienced school pushout. 
Findings also suggested that Black males reported more hopelessness and lower feelings of self-worth than Black females. Black males who experienced school pushout also reported more hopelessness and lower feelings of self-worth when compared to Black males who did not experience school pushout. These findings confirm the findings found in Toldson et al.'s (2014) study that examined the relation between school disciplinary referrals and hopelessness and self-worth among Black males.

When considering gender differences among Black youth in this dissertation study, one should note the within gender comparisons between the Black youth who experienced school pushout and those who have not (e.g., Black females experiencing school pushout compared to Black females who did not experience school pushout) in conjunction with comparing the Black female pushout experience across genders. Stating (a) the experience of Black females who experienced school pushout when compared to Black females who did not experience school pushout and (b) the experience of Black females compared to Black males is an intentional way to avoid gender-biased reporting. Therefore, the narrative regarding the relation between school pushout and future outlook for Black females is not overshadowed by the narrative created when the Black female school pushout experience is compared to the Black male pushout experience (Crenshaw et al., 2015; Morris, 2016).

\section{Limitations}

Limitations of this dissertation study included (a) the homogeneity of the sample, (b) the usage of subscales or newly created scales to measure variables of interest, (c) the period of time chosen for analysis, and (d) data obtained by youth self-report. Other limitations of the study included (e) the difference in sample size between youth who had 
experienced school pushout and those who had not, which if resolved could have resulted in more accurate parameter estimates, (f) the exclusion of the 11- and 12-year-old participant data, which did not allow for an examination of effects at those particular

ages, $(\mathrm{g})$ merging maternal and paternal warmth into parental warmth, and $(\mathrm{h})$ not testing for curvilinear effects, which could have been more informative given the usage of categorical data for some of the study variables.

\section{Implications}

\section{Implications for Research}

In light of school pushout literature gaps, the findings from this dissertation study can inform future research by encouraging more studies that investigate the intersection of school pushout, future outlook, parental warmth, and age and gender. Genderdisaggregated data could be useful in providing data that support the school pushout experiences of Black females and males. The examination of school pushout of Black youth across age groups is scarce, but this dissertation study suggests that there are some relations among school pushout, future outlook, and age that should be further explored. This dissertation study also provided a unique opportunity to capture youth's self-report concerning school pushout, future outlook, and parental warmth.

Additional studies that can assess for the intersection of the aforementioned constructs (i.e., school pushout, hopelessness, self-worth, parental warmth) from the youth's perspective, as this dissertation examined, could be useful to school pushout research. In conjunction with seeking youth as the primary data source for school pushout data, it could also be beneficial to collect youth-reported qualitative and quantitative data. Research designed to include comparisons of youth report on parental 
warmth with parent report of parental warmth to assess for similarities and discrepancies regarding perception of parental warmth could also contribute to the literature base. In general, multi-informant qualitative and quantitative research could be helpful in advancing this research.

Another recommendation is to consider similar sample sizes for comparison data between school pushout and no school pushout groups. The particular sample utilized in this dissertation study could not accommodate for similar sample sizes, as the study was used on a retrospective sample. The sample consisted of $85 \%(n=1465)$ of Black youth that reported school pushout experience.

Studies that investigate the psychological impact of school pushout on Black youth's psychological development are scarce and could assist in the cessation of zero tolerance policy implementation and school pushout tactics as preferred praxis. As this dissertation study revealed, there is a significant indirect relation between school pushout and future outlook for Black youth that should be explored. When Black youth who experience school pushout are more likely to report hopelessness and less self-worth than youth who have never experienced school pushout, there is an apparent connection that should not be ignored.

The data collection site should also be considered when conducting future school pushout studies. Another unique benefit of this dissertation study is that school pushout data were collected from youth in community settings. Oftentimes, school pushout data are collected from youth and/or staff and administration at schools. This option, while more convenient for researchers, may prove to be less robust than data collected outside of schools. For the obvious reason, youth who are accustomed to being pushed out of 
schools may more likely be found outside of the schools. Even if they are in school at the time of the study, those who have been expelled or are out for a suspension would not be available for studies conducted within schools.

\section{Implications for Practice}

The findings shared from this dissertation study should inform practitioners to consider the connection between school pushout and future outlook for Black youth. If there are relations between school pushout and self-worth and school pushout and hopelessness, such that Black youth who have experienced a suspension or expulsion are more likely to report a negative future outlook, parents, clinicians, administrators, and ultimately, Black youth, could benefit from being informed of the relations. Relations of this nature suggest that school pushout could be connected to a negative internalized and externalized value of self.

Parents, school counselors, school social workers, youth and family resource coordinators, teachers, and administrators should also consider the potential moderating effect of parental warmth. The suggestion to consider parental warmth as a protective factor for Black youth who have experienced school pushout should be broached with caution. The concept of promoting parental warmth should be used as an opportunity to encourage the benefit of parent and child connection to increase self-worth and hope for youth who have experienced school pushout as a response to trauma-informed care. School support staff and administrators are not encouraged to use this message as a rationale to support agendas to parent-blame or parent-shame with the intent of connecting parental warmth to school pushout prevention. It is interesting to note that 
within this dissertation study, the majority of youth who participated in this study reported mid to high levels of parental warmth.

Practitioners are encouraged to be familiar with the STPP and it's impact on Black youth. Specifically, practitioners should be aware of the role that implicit racial biases play in personal beliefs about Black youth. For example, Goff et al.'s (2014) findings that Black males are typically seen as adults at the young age of 10 and considered more guilty and accountable for acts than their White counterparts, has implications for how teachers and administrators view Black males and possibly Black youth in general.

Many teachers are not prepared to work with students from historically marginalized populations (Osher et al., 2015). Oftentimes, teachers have not received training in educator preparation programs to feel equipped to effectively manage their classrooms, resulting in high teacher absence rates and turnover (Nocella \& Socha, 2014). Some of the courses that are designed to expose teacher candidates to culturally relevant issues oftentimes perpetuate negative statistics and reaffirm cultural myths and stereotypes (Nocella \& Socha, 2014). In a recent study, Blake et al. (2016) reported findings that schools reflecting higher student-teacher racial/ethnic congruence also reported lower school pushout experiences for Black youth. In light of these compelling findings, cultural competency training and recruitment and retention of Black educators are also recommended to increase agency for Black youth (Blake et al., 2016).

According to the American School Counselor Association (2012), school counselors serve as advocates for youth. School counselors have an obligation to advocate for Black youth and all youth who are victimized within their respective 
schools. Equally important, school counselors have an opportunity to serve as a liaison between youth, teachers, administrators, and parents. School counselors can proactively engage in and facilitate dialogue regarding the exploration of solutions or alternative methods of practice.

When educators and administrators are informed of the positive impact of healthy student-teacher relationships on academic performance and consequentially opt to abandon the criminalizing zeitgeist, the school culture and classroom environment could possibly become a more supportive and caring community for Black youth (Ray et al., 2007). Caring school communities positively impact other developmental factors for students as well, such as student engagement, sense of belonging, and community building (Osher et al., 2015; Ray et al., 2007). School counselors can impact the relationship between students and teachers; continued behavioral and mental health consultation provided to teachers has been effective in improving student-teacher relationships (Gilliam, 2005).

Counselor educators and educator preparation programs can also empower future educators to strengthen their advocacy efforts by restructuring the course offerings to align with a social justice framework. The social justice framework should promote a counter-hegemonic perspective that produces culturally competent educators who are more understanding of the behaviors of Black youth and less likely to subject Black youth to conform to the behavior patterns of their White peers (Blake et al., 2016). Alternatives to school pushout are being considered and practiced by various school districts throughout the United States. Some of the noteworthy alternatives include (a) mindfulness practice in which youth are taught meditation exercises that they 
are encouraged to utilize throughout the day and space within the school that is dedicated to meditation (i.e., meditation room; Mendelson et al., 2010), (b) evidence-based restorative justice programs (Song \& Swearer, 2016), and (c) review of school policies to eliminate zero tolerance school policies. The latter alternative addresses the broader issue of systemic oppression, which highlights another implication for practice. This dissertation study focused on the detrimental usage of zero tolerance school policies to address common and non-violent behavior issues resulting in school pushout; however, the broader and more meaningful discussion is that of recognition that Black youth are being treated differently because they are Black. If solutions are only offered to replace school pushout practices, the greater issue of teachers and administrators identifying problematic behaviors from Black youth at higher rates than youth representing other races will inevitably remain prominent.

\section{Implications for Advocacy}

Urgency surrounds the call to action for parents, youth supporters, and advocates to build agency for and with youth to protect them from STPP victimization. This dissertation study has demonstrated the relation between school pushout and future outlook for Black youth. The findings of this study have also highlighted the potential for parental warmth to stymie the trajectory of negative future outlook for youth who have experienced school pushout.

Advocacy for Black youth in schools and within the greater community is not only important, it should be viewed as a peremptory call to action. Black youth have been subjected to discriminatory school pushout tactics for over 40 years and the racial disparities in treatment have increased over the years. The implications of school 
pushout on Black youth have been outlined within this dissertation and include negative future outlook, grade retention, school failure, drop out, increased exposure to criminal activity, youth detention enrollment, incarceration, and school pushout data sharing with college admissions offices.

The findings of this dissertation study also support the need for policy change at the local, state, and federal levels regarding zero tolerance policy enforcement and racial disparities in treatment of Black youth. School counselors and support staff can be instrumental in serving as liaisons between youth and administrators to prevent school pushout among Black youth. However, there could be some assurance for parents of Black youth who have experienced school pushout in knowing that their level of support, affection, and sensitivity (i.e., parental warmth) concerning their children could potentially serve as a buffer between the school pushout experience and their children's sense of hope and self-worth (Adams-Bass et al., 2014). The findings of this dissertation study are supported by the study's theological frameworks which support the notions that (a) at the microsystem level, parental warmth can make an impact on their children's future outlook (Bronfenbrenner, 1977) and (b) racial/ethnic socialization could be beneficial as parents process the larger systemic issues that are in place to victimize their children with their children (Adams-Bass et al., 2014; Bentley-Edwards et al., 2013).

\section{Conclusion}

Black youth, primarily from Mobile and Prichard Alabama, participated in this dissertation study, as their responses to the MYS were utilized to answer the research questions that examined the aforementioned relations. In an effort to explore the relation between school pushout and future outlook among Black youth, this dissertation study 
examined the relation between suspensions and expulsions and hopelessness and selfworth. The findings of the dissertation study revealed that school pushout (i.e., suspensions and expulsions) had a significant effect on future outlook (i.e., hopelessness and self-worth). Parental warmth was initially explored as a potential protective factor, and the study findings confirmed that parental warmth moderated the relation between school pushout and future outlook when age and gender were added to the model. Age and gender were investigated for potential effects on the relations among the study constructs.

The dissertation study findings suggested that school pushout was related to future outlook for Black youth, as Black youth who had experienced school pushout reported more hopelessness and less self-worth than Black youth who had not experienced school pushout. The dissertation study also supported the notion that parental warmth moderates the relation between school pushout and future outlook with higher levels of parental warmth relating to a more positive future outlook for Black youth who experienced school pushout.

The overwhelming claim of this dissertation study is to highlight the direct relation between school pushout and negative future outlook for Black youth and to simultaneously acknowledge the protective factor of parental warmth as a buffer for the trauma that may ensue when Black youth experience school pushout. If there are any lingering thoughts that resonate with the readers of this study, I hope they are (a) to advocate for Black youth by recognizing and responding to the extant racial disparities within school pushout praxis, (b) to provide support to parents of Black youth who are searching for ways to respond to the systemic racial oppression in their children's 
schools, and (c) to authentically seek solutions to dismantle the STPP such that investigations into protective factors for the STPP—a system insidiously designed to oppress Black youth — are no longer required. 


\section{REFERENCES}

Adams-Bass, V. N., Bentley-Edwards, K. L., \& Stevenson, H. C. (2014). That's not me I see on tv...: African American youth interpret media images of Black females. Women, Gender, and Families of Color, 2(1), 79-100. doi:10.5406/womgenfamcol.2.1.0079

Ainsworth, M. S. (1979). Infant-mother attachment. American Psychologist, 34(10), 932937.

Alexander, M. (2012). The new Jim Crow: Mass incarceration in the age of colorblindness. New York, NY: New Press.

Ali, T., \& Dufresne, A. (2008). Missing out: Suspending students from Connecticut schools. New Haven, CT: Connecticut Voices for Children.

American Psychological Association Zero Tolerance Task Force. (2008). Are zero tolerance policies effective in the schools?: An evidentiary review and recommendations. The American Psychologist, 63(9), 852-862.

Arnold, H. J., \& Feldman, D. C. (1981). Social desirability response bias in self-report choice situations. Academy of Management Journal, 24(2), 377-385. doi: $10.2307 / 255848$

Ayers, W., Dohrn, B., \& Ayers, R. (2001). Zero tolerance: Resisting the drive for punishment in our schools. A handbook for parents, students, educators, and citizens. New York, NY: New Press.

Balfanz, R., \& Fox, J. (2014). Sent home and put off-track: The antecedents, 
disproportionalities, and consequences of being suspended in the ninth grade. Journal of Applied Research on Children: Informing Policy for Children at Risk, 5(2), 1-19.

Bandura, A. (1977). Social learning theory. New York, NY: General Learning Press.

Baumrind, D. (1967). Child care practices anteceding three patterns of preschool behavior. Genetic Psychology Monographs, 75(1), 43-88.

Baumrind, D. (1971). Current patterns of parental authority. Developmental Psychology Mongraph, 4(1p2), 1-103. doi:10.1037/h0030372

Bentley-Edwards, K. L., Thomas, D. E., \& Stevenson, H. C. (2013). Raising consciousness: Promoting healthy coping among African American boys at school. In C. Clauss-Ehlers, Z. Serpell, \& M. Weist (Eds.), Handbook of Culturally Responsive School Mental Health (pp. 121-133). New York, NY: Springer. doi:10.1007/978-1-4614-4948-5_9

Blake, J. J., Smith, D. M., Marchbanks III, M. P., Seibert, A. L., Wood, S. M., \& Kim, E. S. (2016). Does student-teacher racial/ethnic match impact Black students' discipline risk? A test of the cultural synchrony hypothesis. In R. Skiba, K. Mediratta, \& M. Rausch (Eds.), Inequality in School Discipline (pp. 79-98). New York, NY: Palgrave Macmillan.

Bolland, J. (2007). Mobile youth survey overview. Birmingham, AL: University of Alabama at Birmingham.

Bolland, J. M. (2004). Overview of the mobile youth study. Tuscaloosa, AL: The University of Alabama, Institute for Social Science Research. 
Bolland, J. M., McCallum, D. M., Lian, B., Bailey, C. J., \& Rowan, P. (2001). Hopelessness and violence among inner-city youths. Maternal and Child Health Journal, 5(4), 237-244.

Bowlby, J. (1969). Attachment and loss: Attachment. New York, NY: Basic Books. Bronfenbrenner, U. (1977). Toward an experimental ecology of human development. American Psychologist, 32(7), 513-531. doi:10.1037/0003-066X.32.7.513

Brookmeyer, K. A., Henrich, C. C., \& Schwab-Stone, M. (2005). Adolescents who witness community violence: Can parent support and prosocial cognitions protect them from committing violence?. Child Development, 76(4), 917-929. doi:10.1111/j.1467-8624.2005.00886.x

Buri, J. R., \& Mueller, R. A. (1988, April). In the eye of the beholder: Self-Esteem and children's vs. parents' assessments of parental nurturance and discipline. Paper presented at The Annual Meeting of the Midwestern Psychological Association, Chicago, IL.

Cantillon, D. (2006). Community social organization, parents, and peers as mediators of perceived neighborhood block characteristics on delinquent and prosocial activities. American Journal of Community Psychology, 37(1-2), 111-127. doi:10.1007/s10464-005-9000-9

Caton, M. T. (2012). Black male perspectives on their educational experiences in high school. Urban Education, 47(6), 1055-1085. doi:10.1177/0042085912454442

Center for Community Alternatives. (2015). Education suspended: The use of high school disciplinary records in college admissions. Syracuse, NY: Author. Charnofsky, S. (1971). Educating the powerless. Belmont, CA: Wadsworth. 
Chen, X., Liu, M., \& Li, D. (2000). Parental warmth, control, and indulgence and their relations to adjustment in Chinese children: A longitudinal study. Journal of Family Psychology, 14(3), 401-419. doi:10.1037/0893-3200.14.3.401

Christle, C. A., Jolivette, K., \& Nelson, C. M. (2005). Breaking the school to prison pipeline: Identifying school risk and protective factors for youth delinquency. Exceptionality, 13(2), 69-88. doi:10.1207/s15327035ex1302_2

Church, W. T., Tomek, S., Bolland, K. A., Hooper, L. M., Jaggers, J., \& Bolland, J. M. (2012). A longitudinal examination of predictors of delinquency: An analysis of data from the Mobile Youth Survey. Children and Youth Services Review 34(12), 2400-2408. doi:10.1016/j.childyouth.2012.09.007

Cornell, D. G., \& Mayer, M. J. (2010). Why do school order and safety matter?. Educational Researcher, 39(1), 7-15. doi:10.3102/0013189X09357616

Craven, J. (2015, December 18). The girl who was assaulted by a cop on camera at Spring Valley High is now facing charges. The Huffington Post. Retrieved from http://www.huffingtonpost.com/entry/charges-assault-spring-valleyhigh_us_56733c14e4b014efe0d4d59c

Crenshaw, K., Ocen, P., \& Nanda, J. (2015). Black girls matter: Pushed out, overpoliced, and underprotected. New York, NY: Center for Intersectionality and Social Policy Studies.

Dolovich, S. (2011). Exclusion and control in the carceral state. Berkeley Journal of Criminal Law, 16(2), 259-339.

Dornbusch, S. M., Ritter, P. L., Leiderman, P. H., Roberts, D. F., \& Fraleigh, M. J. (1987). The relation of parenting style to adolescent school performance. Child 
Development, 58(5), 1244-1257. doi:10.2307/1130618

Doyle, A. B., \& Markiewicz, D. (2005). Parenting, marital conflict and adjustment from early-to mid-adolescence: Mediated by adolescent attachment style?. Journal of Youth and Adolescence, 34(2), 97-110. doi:10.1007/s10964-005-3209-7

Dunn, E. C., Milliren, C. E., Evans, C. R., Subramanian, S. V., \& Richmond, T. K. (2015). Disentangling the relative influence of schools and neighborhoods on adolescents' risk for depressive symptoms. American Journal of Public Health, 105(4), 732-740.

Deutsch, A. R., Crockett, L. J., Wolff, J. M., \& Russell, S. T. (2012). Parent and peer pathways to adolescent delinquency: Variations by ethnicity and neighborhood context. Journal of Youth and Adolescence, 41(8), 1078-1094.

Farrington, D. P. (1989). Early predictors of adolescent aggression and adult violence. Violence and Victims, 4(2), 79-100.

Finn, J. D., \& Servoss, T. J. (2015). Misbehavior, suspensions, and security measures in high school: Racial/ethnic and gender differences. Journal of Applied Research on Children: Informing Policy for Children at Risk, 5(2), 1-50.

Fleming, C. B., Mason, W. A., Thompson, R. W., Haggerty, K. P., \& Gross, T. J. (2015). Child and parent report of parenting as predictors of substance use and suspensions from school. The Journal of Early Adolescence, 36(5), 625-645. doi: $10.1177 / 0272431615574886$

Fuentes, A. (2014). The schoolhouse as jailhouse. In A. Nocella, P. Parmar, \& D. Stovall (Eds.), From education to incarceration: Dismantling the school-to-prison pipeline (pp. 37-53). New York, NY: Peter Lang. 
George, J. A. (2015). Stereotype and school pushout: Race, gender and discipline disparities. Arkansas Law Review, 68, 101-129.

Gilliam, W. S. (2005). Prekindergarteners left behind: Expulsion rates in state prekindergarten systems. New Haven, CT: Foundation for Child Development.

Gilliam, W. S., Maupin, A. N., Reyes, C.R., Accavitti, M., \& Shic, F. (2016, September). Do early educators' implicit biases regarding sex and race relate to behavior expectations and recommendations of preschool expulsions and suspensions? (Yale University Child Study Center Research Brief). Retrieved from http://ziglercenter.yale.edu/publications/Preschool\%20Implicit\%20Bias\%20Polic y\%20Brief_final_9_26_276766_5379.pdf

Gilliam, W. S., \& Shahar, G. (2006). Preschool and child care expulsion and suspension: Rates and predictors in one state. Infants \& Young Children, 19(3), 228-245. doi:10.1097/00001163-200607000-00007

Glass, I. (Producer). (2014, October 17). Is this working? [Audio podcast]. Retrieved from http://www.thisamericanlife.org/radio-archives/episode/538/is-this-working Goff, P. A., Jackson, M. C., Di Leone, B. A. L., Culotta, C. M., \& DiTomasso, N. A. (2014). The essence of innocence: Consequences of dehumanizing Black children. Journal of Personality and Social Psychology, 106(4), 526-544. doi:10.1037/a0035663

Gregory, J. F. (1997). Three strikes and they're out: African American boys and American schools' responses to misbehavior. International Journal of Adolescence and Youth, 7(1), 25-34. doi:10.1080/02673843.1997.9747808 
Gregory, A., \& Thompson, A. R. (2010). African American high school students and variability in behavior across classrooms. Journal of Community Psychology, 38(3), 386-402. doi:10.1002/jcop.20370

Gresham, F. M., \& Elliott, S. N. (1990). Social skills rating system. Minneapolis, MN: NCS Pearson.

Gun Free Schools Act of 1994, 20 U.S.C. $§ \S 8921-8923$ (2012).

Harter, S. (1982). The perceived competence scale for children. Child Development, 53(1), 87-97. doi:10.2307/1129640

Heitzeg, N. A. (2009). Education or incarceration: Zero tolerance policies and the school to prison pipeline. In Forum on Public Policy Online, 2009(2), 1-21. Oxford Round Table.

Heitzeg, N. A. (2014). Criminalizing education: Zero tolerance policies, police in the hallways, and the school to prison pipeline. In A. Nocella, P. Parmar, \& D. Stovall (Eds.), From education to incarceration: Dismantling the school-to-prison pipeline (pp. 11-36). New York, NY: Peter Lang.

Hirschfield, P. J. (2008). Preparing for prison? The criminalization of school discipline in the USA. Theoretical Criminology, 12(1), 79-101. doi:10.1177/1362480607085795

Hoge, D. R., Smit, E. K., \& Hanson, S. L. (1990). School experiences predicting changes in self-esteem of sixth-and seventh-grade students. Journal of Educational Psychology, 82(1), 117.

Huang, C. Y., \& Guo, S. E. (2009). Stress, perceived support, resourcefulness and depressive symptoms in Taiwanese adolescents. Journal of Clinical Nursing, 
18(23), 3271-3279. doi:10.1111/j.1365-2702.2009.02899.x

Hughes, J., \& Kwok, O. M. (2007). Influence of student-teacher and parent-teacher relationships on lower achieving readers' engagement and achievement in the primary grades. Journal of Educational Psychology, 99(1), 39-51. doi:10.1037/0022-0663.99.1.39

Izzo, C., Weiss, L., Shanahan, T., \& Rodriguez-Brown, F. (2000). Parental self-efficacy and social support as predictors of parenting practices and children's socioemotional adjustment in Mexican immigrant families. Journal of Prevention \& Intervention in the Community, 20(1-2), 197-213. doi:10.1300/J005v20n01_13

Jaggers, J. W., Bolland, A. C., Tomek, S., Church, W. T., Hooper, L. M., Bolland, K. A., \& Bolland, J. M. (2015). Does biology matter in parent-child relationships? Examining parental warmth among adolescents from low-income families. Journal of Family Issues, 1-23. doi: 10.1177/0192513X15610156.

Jargowsky, P. A. (1997). Poverty and place: Ghettos, barrios, and the American city. New York, NY: Russell Sage.

Kasser, T., Koestner, R., \& Lekes, N. (2002). Early family experiences and adult values: A 26-year, prospective longitudinal study. Personality and Social Psychology Bulletin, 28, 826-835. doi:10.1177/0146167202289011

Kazdin, A.E., French, N.H., Unis, A.S., Esveldt-Dawson, K., \& Sherick, R.B. (1983). Hopelessness, depression, and suicidal intent among psychiatrically disturbed inpatient children. Journal of Consulting and Clinical Psychology, 51(4), 504510. doi:10.1037/0022-006X.51.4.504

Khaleque, A., \& Rohner, R. P. (2002). Perceived parental acceptance-rejection and 
psychological adjustment: A meta-analysis of cross-cultural and intracultural studies. Journal of Marriage and Family, 64(1), 54-64. doi:10.1111/j.17413737.2002.00054.x

Khaleque, A., \& Rohner, R. P. (2012). Pancultural associations between perceived parental acceptance and psychological adjustment of children and adults: A metaanalytic review of worldwide research. Journal of Cross-Cultural Psychology, 43(5), 784-800. doi:10.1177/0022022111406120

Khalifa, M. A., Gooden, M. A., \& Davis, J. E. (2016). Culturally responsive school leadership: A synthesis of the literature. Review of Educational Research, 1-40. doi:10.3102/0034654316630383

Kinsler, J. (2011). Understanding the black-white school discipline gap. Economics of Education Review, 30(6), 1370-1383. doi:10.1016/j.econedurev.2011.07.004

Kliewer, W., \& Sandler, I. N. (1992). Locus of control and self-esteem as moderators of stressor-symptom relations in children and adolescents. Journal of Abnormal Child Psychology, 20(4), 393-413. doi:10.1007/BF00918984

Krezmien, M. P., Leone, P. E., \& Wilson, M. G. (2014). Marginalized students, school exclusion, and the school-to-prison pipeline. In W. Church, A. Roberts, \& D. Springer (Eds.), Juvenile Justice Sourcebook (pp. 267-284). New York, NY: Oxford University Press.

Kuperminc, G. P., Leadbeater, B. J., Emmons, C., \& Blatt, S. J. (1997). Perceived school climate and difficulties in the social adjustment of middle school students. Applied Developmental Science, 1(2), 76-88. doi:10.1207/s1532480xads0102_2

Ladson-Billings, G. (1995). Toward a theory of culturally relevant pedagogy. American 
Educational Research Journal, 32(3), 465-491.

Laible, D. (2007). Attachment with parents and peers in late adolescence: Links with emotional competence and social behavior. Personality and Individual Differences, 43(5), 1185-1197. doi:10.1016/j.paid.2007.03.010

Lamborn, S.D., Mounts, N.S., Steinberg, L., \& Dornbusch, S. (1991). Patterns of competence and adjustment among adolescents from authoritative, authoritarian, indulgent, and neglectful families. Child Development, 62, 1049-1065.

Laura, C. T. (2014). Being bad: My baby brother and the school-to-prison pipeline. New York, NY: Teachers College Press.

Lopez-Tamayo, R., LaVome Robinson, W., Lambert, S. F., Jason, L. A., \& Ialongo, N. S. (2016). Parental monitoring, association with externalized behavior, and academic outcomes in urban african-american youth: A moderated mediation analysis. American Journal of Community Psychology, 57, 366-379. doi:10.1002/ajcp.12056

Losen, D. J., \& Martinez, T. E. (2013). Out of school and off track: The overuse of suspensions in American middle and high schools. K-12 Racial Disparities in School Discipline. UCLA: The Civil Rights Project/Proyecto Derechos Civiles. Retrieved from http://escholarship.org/uc/item/8pd0s08z

Losen, D. J., \& Skiba, R. J.(2010). Suspended education: Urban middle schools in crisis. UCLA: The Civil Rights Project. Retrieved from http://eprints.cdlib.org/uc/item/8fh0s5dv

Martin, N., \& Halperin, S. (2006). Whatever it takes: How twelve communities are reconnecting out-of-school youth. American Youth Policy Forum. Forum 
conducted at the American Youth Policy Forum, Washington, DC. Retrieved from http://www.aypf.org

Matos, A. (2014, September 5). Minneapolis schools ban suspensions of youngest students. Star Tribune. Retrieved from http://www.startribune.com/minneapolisschools-ban-suspensions-of-youngest-students/274043091/

McIntyre, J. G., \& Dusek, J. B. (1995). Perceived parental rearing practices and styles of coping. Journal of Youth and Adolescence, 24(4), 499-509. doi:10.1007/BF01537194

Mendelson, T., Greenberg, M. T., Dariotis, J. K., Gould, L. F., Rhoades, B. L., \& Leaf, P. J. (2010). Feasibility and preliminary outcomes of a school-based mindfulness intervention for urban youth. Journal of Abnormal Child Psychology, 38(7), 985994. doi: 10.1007/s10802-010-9418-X

Mendez, L. M. R., \& Knoff, H. M. (2003). Who gets suspended from school and why: A demographic analysis of schools and disciplinary infractions in a large school district. Education and Treatment of Children, 26(1), 30-51.

Morris, M. W. (2016). Pushout: The criminalization of Black girls in schools. New York, NY: New Press.

Morrison, B. (2001). The school system: Developing its capacity in the regulation of a civil society. In H. Strang, \& J. Braithwaite (Eds.), Restorative justice and civil society (pp. 195-210). Cambridge, UK: Cambridge University Press.

Muschert, G. W. (2007). The Columbine victims and the myth of the juvenile superpredator. Youth Violence and Juvenile Justice, 5(4), 351-366. doi:10.1177/1541204006296173 
Murphey D., Bandy T., Schmitz H., \& Moore K. (2013, December). Caring adults: Important for positive child well-being. (Child Trends Research Brief No. 54). Retrieved from http://www.childtrends.org/wp-content/uploads/2013/12/201354CaringAdults.pdf

Murry, V. M., \& Brody, G. H. (1999). Self-regulation and self-worth of Black children reared in economically stressed, rural, single mother-headed families: The contribution of risk and protective factors. Journal of Family Issues, 20(4), 458484. doi:10.1177/019251399020004003

Nelson, C. M. (2014). Students with learning and behavioral disabilities and the schoolto-prison pipeline: How we got here, and what we might do about it. Special Education Past, Present, and Future: Perspectives from the Field (Advances in Learning and Behavioral Disabilities) Emerald Group Publishing Limited, 27, 89-115.

Nielsen, F. (1986). Hispanics in high school and beyond. In M. Olivas (Ed.), Latino college students (pp. 71-103). New York, NY: Teachers College Press.

Nocella, A. J., \& Socha, K. (2014). The new eugenics: Challenging urban education and special education and the promise of hip hop pedagogy. In A. Nocella, P. Parmar, \& D. Stovall (Eds.), From education to incarceration: Dismantling the school-toprison pipeline (pp. 165-182). New York, NY: Peter Lang.

Noguera, P. A. (2003). Schools, prisons, and social implications of punishment: Rethinking disciplinary practices. Theory into Practice, 42(4), 341-350. doi:10.1207/s15430421tip4204_12 
Oates, G. L. (2003). Teacher-student racial congruence, teacher perceptions, and test performance. Social Science Quarterly, 84(3), 508-525. doi:10.1111/15406237.8403002

Osher, D., Fisher, D., Amos, L., Katz, J., Dwyer, K., Duffey, T., \& Colombi, G.D. (2015). Addressing the root causes of disparities in school discipline: An educator's action planning guide. Washington, DC: National Center on Safe Supportive Learning Environments.

Patterson, G. R., \& Stouthamer-Loeber, M. (1984). The correlation of family management practices and delinquency. Child Development, 55(4), 1299-1307. doi:10.2307/1129999

Quin, D., \& Hemphill, S. A. (2014). Students' experiences of school suspension. Health Promotion Journal of Australia, 25(1), 52-58. doi:10.1071/HE13097

Ray, S. L., Lambie, G., \& Curry, J. (2007). Building caring schools: Implications for professional school counselors. Journal of School Counseling, 5(14), 1-23.

Rodgers, R. H. (1966). The occupational role of the child: A research frontier in the developmental conceptual framework. Social Forces, 45(2), 217-224.

Savage, J. (2014). The association between attachment, parental bonds and physically aggressive and violent behavior: A comprehensive review. Aggression and Violent Behavior, 19(2), 164-178.

Scales, P. C., \& Leffert, N. (1999). Developmental assets: A synthesis of the scientific research on adolescent development. Search Institute.

Schiff, M., \& Bazemore, G. (2012). “Whose kids are these?”: Juvenile justice and 
education partnerships using restorative justice to end the "school-to-prisonpipeline". In Keeping Kids In School and Out of Courts (68-82). Retrieved from http://www.nycourts.gov/ip/justiceforchildren/publications.shtml

Simons, R. L., Simons, L. G., Burt, C. H., Drummund, H., Stewart, E., Brody, G. H., ... \& Cutrona, C. (2006). Supportive parenting moderates the effect of discrimination upon anger, hostile view of relationships, and violence among African American boys. Journal of Health and Social Behavior, 47(4), 373-389. doi:10.1177/002214650604700405

Skiba, R. J. (2000). Zero tolerance, zero evidence: An analysis of school disciplinary practice. Policy Research Rep. No. SRS2. Bloomington, IN: Education Policy Center. doi:10.1002/yd.23320019204

Skiba, R. J., Horner, R. H., Chung, C. G., Rausch, M. K., May, S. L., \& Tobin, T. (2011). Race is not neutral: A national investigation of African American and Latino disproportionality in school discipline. School Psychology Review, 40(1), 85-107.

Skiba, R. J., \& Knesting, K. (2001). Zero tolerance, zero evidence: An analysis of school disciplinary practice. New Directions for Youth Development, 2001(92), 17-43. doi:10.1002/yd.23320019204

Skiba, R. J., Michael, R. S., Nardo, A. C., \& Peterson, R. L. (2002). The Urban Review, 34(4), 317-342.

Skiba, R. J., \& Peterson, R. L. (2000). School discipline at a crossroads: From zero tolerance to early response. Exceptional Children, 66(3), 335-346.

Skiba, R. J., \& Rausch, K. (2006). Zero tolerance, suspension, and expulsion: Questions of equity and effectiveness. In C. Evertson, \& C. Weinstein (Eds.), Handbook of 
classroom management: Research, practice, and contemporary issues. Mahwah, NJ: Lawrence Erlbaum Associates. doi:10.4324/9780203874783.ch41

Smith, E. J., \& Harper, S. R. (2015). Disproportionate impact of K-12 school suspension and expulsion on Black students in southern states. Philadelphia, PA: University of Pennsylvania, Center for the Study of Race and Equity in Education.

Song, S. Y., \& Swearer, S. M. (2016). The cart before the horse: The challenge and promise of restorative justice consultation in schools. Journal of Educational and Psychological Consultation, 26(4), 313-324. doi:10.1080/10474412.2016.1246972

Spencer, M. B., Fegley, S. G., \& Harpalani, V. (2003). A theoretical and empirical examination of identity as coping: Linking coping resources to the self processes of African American youth. Applied Developmental Science, 7(3), 181-188. doi:10.1207/S1532480XADS0703_9

State of New Jersey, Department of Education. (n.d.) Preschool student suspension/expulsion guidance. Retrieved from http://www.nj.gov/education/ece/psguide/suspension.htm

Stoddard, S. A., Henly, S. J., Sieving, R. E., \& Bolland, J. (2011). Social connections, trajectories of hopelessness, and serious violence in impoverished urban youth. Journal of Youth and Adolescence, 40(3), 278-295. doi:10.1007/s10964-010$9580-\mathrm{z}$

Stotland, E. (1969). The psychology of hope. San Francisco, CA: Jossey-Bass.

Suspension Stories. (2015). Brain dead. Retrieved from http://www.suspensionstories.com/ 
Taliaferro, L. A., \& Muehlenkamp, J. J. (2014). Risk and protective factors that distinguish adolescents who attempt suicide from those who only consider suicide in the past year. Suicide and Life-Threatening Behavior, 44(1), 6-22. doi:10.1111/sltb.12046

Taylor, L. D., Davis-Kean, P., \& Malanchuk, O. (2007). Self-esteem, academic selfconcept, and aggression at school. Aggressive Behavior, 33(2), 130-136. doi:10.1002/ab.20174

Tenenbaum, H. R., \& Ruck, M. D. (2007). Are teachers' expectations different for racial minority than for European American students? A meta-analysis. Journal of Educational Psychology, 99(2), 253. doi:10.1037/0022-0663.99.2.253

Theriot, M. T., Craun, S. W., \& Dupper, D. R. (2010). Multilevel evaluation of factors predicting school exclusion among middle and high school students. Children and Youth Services Review, 32(1), 13-19. doi:10.1016/j.childyouth.2009.06.009

Toldson, I.A., \& Ebanks, M. E. (2014). Collateral damage in the classroom: How race and school environment influence teachers'attitudes and behaviors toward their students. In Y. Sealey-Ruiz, C.W. Lewis, \& I. Toldson (Eds.) Teacher Education and Black Communities: Implications for Access, Equity, and Achievement (pp. 293-315). Charlotte, NC: Information Age.

Toldson, I. A., McGee, T., \& Lemmons, B. P. (2014). Reducing suspensions by improving academic engagement among school-age Black males. In D. J. Losen (Ed.) Closing the School Discipline Gap: Equitable Remedies for Excessive Exclusion (pp. 107-117). New York, NY: Teachers College.

U.S. Department of Education Office for Civil Rights. (2014). Civil rights data 
collection: Data snapshot (school discipline). Retrieved from http://ocrdata.ed.gov/Downloads/CRDC-School-Discipline-Snapshot.pdf

U.S. Department of Education Office for Civil Rights. (2016). Civil rights data collection: Data snapshot (school discipline). Retrieved from http://ocrdata.ed.gov/DataInfo1314

U.S. Department of Education, Policy and Programs Studies Service. (2016). State and local expenditures on corrections and education: A brief from the U.S. Department of Education, Policy and Program Studies Service. Retrieved from http://www2.ed.gov/rschstat/eval/other/expenditures-correctionseducation/brief.pdf

U.S. Government Accountability Office. (2016). K-12 education: Better use of information could help agencies identify disparities and address racial discrimination. Washington, DC: U.S. Government Printing Office. Retrieved from: http://www.gao.gov/assets/680/676745.pdf

van den Bergh, L., Denessen, E., Hornstra, L., Voeten, M., \& Holland, R. W. (2010). The implicit prejudiced attitudes of teachers: Relations to teacher expectations and the ethnic achievement gap. American Educational Research Journal, 47(2), 497527. doi:10.3102/0002831209353594

Vanderhaar, J., Munoz, M., \& Petrosko, J. (2014). Reconsidering the alternatives: The relationship between suspension, disciplinary alternative school placement, subsequent juvenile detention, and the salience of race. Journal of Applied Research on Children: Informing Policy for Children at Risk, 5(2), 1-32. 
Van Dorn, R. A., Bowen, G. L., \& Blau, J. R. (2006). The impact of community diversity and consolidated inequality on dropping out of high school. Family Relations, 55(1), 105-118. doi:10.1111/j.1741-3729.2006.00360.x

Van Voorhees, B. W., Paunesku, D., Kuwabara, S. A., Basu, A., Gollan, J., Hankin, B. L., ... \& Reinecke, M. (2008). Protective and vulnerability factors predicting newonset depressive episode in a representative of U.S. adolescents. Journal of Adolescent Health, 42(6), 605-616. doi:10.1016/j.jadohealth.2007.11.135

Vazsonyi, A. T., Pickering, L. E., \& Bolland, J. M. (2006). Growing up in a dangerous developmental milieu: The effects of parenting processes on adjustment in innercity African American adolescents. Journal of Community Psychology, 34(1), 47 73. doi:10.1002/jcop.20083

Verdugo, R. R. (2002). Race-ethnicity, social class, and zero-tolerance policies: The cultural and structural wars. Education and Urban Society, 35(1), 50-75. doi:10.1177/001312402237214

Wald, J., \& Losen, D. J. (2003). Defining and redirecting a school-to-prison pipeline. New Directions for Youth Development, 2003(99), 9-15. doi:10.1002/yd.51

Wallace, J. M., Goodkind, S., Wallace, C. M., \& Bachman, J. G. (2008). Racial, ethnic, and gender differences in school discipline among U.S. high school students: 1991-2005. The Negro Educational Review, 59(1-2), 47-62.

Walker-Barnes, C. J., \& Mason, C. A. (2004). Delinquency and substance use among gang-involved youth: The moderating role of parenting practices. American Journal of Community Psychology, 34(3-4), 235-250. doi:10.1007/s10464-004$7417-1$ 
Webb, P., \& Kritsonis, W. A. (2006). Zero-Tolerance Policies and Youth: Protection or Profiling?. National Journal for Publishing and Mentoring Doctoral Student Research, 3(1), 1-8.

Wright, J. P., Morgan, M. A., Coyne, M. A., Beaver, K. M., \& Barnes, J. C. (2014). Prior problem behavior accounts for the racial gap in school suspensions. Journal of Criminal Justice, 42(3), 257-266. doi:10.1016/j.jcrimjus.2014.01.001 
APPENDIX 
Table 17

Correlation Table of Study Constructs

\begin{tabular}{|c|c|c|c|c|c|c|c|}
\hline & & Gender & Pushout & Hopelessness & Self-worth & Parental Warmtl & Age \\
\hline \multirow[t]{3}{*}{ Gender } & Pearson Correlation & 1 & $-.138 * *$ & $-.151 * *$ & $.070 * *$ & -0.032 & 0.001 \\
\hline & Sig. (2-tailed) & & 0 & 0 & 0.004 & 0.185 & 0.97 \\
\hline & $\mathrm{N}$ & 1728 & 1728 & 1728 & 1728 & 1728 & 1728 \\
\hline \multirow[t]{3}{*}{ Pushout } & Pearson Correlation & $-.138 * *$ & 1 & $.048^{*}$ & $-.166^{* *}$ & -0.029 & -0.039 \\
\hline & Sig. (2-tailed) & 0 & & 0.046 & 0 & 0.233 & 0.107 \\
\hline & $\mathrm{N}$ & 1728 & 1728 & 1728 & 1728 & 1728 & 1728 \\
\hline \multirow[t]{3}{*}{ Hopelessness } & Pearson Correlation & $-.151 * *$ & $.048 *$ & 1 & $-.281 * *$ & $-.093 * *$ & -0.031 \\
\hline & Sig. (2-tailed) & 0 & 0.046 & & 0 & 0 & 0.196 \\
\hline & $\mathrm{N}$ & 1728 & 1728 & 1728 & 1728 & 1728 & 1728 \\
\hline \multirow[t]{3}{*}{ Self-worth } & Pearson Correlation & $.070 * *$ & $-.166^{* *}$ & $-.281 * *$ & 1 & $.111 * *$ & $.123 * *$ \\
\hline & Sig. (2-tailed) & 0.004 & 0 & 0 & & 0 & 0 \\
\hline & $\mathrm{N}$ & 1728 & 1728 & 1728 & 1728 & 1728 & 1728 \\
\hline \multirow[t]{3}{*}{ Parental Warmth } & Pearson Correlation & -0.032 & -0.029 & $-.093 * *$ & $.111^{* *}$ & 1 & 0.015 \\
\hline & Sig. (2-tailed) & 0.185 & 0.233 & 0 & 0 & & 0.545 \\
\hline & $\mathrm{N}$ & 1728 & 1728 & 1728 & 1728 & 1728 & 1728 \\
\hline \multirow[t]{3}{*}{ Age } & Pearson Correlation & 0.001 & -0.039 & -0.031 & $.123 * *$ & 0.015 & 1 \\
\hline & Sig. (2-tailed) & 0.97 & 0.107 & 0.196 & 0 & 0.545 & \\
\hline & $\mathrm{N}$ & 1728 & 1728 & 1728 & 1728 & 1728 & 1728 \\
\hline
\end{tabular}

Note: $* *=$ significant at $p<0.01$

Note: * significant at $p<0.05$ 


\title{
CURRICULUM VITA
}

\author{
KISH CUMI \\ 1905 S. $1^{\text {ST }}$ Street \\ Louisville, Kentucky 40292 \\ kish.cumi@louisville.edu
}

\section{Education}

Ph.D. Candidate, University of Louisville (CACREP-aligned), November 2016

Counselor Education and Supervision, Department of Counseling and Human

Development

Dissertation Topic: School-to-Prison Pipeline Intervention

Master of Arts in Education, Wake Forest University (CACREP), May 2003

Counselor Education, School Counseling Concentration

Bachelor of Arts Degree, Wake Forest University, May 2001

Psychology Major, Dance Minor, Merit Supplemental Scholar, Student Athlete

Academic Honors

\section{Holmes Scholar, 2014-Present}

Holmes Research Committee Member

Scholar Induction, 2002

Chi Sigma Iota, International Honor Society for Counselors

\section{Teaching Experience}

\section{Adjunct Lecturer of Counseling, Fall 2015 - Present}

Department of Counseling, Wake Forest University, Online Master of Arts in Counseling

Courses: Practicum (Fall 2015)/Internship (Spring 2016, Summer 2016, Fall 2016)

\section{Guest Lecturer, Fall 2015}

Department of Counseling and Human Development, University of Louisville Course: Teaching and Ethics in Counselor Education 


\section{Guest Lecturer, Fall 2014}

Department of Educational and Counseling Psychology, Counseling, and College Student Personnel, University of Louisville

Course: Clinical Mental Health Practicum and Internship

\section{Graduate Teaching Assistant, Summer 2014}

Department of Educational and Counseling Psychology, Counseling, and College Student Personnel, University of Louisville

Course: Career Counseling

Supervisor: Patrick Hardesty, Ph.D.

\section{Graduate Teaching Assistant, Spring 2014}

Department of Educational and Counseling Psychology, Counseling, and College Student Personnel, University of Louisville

Course: Theories and Techniques of Counseling and Psychotherapy

Supervisor: Nancy Cunningham, Ph.D.

\section{Supervision Experience}

\section{University Supervisor, Fall 2015 - Present}

Department of Counseling, Wake Forest University

Course: Practicum

\section{Doctoral Student Supervisor, Fall 2013 - Fall 2015}

Department of Educational and Counseling Psychology, Counseling, and College Student Personnel, University of Louisville

Supervisors: Richard Balkin, Ph.D., 2014-2015 and Nancy Cunningham, Ph.D., 20132014

\section{Research Experience}

Graduate Research Assistant, 2014-Present

Counselor Education and Supervision, University of Louisville Supervisor: Lisa Hooper, Ph.D.

\section{Graduate Research Assistant, 2014-2015}

Counselor Education and Supervision, University of Louisville Supervisor: Richard Balkin, Ph.D.

\section{Graduate Research Assistant, 2002-2003}

Counseling Education, Wake Forest University

Supervisor: Debbie Newsome, Ph.D.

Research Assistant, 2000-2001

Department of Psychology, Wake Forest University 


\section{Publications}

Cumi, K., Washington, A. R., \& Daneshzadeh, A. (in press). Standing in solidarity with Black girls to dismantle the school-to-prison pipeline. In R. Elmesky, C. Yeakey, \& O. Marcucci (Eds.), The power of resistance: Culture, ideology and social reproduction in global contexts. Saint Louis, MO: Emerald Press.

Balkin, R. S., Perepiczka, M., Sowell, S., Cumi, K., \& Gnilka, P. The forgiveness reconciliation model: An empirically supported process for humanistic counseling. Journal of Humanistic Counseling, 55(1), 55-65. doi: 10.1002/johc.12024

Cumi, K. (in progress). School-to-prison pipeline intervention: Sounding the alarm for school counselors and educators to collaboratively advocate for Black and Brown youth.

\section{Presentations}

Washington, A., Cumi, K., \& Daneshzadeh, A. (2016, March). Standing in solidarity with Black girls to dismantle the school-to-prison pipeline. Presentation at Ohio State University’s Hip Hop Literacies Conference, Columbus, OH.

Cumi, K. (2016, February). School-to-prison pipeline: Exploring the relationship between school push-out and future outlook for Black youth. Poster presentation at The American Association of Colleges for Teacher Education Conference, Las Vegas, NV.

Perepiczka, M., Balkin, R. S., Sowell, S., \& Cumi, K. (2015, June). Life balance of Counselor Education and Supervision doctoral students. Presented at the Association for Humanistic Counseling Conference, Cleveland, $\mathrm{OH}$.

Cumi, K., Sowell, S., Rogers, T. J., Rock, E., Balkin, R. S., \& Harris, C. (2015, March). Using single case research design for tracking school counseling outcomes. Presented at the Evidence-Based School Counseling Conference, Erlanger, KY.

Balkin, R. S., Perepiczka, M., Sowell, S., \& Cumi, K. (2015, March). Empirically supported model and measure of the process of clients' work through forgiveness and conflict. Poster presentation at the American Counseling Association Conference, Orlando, FL.

Balkin, R. S., Perepiczka, M., Sowell, S., Cumi, K., \& Gnilka, P. (2014, September). Empirically supported model and measure of the process of clients' work through forgiveness and conflict. Presented at the Association for Assessment and Research in Counseling National Assessment and Research Conference, Moline, IL. 


\section{Clinical Experience}

Counselor Intern, Fall 2014 - Summer 2015

University of Louisville Cardinal Success Program (Clinical Counseling

Center/Community Signature Partnership Initiative), The Academy at Shawnee (High

School), Louisville, KY

\section{Leadership and Advocacy Intern, Fall 2014}

University of Louisville Cardinal Success Program (Clinical Counseling

Center/Community Signature Partnership Initiative), The Academy at Shawnee (High

School), Louisville, KY

Chief Executive Officer/Founder, 2008-2011

Empowering Youth through Education/EYE Partners, LLC (Tutoring and Mentoring Services), Winston-Salem/Forsyth, Guilford, and Charlotte-Mecklenburg counties, North Carolina

Coordinator, 2007-2008

Cura Personalis Mentoring Program, Fairfield University, Fairfield, CT

Certified School Counselor, North Carolina, 2003

School Counselor/Testing Coordinator, 2002-2005

Gillespie Elementary School, Guilford County Schools, Greensboro, NC

School Counselor Intern, 2002-2003

Brightwood Elementary School, Guilford County Schools, Greensboro, NC

Substitute Teacher (K-12), 2001-2002

Winston-Salem/Forsyth County Schools, Winston-Salem, NC

Additional University Employment

Graduate Assistant, Fall 2015-Present

Dean's Office/Office of Academic Affairs and Unit Effectiveness, College of Education and Human Development, University of Louisville

Graduate Assistant, Fall 2013-Fall 2014

Minority Teacher Recruitment Project, Education Advising and Student Services Office, University of Louisville

Assistant Director, Fall 2006-Fall 2007

Center for Multicultural Relations, Office of Student Diversity Programs, Fairfield

University 
Graduate Assistant, Fall 2002-Spring 2003

Office of Multicultural Affairs, Elon University

\section{Grant Experience}

Principal Investigator, No Child Left Behind, Supplemental Education Services Provider Grant, Empowering Youth through Education. Funded by U.S. Department of Education (2008-2011). Award amount: (\$100,000-\$315,000 annual award)

\section{University Service/Accreditation}

\section{Reviewer, Fall 2015 - Present}

Preparing and creating documents for review by the Council for the Accreditation of Educator Preparation (CAEP) and the Education Professional Standards Board (EPSB), College of Education and Human Development, University of Louisville

\section{Reviewer, Fall 2014 - Spring 2015}

Assisted in preparing documents for review by the Council for Accreditation of Counseling and Related Educational Programs (CACREP), Master of Education in Counseling and Personnel Services, University of Louisville

\section{Student Representative, Fall 2015 - Present}

Heuser Endowed Chair in Urban Education Partnerships Search Committee, College of Education and Human Development, University of Louisville

\section{Student Representative, Fall 2015 - Present}

Curriculum Committee, College of Education and Human Development, University of Louisville

\section{Student Representative, Fall 2015 - Present}

Grievance Committee, College of Education and Human Development, University of Louisville

\section{Student Representative, Fall 2015 - Present}

Nystrand Center of Excellence in Education Advisory Board, College of Education and Human Development, University of Louisville

\section{Department Student Representative, Spring 2015}

Graduate Student Association, Department of Educational and Counseling Psychology, Counseling, and College Student Personnel, University of Louisville

Advisor, 2013-2014

Minority Future Educators Association, University of Louisville 
Training Certification, Fall 2016

Creating Lasting Family Connections (NREPP), Certified Trainer, Austin, TX

\section{Participant, Fall 2015}

Penn Equity Institute for Doctoral Students, Center for the Study of Race and Equity in Education, University of Pennsylvania, Webinar Series

\section{Participant, Summer 2015}

Holmes Scholars Summer Policy Institute/Capitol Hill lobbying, Washington, D.C.

Attendee, Spring 2015

American Association of Colleges for Teacher Education/Holmes Scholars Conference, Atlanta, GA

\section{Participant, Fall 2014}

Thrivals Idea Festival, University of Louisville, Louisville, KY

\section{Participant, 2013-Present}

Professional Development, Life Skills, Academic Development, Networking (PLAN) Workshops, School of Interdisciplinary and Graduate Studies, University of Louisville, Louisville, KY

\section{Participant, Summer 2014}

College Women's Leadership Conference, University of Louisville, Louisville, KY

\section{Participant, Spring 2014}

Women's Leadership Conference, University of Louisville, Louisville, KY

\section{Attendee, Spring 2014}

Academic Challenges that Impact Student Success; Cultural Awareness and Identity Formation through Academic and Co-Curricular Experiences; Engagement Theories, Concepts, and Strategies; Social Justice Movements (ACES) Black \& Latino Student Symposium, University of Louisville, Louisville, KY

\section{Participant, Fall 2013-Spring 2014}

Professional Learning Community Rounds, Jefferson County Public Schools, Louisville, KY

\section{Participant, Fall 2013}

Envision Equity Scorecard Report Forum, Jefferson County Public Schools, Louisville, KY 


\section{Participant, Fall 2013}

National Adopt-A-School Initiative Training (Youth Advocacy/Mentoring Program),

Louisville, KY

\section{Professional Affiliations}

American Counseling Association

Kentucky Counseling Association 